\title{
INTERNATIONAL TRADE AGREEMENTS
}

\author{
Zhang Wei
}

SUBMITTED IN PARTIAL FULFILLMENT OF THE REQUIREMENTS FOR THE DEGREE OF DOCTOR OF PHILOSOPHY AT

UNIVERSITY OF ADELAIDE

ADELAIDE, SOUTH AUSTRALIA

JUNE 2009 


\section{Table of Contents}

Table of Contents $\quad$ ii

Abstract $\quad$ v

Declaration vii

Acknowledgements viii

1 Introduction $\quad 1$

2 Literature Review $\quad 8$

2.1 Introduction . . . . . . . . . . . . . . . . . 8

2.2 The Multilateral Trading Regime and the History of RTAs . . . . . . 9

2.3 Theoretical Welfare Analysis . . . . . . . . . . . . . . . . 12

2.3.1 Traditional Theories of RTAs . . . . . . . . . . . . . 12

2.3.2 The Vanek-Kemp Analysis . . . . . . . . . . . . . . . . . . 15

2.3.3 New Motivations for Forming RTAs . . . . . . . . . . . 16

2.4 The Dynamic Time-path Issue and the Stability of RTAs . . . . . . . 19

2.4.1 The Effects of the Formation of RTAs on Tariffs and World Welfare . . . . . . . . . . . . . . . 19

2.4.2 Dynamic Motivations of Forming RTAs and Stable Structures of Trading Blocs . . . . . . . . . . . . . . . . . . . . . 23

2.5 Conclusion . . . . . . . . . . . . . . . . . . . . . 32

3 Trade Agreements in a Welfare-Maximising World 34

3.1 Introduction . . . . . . . . . . . . . . . . . . . . 34

3.2 The Static Trade Model . . . . . . . . . . . . . . . . . . 35

3.2.1 Basic Framework . . . . . . . . . . . . . . . . . . . 35

3.2 .2 Trade Equilibrium . . . . . . . . . . . . . . . . . 36

3.2.3 Social Welfare, Government Objective and Optimal Tariffs . . 39

3.3 Trade Liberalisation through Bilateral FTAs or an MTA . . . . . . . 40 
3.4 Dynamic Negotiation Game . . . . . . . . . . . . . . . . 50

3.4.1 Setup of the Game . . . . . . . . . . . . . . 50

3.4.2 Equilibrium Outcome $(\mathrm{s}) \ldots \ldots \ldots . \ldots . \ldots 54$

3.5 Conclusion . . . . . . . . . . . . . . . . . 56

4 Trade Agreements under the Political Pressures from the Import$\begin{array}{ll}\text { Competing Sector } & 58\end{array}$

4.1 Introduction . . . . . . . . . . . . . . . . . . . . . 58

4.2 The Static Trade Model . . . . . . . . . . . . . . . . . . . 60

4.2 .1 Basic Framework . . . . . . . . . . . . . . 60

4.2 .2 Trade Equilibrium . . . . . . . . . . . . . . . . 63

4.2.3 Equilibrium Tariffs and Political Contributions in the Presence of Political Pressures . . . . . . . . . . . . . . . . . 64

4.3 Trade Liberalisation in the Presence of Political Pressures . . . . . . . 66

4.4 Dynamic Negotiation Game . . . . . . . . . . . . . . . . . 78

4.4.1 Setup of the Game . . . . . . . . . . . . . . 78

4.4.2 Equilibrium Outcome(s) . . . . . . . . . . . . . . 79

4.5 Conclusion . . . . . . . . . . . . . . . . . . . 83

5 Trade Agreements under Political Pressures from All Sectors $\quad 85$

5.1 Introduction . . . . . . . . . . . . . . . . . . 85

5.2 The Static Trade Model . . . . . . . . . . . . . . . . . . . 87

5.2 .1 Basic Framework . . . . . . . . . . . . . . . . . 87

5.2 .2 Trade Equilibrium . . . . . . . . . . . . . . . . . . 88

5.2.3 Equilibrium Tariffs and Political Contributions in the New Political Framework . . . . . . . . . . . . . . . 90

5.3 Trade Liberalisation in the New Political Framework . . . . . . . . . 92

5.4 Dynamic Negotiation Game . . . . . . . . . . . . . . . . . . 103

5.5 Conclusion . . . . . . . . . . . . . . . . . . . 106

6 Trade Agreements in an Asymmetric World 108

6.1 Introduction . . . . . . . . . . . . . . . . . . . . . . . 108

6.2 The Static Trade Model . . . . . . . . . . . . . . . . . . . . 110

6.2 .1 Basic Framework . . . . . . . . . . . . . . . . 110

6.2.2 Equilibrium Tariffs and Export Subsidies in the Asymmetric

World ....................... . . 111

6.3 Trade Liberalisation in the Asymmetric World . . . . . . . . . . . . . 112

6.4 Dynamic Negotiation Game . . . . . . . . . . . . . . . . . . . 123

6.5 Conclusion . . . . . . . . . . . . . . . . . . . 128

7 Conclusion and Further Research $\quad 130$ 
Appendix 


\section{Abstract}

In recent years, the use of the mode of regional trade liberalisation has proliferated, while the multilateral talks through the WTO have proceeded slowly, resulting in a debate on the role of bilateral and multilateral trade liberalisation. This thesis aims to provide new insights to this debate by studying the welfare effects of different types of trade agreements and the equilibrium outcome(s) of trade negotiation. We apply the three-country and three-good "competing-exporters model" developed by Bagwell and Staiger (1999) as our basic trade framework. By comparing the equilibrium welfare of each country under different structures of trading blocs, we clarify the welfare impacts of each trade agreement. Then we model the process of trade negotiation as a trade negotiation game, in which each country endogenously decides whether to negotiate through multilateral or bilateral trade liberalisation. By solving the equilibrium of the game, the stable structure of trading blocs and the path(s) to reach it can be found.

We start with a framework in which all countries are welfare maximising. We find that at the early stage of trade negotiation, a free trade agreement (FTA) is Pareto welfare improving, despite the fact that member countries benefit more than

any non-member. Although being the hub is the best position, a spoke is in a worse position than being outside a single FTA. Thus, a "hub-and-spoke" structure cannot 
be achieved and the unique equilibrium outcome of trade negotiation is given by multilateral free trade (MFT) through a multilateral trade agreement (MTA).

The welfare-maximising analysis is followed by the examination of cases in which each government is politically motivated. The political structure we use is similar to Ornelas (2005), which follows the basic framework developed by Grossman and Helpman (1995), emphasising the interaction between lobby groups representing the special interest of one industry and the government in their home country. We first consider a circumstance where the political pressures are only from the importcompeting sector. It is then generalised to a case in which all sectors are allowed to lobby the local government. Furthermore, the analysis is extended into an asymmetric world that includes two big countries and one small country.

Our results show that political economy forces usually reduce the likelihood of forming trade agreements and that when the political concerns are sufficiently large, all trade agreements can be prevented by political pressures. Also, our findings suggest that the option of bilateral FTAs does not cause an initially infeasible MFT to become feasible, while a previously feasible MFT is likely to be blocked by the option of FTAs. Thus, our thesis provides some evidence to support the argument that the formation of FTAs can be a "stumbling block" for global trade liberalisation. 


\section{Declaration}

This work contains no material which has been accepted for the award of any other degree or diploma in any university or other tertiary institution and, to the best of my knowledge and belief, contains no material previously published or written by another person, except where due reference has been made in the text.

I give consent to this copy of my thesis, when deposited in the University Library, being made available for loan and photocopying, subject to the provisions of the Copyright Act 1968 .

Signature of Author 


\section{Acknowledgements}

I would like to thank my supervisors, Professor Christopher Findlay and Professor Richard Pomfret, for their priceless encouragement, support and guidance during this research. They introduced me to this interesting area and provided me with great suggestions and assistance in producing this thesis. Without their direction, this work would never have come into existence.

I am indebted to all the staff at the School of Economics for their great help. In particular, thanks to Dr Ralph Bayer for his excellent advice, useful references and friendly talks throughout my postgraduate study, to Professor Jonathan Pincus for his detailed comments on several chapters of this thesis, and to Dr Raul Barreto, who has provided me with significant help on how to generalise my analytical framework.

I appreciate the generous financial support provided by the University of Adelaide, including the School of Economics, without which I could not have completed my PhD study in Adelaide.

I would also like to express my thanks to all my classmates and friends in Adelaide, who have given me technical assistance, moral support and companionship.

Finally, I dedicate my thesis to my family for their understanding and love. Without their support, I would never have had the opportunity to study in Adelaide and complete this thesis. 


\section{Chapter 1}

\section{Introduction}

In recent years, the mode of regional trade liberalisation has proliferated, while the multilateral talks through the WTO have proceeded slowly. Some 421 Regional Trade Agreements (RTAs) have been notified to the GATT/WTO up to December 2008, of which almost 300 were notified after January 1995. ${ }^{1}$ Over 200 RTAs are currently in force; an additional set of "trading blocs" are estimated by the WTO to be operational although not yet notified. By the end of 2010, if the RTAs reportedly planned or already under negotiation are concluded, the total number of RTAs in force might well approach 400. Nearly all WTO members are party to one or more regional trade agreements. $^{2}$ Thus, preference seems to have shifted away from multilateralism to regionalism. However, the debate on the effects of RTAs has remained in spite of such widespread regional integration. Since Jacob Viner (1950) articulated the principal concepts of trade creation and trade diversion, concerns have been raised over the following issues. The first debate, which arose when the first wave of RTAs occurred 20-30 years after the end of World War II, focuses on whether RTAs lead to higher

\footnotetext{
${ }^{1}$ We will use the term "regional trade agreement" to include preferential trade agreements between countries, even if they are not geographically contiguous or nearby.

${ }^{2}$ See the WTO website: http://www.wto.org/english/tratop_e/region_e/region_e.htm.
} 
or lower welfare for their members and non-members. The second set of questions deals with the motivations behind the formation of RTAs, as a larger number and different types of "trading blocs" have been achieved. In addition, researchers are concerned with the stability of RTAs and their effects on the global trading system. In Bhagwati's (1991) phrase, the question is whether the formation of RTAs is a "building block" or a "stumbling block" for global trade liberalisation.

This thesis aims to answer these questions in several different frameworks, and focuses on the dynamic time-path and stability issues of RTAs. We consider RTAs in the form of free trade agreements (FTAs). We examine the welfare effects of FTAs and a multilateral trade agreement (MTA) and further investigate the stable outcome(s) of trade negotiation when the formation of trade agreements is endogenously determined. Our study follows the analytical framework established by Yi (1996) for the case of customs unions (CUs). This is one of the earliest papers regarding the stable structures of trading blocs. Yi's (1996) work indicates that two models may be required to analyse the stability of RTAs. The analysis should begin with a static trade model to clarify the welfare effects of RTAs by solving the equilibrium welfare for each structure of trading blocs, then it is required to model the process of trade liberalisation as a negotiation game. By solving the equilibrium of the game, the stable structure of trading blocs and the path(s) to reach it can be found.

Inspired by Yi's (1996) seminal work on CUs, we examine the case of FTAs. This is partly because most RTAs are currently in the form of FTAs, while the European Union (EU) may be the only successful CU in the world. The methodology of our thesis is also based on Mukunoki and Tachi (2006), one of the first papers to investigate dynamic motivations to form overlapping FTAs (where the phrase "hub-and-spoke" 
is used) and their effects on the feasibility of multilateral free trade (MFT). We add to their analysis in the following respects. First, Mukunoki and Tachi (2006) assume in the trade model that there is a single firm in each country and firms produce homogenous goods. Under this assumption, trade deflection cannot be avoided even if rules of origin are completely implemented. Instead, we apply the three-country and three-good "competing-exporters model" developed by Bagwell and Staiger (1999) as our basic trade framework, which can solve the problem of trade deflection. Another reason for using this framework is that it can be used to analyse the political concerns of a government about a separate sector (e.g., the import-competing sector). ${ }^{3}$ Second, some ambiguous results from Mukunoki and Tachi (2006) arise from the exogeneity of tariffs. In our analysis, tariffs are endogenous. Moreover, the possibility of multilateral trade negotiation is ignored in Mukunoki and Tachi (2006) while in our trade negotiation game it is assumed that each country endogenously decides whether to negotiate through multilateral or bilateral trade liberalisation, as suggested by Aghion, Antràs, and Helpman (2007). In addition, countries move sequentially with a fixed order during the negotiation, so we can examine whether there is a first-mover advantage in trade negotiation.

We start with a framework in which all countries are welfare maximising. We find that when tariffs are endogenised, the welfare effects of FTAs are unambiguous and different from the results of Mukunoki and Tachi (2006). At the early stage of trade negotiation, an FTA becomes Pareto welfare improving, mainly because the FTA members reduce their external tariffs against the non-member. Moreover, although being the hub is still the best position, a spoke position is even worse than

\footnotetext{
${ }^{3} \mathrm{~A}$ general limitation of a three-country model is that it can hardly capture the possibility of strategic RTAs (e.g., A and B form an RTA because C and D have).
} 
being outside a single FTA. This directly leads to the result that a "hub-and-spoke" structure cannot be achieved and the unique equilibrium outcome of trade negotiation is given by MFT through an MTA.

Our welfare-maximising analysis is followed by the examination of cases in which the objective of each government is political. The political structure we use is similar to Ornelas (2005), which follows the basic framework developed by Grossman and Helpman (1995), emphasising the interaction between lobby groups representing the special interest of one industry and the government in their home country. We first consider a circumstance where the political pressures are only from the importcompeting sector. We find that the welfare effects of most trade agreements are analogous to what was obtained in the previous welfare-maximising framework except that the welfare ranking between a country outside a single FTA (an "outside country") and a spoke becomes ambiguous. In particular, when the political concerns are sufficiently large, a spoke is better off than an outside country. Since the objective of each government tends to include not only the national welfare but also political contributions, the motivation of forming a trade agreement becomes more complex. We show that the forces of political economy reduce the chance to form a trade agreement. Moreover, the equilibrium outcome of trade negotiation in this case depends on the following two parameters. One is the relative concern to each government about political contributions and the other is the relative bargaining power of each government against the lobby group. As long as either of these parameters is small enough, MFT can be achieved and the path to achieving this outcome depends on whether the outside country has the incentive to endorse an additional FTA to become a spoke. If this motivation exists, MFT will be achieved through overlapping 
FTAs. Otherwise, it will usually be achieved through an MTA. As the value of these two parameters increases, it is likely that a single FTA is the equilibrium outcome. If both of them become sufficiently large, no agreement will be achieved.

This political framework is then generalised to a case in which all sectors are allowed to lobby the local government. To take into account the interaction between the lobbying actions from export sectors and the respective government policies, we allow each government to provide export subsidies, and both tariffs and export subsidies are endogenous. Moreover, we assume that trade negotiation only concerns removing tariffs. In other words, when a trading bloc is formed, tariffs within this area must be eliminated, but each country can still on its own choose export subsidies. We allow export subsidies to exist during the process of trade liberalisation mainly because, in practice, export subsidies in many countries are difficult to restrain. Under this new assumption, we find that the welfare effects of both FTAs and an MTA are ambiguous, and MFT (i.e., all tariffs in the world are eliminated) leads to the optimal outcome regarding the total welfare of the world if and only if all export subsidies are removed. In addition, we show that the equilibrium outcome of trade negotiation in this case can either be MFT through an MTA or without any agreement, while regional trade liberalisation does not appear as an equilibrium path at all. The result depends on the relative concern to each government about political contributions and the endowment ratio between different sectors in each country. Given the endowment of each country, MFT is achieved through an MTA if the political concerns are relatively small, and it improves the welfare of all countries. In contrast, when the political concerns are sufficiently large, no trade agreement can be achieved. This outcome is ascribed to the distortion and bias caused by the political economy. If 
each government's weight on political contribution from lobby groups is much larger than social welfare, the opportunity to achieve a welfare-improving trade agreement can be obstructed by politics.

Our analysis is further extended into an asymmetric world including two big countries and one small country. In this asymmetric framework, we also find that the welfare effects of most trade agreements are ambiguous, although an FTA between a big country and a small country usually makes the big country worse off. The eventual extent of trade liberalisation still depends on the two parameters mentioned above. Nevertheless, the equilibrium outcome of trade negotiation is completely different from what was obtained in the symmetric case. We realise that trade negotiation ends up with a "hub-and-spoke" system, a single FTA or no agreement, while MFT can never be sustained as an equilibrium outcome. Given the endowment of each country, when political concerns are relatively small, a "hub-and-spoke" system with a big country as a hub can be achieved. As the weight put on political contributions increases, a single FTA between the two big countries can be the equilibrium outcome. When political concerns become sufficiently large, there will be no agreement. This result provides an example in which the formation of FTAs is a "stumbling block" for global trade liberalisation.

Our thesis is organised as follows. The next chapter describes the background and history of the formation of RTAs and reviews the key theoretical contributions regarding the debates on it, especially the recently developed themes addressing the dynamic time-path and stability issues. Chapter 3 analyses the framework in which all countries are welfare maximising. The next three chapters study the cases in which each government is politically motivated. Chapter 4 considers a circumstance 
in which the political pressures are only from the import-competing sector, while Chapter 5 allows all sectors to lobby the local government. Chapter 6 further discusses an asymmetric world including two big countries and one small country. The final chapter summarises the results and suggests directions for further research. 


\section{Chapter 2}

\section{Literature Review}

\section{$2.1 \quad$ Introduction}

In this chapter, we review the key theoretical contributions concerning the debates on RTAs, especially the recently developed themes addressing the dynamic time-path and stability issues ${ }^{1}$. The chapter is organised as follows. The next section briefly describes the multilateral trading regime in which RTAs are formed and overviews the history of RTAs and their characteristics in each period. Some key traditional theories with reference to the welfare effects of RTAs are discussed in section 2.3. We look at the more recent works focusing on the dynamic time-path and stability issues of RTAs in section 2.4. The final section concludes.

\footnotetext{
${ }^{1}$ Baldwin (2008) has recently provided a more detailed survey of the literature.
} 


\subsection{The Multilateral Trading Regime and the His- tory of RTAs}

Since World War II, global trade liberalisation has resulted in a more and more integrated world economy. The process started with the signing of the GATT in 1947, after which international trade tended to be governed in this framework. After eight successive rounds of GATT negotiations, this agreement became incorporated into the Marrakesh Agreement in 1994, which brought about the historic reform of the world's trading system to establish the WTO. The essential stance of the WTO is the non-discriminatory trade policy proposition, which is embodied in the Most Favoured Nation (MFN) principle in Article I of the GATT. Within this principle, each WTO member is required to treat other members the same as the most favoured nation in terms of trade policies. In other words, member countries are not allowed to discriminate in their trade policies against other members.

Therefore, it seems that RTAs based on discriminatory tariff reductions apparently conflict with the MFN clause in Article I of the GATT. However, three crucial alternative provisions for trade preferences within the GATT system allow RTAs to form without violating the multilateral trading regime. First, developed countries are allowed to offer developing countries non-reciprocal trade preferences, i.e., developed countries can lower trade barriers on imports from some developing countries without imposing any liability on them. On the basis of this provision, some nonreciprocal preference programs are implemented, including the Generalised System of Preferences (GSP), offered to nearly all developing countries to boost their exports to developed countries. This kind of program affects the motivations for developing 
countries to form RTAs. On the one hand, mutual regional integration may make them lose the benefits from non-reciprocal trade preferences. On the other hand, since these non-reciprocal preference schemes are voluntary and non-binding, they often exclude the favourite export sectors of developing countries, resulting in limited benefits to them. In addition, some programs are impermanent and need to be renewed. In addition, they can be withdrawn or circumscribed on the basis of matters such as labour rights' compliance without running foul of WTO law (Howse 2003). Thus, such bargaining power may make the non-reciprocal programs reciprocal, which further diminishes the potential gains of developing countries.

Another exemption from MFN requirements aiming to promote trade among developing countries is covered by the 1979 Enabling Clause, which permits any preferential arrangements among developing countries in goods trade. Under this provision, it is not necessary to establish a full FTA; preferential tariff reduction in partial goods is allowed. All RTAs among developing countries such as ASEAN are formed within this framework.

The third source of RTAs derives from Article XXIV of the GATT, stating that any members of the WTO can form an FTA or a CU. The European Economic Community (EEC) and the North American Free Trade Agreement (NAFTA) were founded on the basis of this provision and interest of most theoretical and empirical studies is expressed in RTAs under this clause. There are two key requirements of Article XXIV. One is that "substantially all trade" must be included, implying that members cannot exchange trade preferences partially, as is the case under the Enabling Clause. The other is that in terms of CUs, the "general incidence of duties and other regulations of commerce" against non-members is not allowed on the whole 
to be higher or more restrictive than before the formation of the union; in the case of FTAs, each member must not enhance trade barriers against non-members.

The reason for such requirements is to prevent members from selective liberalisation by only including those specific sectors in which exports are expected to grow within the union. These RTAs will probably be trade diverting and make the rest of the world worse off. However, Article XXIV has not actively come into force, to some extent because "substantially all trade" has never been clearly defined.

Historically, RTAs are also categorised into "old regionalism" and "new regionalism" in terms of the degree of integration. The first wave of RTAs led by the EEC during the first 20-30 years after World War II can be viewed as the old regionalism. In this era, integration mainly involved preferential tariff reductions in commodities. Many RTAs were created among developing countries themselves, most of which had little success. Led by the US from the mid-1980s, RTAs tended to absorb some elements of deeper integration, which went beyond the commodity trade and traditional discriminatory tariff reduction policies. It incorporated the elements of behind-borders institutional integration and internal factor mobility. Another characteristic is that more and more RTAs were formed between developed countries and developing countries, NAFTA being the first FTA to link developing countries and developed countries. 


\subsection{Theoretical Welfare Analysis}

\subsubsection{Traditional Theories of RTAs}

The theoretical analysis on the welfare effects of RTAs develops with the historic trends of regionalism and the improvement of international trade theories. Most works on the old regionalism, characterised by preferential tariff reductions, are within the Heckscher-Ohlin-Samuelson theoretical framework, which emphasises the gains from the more efficient reallocation of resources consistent with their comparative advantage through international trade. However, such discussion on RTAs is more complicated than the pure global trade analysis because in general RTAs will give rise to a "second best" result, some of which may be welfare increasing while others may be welfare reducing, depending on the particular projects.

Viner's (1950) partial equilibrium analysis provides a dramatic illustration of this ambiguous effect, articulating the two influential concepts of trade creation and trade diversion. He suggests that:

"From the free-trade point of view, whether a particular customs union is a move in the right or in the wrong direction depends, therefore, so far as the argument has yet been carried, on which of the two types of consequences ensue from that customs union. Where the trade-creation force is predominant, one of the members at least must benefit, both may benefit, the two combined must have a net benefit, and the world at large benefits; but the outside world loses, in short-run at least here the trade-diverting effect is predominant, one at least of the member countries is bound to be injured, both may be injured, the two combined will suffer a net injury, and there will be injury to the outside world 
and to the world at large. ${ }^{2} "(\mathrm{pp} .44)$

Viner further concludes that no general conclusion can cover all cases successfully and intuitively implies the better result from unilateral tariff reduction on a nondiscriminatory basis.

This theory provides a seminal contribution to the analysis of customs unions. However, Viner's arguments, which lack rigorous explanation, merely tell us that the effects of membership are ambiguous without giving much more guidance on these questions, and are thereby do little to explain why RTAs are formed. Following his work, studies in the 1950s and 1960s primarily focused on clearly defining the concepts of trade creation and trade diversion and seeking the conditions under which one effect is more likely to dominate the other.

As documented by Meade (1955), Viner's analysis is best constructed in a model with a horizontal supply curve and a vertical demand curve. Within such a framework, there is either an unambiguous trade creation effect or an unambiguous trade diversion effect, but not both, so it avoids the uncertainties in Viner's more general model. It is further argued that welfare effects on a union member depend on not only the magnitudes of trade creation and trade diversion but also on the extent of the change in price. Another implication is that trade diversion is certainly associated with a welfare loss and trade creation with a welfare gain. However, if we drop the extreme assumption of a vertical demand curve, then it becomes possible that even a purely trade-diverting CU may be welfare improving. This conclusion is explained by Lipsey (1957) within a general equilibrium model, showing that since the new domestic price is located below the pre-union price paid by the domestic consumers, despite being

\footnotetext{
${ }^{2}$ This quotation is actually found in Pomfret (1997).
} 
above the pre-union world price because of trade diversion, it will promote the import, resulting in an increase in consumer surplus, regardless of whether it is from the leastcost supplier or not. On this point, Bhagwati (1971) further claims that even if the demand curve is vertical, a trade-diverting union member may lead to a net increase in welfare as long as the supply curve is positively sloped but not vertical because there is a replacement of the inefficient domestic production by the imports from its partner.

There is another limitation in the Viner-Meade analysis - to some extent they ignore the terms-of-trade effects while they emphasise the trade creation and trade diversion effects. The supply curve with infinite elasticities excludes the possibility of price effects and if we introduce an upward sloping supply curve, ensuring a country may import from both its partners and the rest of the world, then the terms of trade of its partners will certainly improve (Mundell 1964) and the rest of the world will certainly be worse off. Therefore, a CU can benefit the members owing to the improvement in the terms of trade it brings, at the expense of the rest of world, and if this effect is sufficiently significant, a preferential tariff reduction could be even superior to a non-preferential tariff reduction, from the perspective of union members. This conclusion helps to explain why RTAs are formed.

In spite of the widely observed limitations in the Viner-Meade framework, their analysis on trade creation and trade diversion, "representing a kind of conventional wisdom and coherent theoretical structure" (Burfisher, Robinson, and Thierfelder 2004), remains popular, emerging as a baseline in most textbooks and research literature, in part because it provides an effective tool to assess the ambiguous welfare effects of RTAs. 


\subsubsection{The Vanek-Kemp Analysis}

Diverging from the conventional RTA theories in the Viner-Meade framework, a substream has been launched by Vanek (1965), Ohyama (1972), and Kemp and Wan (1976). Instead of the concerns on who gains and who loses when an RTA is formed, they look for the tractable condition under which there necessarily exists a welfareimproving CU. They suggest that if the net trade vector with the rest of the world is fixed at the pre-union level, which can ensure the welfare of the rest of the world keeps constant, a new equilibrium with Pareto improvement for union members can be attained by a system of lump-sum compensatory payments only involving union members.

This proposition provides a general and unambiguous welfare result for a CU. It does not add any restriction to the characteristics of these countries. Thus, the conclusion holds regardless of the size, the number, the economic development level and the proximity of these countries. The sufficient condition for union welfare improvement is simply to choose any subset of the trading countries to form a $\mathrm{CU}$ and to freeze the net trade vector with the rest of the world. However, the assumption of freezing such a net trade vector may hardly come true in reality. First, there is no motive for the union members to take into account the welfare of the rest of the world. In particular, when the trade vector with the rest of the world is maintained, the common external tariff usually has to reduce, and this may not necessarily lead to optimal welfare from the perspective of union members. Second, under the assumption of infinite supply elasticities, it is impossible to control such a net trade vector with the rest of the world. In addition, the Kemp-Wan analysis mainly focuses on CUs, which is only one of the several types of RTAs. Their conclusion seems difficult 
to apply to FTAs, because the external trade barriers differ across the members of an FTA. Nevertheless, Panagariya and Krishna (2002) extend the proposition to the case of FTAs and obtain an analogous result. They prove that forming an FTA between any two or more countries will make no country worse off and the members of the FTA likely to benefit if each member country freezes its individual net trade vectors with the rest of the world at the pre-FTA level by adjusting tariffs respectively.

Another fascinating implication of the Kemp-Wan proposition is that if this type of welfare-improving $\mathrm{CU}$ can be formed, it will move in the direction of global free trade. In other words, it supports the view that the formation of RTAs is a "building block" for global trade liberalisation. On the other hand, some rationales for why the formation of CUs is not accelerating global trade liberalisation are presented. In our view, some points here are questionable. First, the limited evidence in the paper indeed shows that the incentive to move towards global free trade is not strong. Second, the five reasons suggested seem to only explain why global free trade cannot be achieved through the process of CU formation, while in fact there are other channels, such as FTAs and multilateral negotiation through which the world may become free trading.

\subsubsection{New Motivations for Forming RTAs}

We have outlined above the theoretical works on the old regionalism, for the most part the Viner-Meade framework and the Vanek-Kemp branch. As the new regionalism emerged in 1980s, the features of which suggest that the welfare effects of RTAs cannot be sufficiently explained by old trade theory, new trade theory is introduced to analyse this issue. Considerations go beyond the gains from the reallocation of 
resources, which are originally derived from old trade theory based on comparative advantage. Rather, they highlight other sources of growth and welfare improvement from trade liberalisation taking into account imperfect competition, scale economies, technology flows, geographic characteristics, political economy considerations, and dynamic effects on economic growth. Although in general the effects of RTAs remain ambiguous, a more positive attitude towards them is embodied in this literature.

Imperfect competition is a fresh idea of new trade theory that has been integrated into the analysis of new regionalism. Winters (1997) explores a model with imperfect competition to examine the terms-of-trade effects of RTAs, especially on excluded countries. He shows that the change in volume of trade is not a reliable guide to draw welfare conclusions for non-member countries and that the price effects should be considered more important. Based on this theoretical foundation, Chang and Winters (2002) employ a Betrand competition model to estimate the effects of MERCOSUR on the pricing of non-member exports to Brazil and find that the decline in such prices is statistically significant.

The importance of economies of scale is another additional component of new trade theory that is included in the works of new regionalism. This point is reflected in Wonnacott and Lutz (1989) and Wonnacott (1996), suggesting that scale economies can be a source of gains from regional integration. It is pointed out that the possibility of trade diversion will be reduced if the scale economies resulting from RTAs can make initial inefficient members lower the costs of production.

Political economy considerations are also incorporated to explain the role of interest groups in forming RTAs. Grossman and Helpman (1995) model regional trade negotiations as a process of providing a balance among interest groups and claim that 
political preference may not lead to a social welfare-maximising decision. Therefore, it is probable that countries will sign trade-diverting agreements. However, Baldwin's (1995) domino theory of regionalism derives an opposite conclusion from a similar political economy framework. From another perspective, he emphasises the role of interest groups in non-member countries. It is argued that trade and investment diversion to member countries will lead the exporters in non-member countries to push their governments to either join the existing RTAs or create new RTAs to avoid the potential damage when they are excluded. In other words, countries will have the incentive to form RTAs because they are afraid of exclusion. In this sense, if this enlargement can trigger the domino effect, the process of forming RTAs will move in the right direction of global free trade.

In the 1990s another debate was raised and popularised on the concept of "natural trading partners". This was originally introduced by Wonnacott and Lutz (1989), who argued that some criteria, associated with characteristics of members, can be considered for RTA partner selection to minimise trade diversion. Following Wonnacott and Lutz's (1989) suggestion, Summers (1991), Krugman (1993), and Frankel, Stein, and Wei (1995) find that RTAs are more likely to be welfare improving with larger pre-RTA trade volumes, due to less extra-regional trade to be diverted and lower transport costs between members. In this sense, forming an RTA between geographically close neighbours may be economically more efficient because of lower transportation costs. However, this idea is questioned by other theorists, who instead claim neither proximity nor volume of trade is a good guide to this outcome. For instance, Bhagwati and Panagariya (1996a) illustrate how an RTA with a distant partner is superior to one with a neighbour. 
Other studies provide further explanation for the gains from RTAs. For instance, Ethier (1998) suggests that RTAs, especially between developing and developed countries, arise as a consequence of the success of past multilateralism among developed countries. It is explained that developing countries are motivated to seek RTAs with relatively liberalised developed countries to attract more foreign direct investment inflows from them. Meanwhile, developing countries are forced to "lock in" their trade reform policies to improve their domestic productivity.

\subsection{The Dynamic Time-path Issue and the Stabil- ity of RTAs}

\subsubsection{The Effects of the Formation of RTAs on Tariffs and World Welfare}

Thus far, most of the literature mentioned concerns the static issue of RTAs, dealing with the direct effects of RTAs on trade flows and welfare. Since the dynamic timepath issue was addressed by Bhagwati (1993), extensive questions have been raised about the effects of RTAs on further trade liberalisation, and the debate on whether the formation of RTAs is a "building block" or a "stumbling block" for global free trade has never stopped. Moreover, analysts are also interested in the stable structures of trading blocs when trade policies are endogenously determined.

Early research about the dynamic time-path issue of RTAs mainly focuses on change in tariffs after the formation of RTAs, and the relationship between the size of trading blocs and the welfare in the world. Kennan and Riezman (1990) explore 
an N-country model in which the optimal tariffs are endogenously chosen by each country. They realise that the effect of tariff variations is ambiguous. However, in their numerical examples with three countries, they find that when an FTA is formed, tariffs imposed by the FTA members decrease and those imposed by the non-member increase. If the two FTA members move further to achieve a CU by coordinating external tariffs, this will increase the tariffs of the members and decrease the tariffs of the non-member. In other words, external tariffs of a CU will be higher than those of a corresponding FTA. They further show that when the endowment of the exporting sector in each country is relatively small, a pair of countries can benefit by forming a CU compared with MFT. This implies that MFT may not be an equilibrium outcome of trade liberalisation. This result is explained by two motivations of forming a CU, one of which is to internalise the terms-of-trade externality of tariffs and the other is to enhance market power by increasing the size of the bloc.

To further investigate the relationship between the size of trading blocs and world welfare, Krugman (1991) constructs a world with a large number of symmetric "provinces". Each province produces a distinct good, and all the goods symmetrically go into the utility function of each consumer with a constant elasticity of substitution between any pair of goods. These countries can expand to form some equally sized trading blocs in the form of CUs. With the help of simulation, it is confirmed that for a reasonable value of the elasticity of substitution, the external tariffs increase as the size of trading blocs expands, which is also explained by the rise in market power. It is also suggested that the maximal world welfare is achieved when there is only a single trading bloc or there are many, both of which represent MFT. The former case represents that all tariffs in the world are removed after the formation of a big $\mathrm{CU}$ 
including all countries, and the latter indicates that imposing no tariff is the optimal for each country. In contrast, global welfare is minimised when the number of trading blocs is three. The intuition is as follows. When the single bloc is divided into two, distortion caused by tariffs imposed between the two blocs will obviously decrease world welfare. If the number of trading blocs keeps rising, it will lead to two opposite effects. On the one hand, there is benefit resulting from the reduction in external tariffs. On the other hand, the division of trading blocs creates tariffs between the previous blocs and the new bloc, lessening the world welfare. Krugman (1993) argues that when the number of trading blocs is small, the negative effect is relatively more significant. As the number grows, the positive effect tends to dominate the negative one. This explains why world welfare declines first and rebounds eventually when the size of trading blocs becomes smaller.

The analysis by Krugman has made a crucial contribution to the question about the relationship between the number of blocs and world welfare. Nevertheless, the strong and symmetric assumptions have been criticised by the later literature. Srinivasan (1993) and Deardorff and Stern (1994) provide two simple examples to show that the composition of each bloc rather than the number may be more important to determine world welfare. In their examples, it is found that global welfare can be maximised if each bloc includes all types of countries. Krugman's work is extended by Bond and Syropoulos (1996), who focus not only on the absolute size but also the relative size of trading blocs. They suggest that the effects of symmetrically expanding blocs on external tariffs are highly sensitive to the endowment of the import sector in each country. In a special case where there is no endowment in the import sector, as shown by Krugman, it is confirmed that external tariffs increase with the size of each 
bloc. On the other hand, if the endowment of the import sector is relatively large, it is likely that tariffs decrease with the bloc size. Thus, world welfare is also dependent on the import sector of each country and the value of the elasticity of substitution, and the minimal global welfare may not be achieved when there are three blocs. They further examine the effects of change in the relative size of trading blocs, and show that a sufficient increase in the relative size of a trading bloc can raise its members' welfare over global free trade by enhancing their relative market power. This result provides another example in which RTAs become "stumbling blocks" towards MFT.

In the literature discussed in this section so far, trading blocs are considered in the form of CUs. Indeed, there are also several influential works addressing the issue of FTAs. Bagwell and Staiger (1997) set up a welfare-maximising framework to analyse the transition period during which an FTA is being formed. They find that at the early stage, the FTA may temporarily bring about higher multilateral tariffs owing to the anticipation of a future drop in trade volumes and that when the FTA is fully implemented, external tariff levels will not be higher than pre-FTA. In their later work (1999), they also realise that an FTA between two countries encourages them to reduce the external tariffs against the non-member owing to the terms-oftrade changes, referred to as tariff-complementarity effect. Richardson (1993) analyses the effects of an FTA on external tariffs in a political economy framework and also suggests that an FTA can cause each member government to lower external tariffs to gain more tariff revenue. Richardson (1995) further shows that indirect trade deflection can result from the formation of an FTA even with the existence of rules of origin, which can initiate a competition for tariff revenue among member countries and lead to lower external tariffs. In contrast, Panagariya and Findlay (1996) demonstrate 
a case in which an FTA leads to higher external tariffs. They attribute this result to the lobbying activities of the labour in the import sector. When an FTA is enacted, the wages in the import sector will be driven down, and therefore more workers will lobby for protection against the non-member. If the lobbying activity is sufficiently influential, external tariffs will rise.

\subsubsection{Dynamic Motivations of Forming RTAs and Stable Struc- tures of Trading Blocs}

The studies introduced in the previous section have focused on the effects of the formation of RTAs on external tariffs and world welfare. The results from these studies to some extent provide implications about whether RTAs are "stumbling blocks" or "building blocks" towards MFT. However, this approach is not complete because these studies assume that the formation of trading blocs is exogenously specified. As suggested by Bhagwati and Panagariya (1996b), even if the optimal path of forming trading blocs is recognised, we cannot guarantee that trade liberalisation in the real world will occur in this fashion. By adapting a figure from Bhagwati (1993), they illustrate the possible time-paths such that regional trade liberalisation becomes stagnant before MFT is achieved. Since then, instead of considering only the path of trade liberalisation, which leads to optimal world welfare, more attention has been paid to the dynamic motivations of forming RTAs and the stable structures of trading blocs. Questions have been addressed to whether countries have the incentive to form RTAs, how the motivations change when some RTAs have already been enacted, and what structures of trading blocs are the equilibrium outcomes of trade liberalisation if the formation of trading blocs is endogenously determined. 
Baldwin (1995) analyses the motivations for non-members to join an existing trading bloc. By applying a political economy model, it is shown that as one country accedes to the bloc, it will increase the gains for the remaining non-members to enter. Thus, the expansion of a trading bloc can lead to a "domino effect", inducing further expansion until MFT is achieved. The key limitation of this work is that the member countries are assumed to always welcome the new entrants. This weakness is improved by Yi (1996), who models the formation of CUs as a coalition formation game in an oligopoly market. It is suggested that forming CUs improves the total welfare of member countries at the expense of the rest of world. Moreover, MFT will be achieved under the open membership rule, while the expansion towards MFT may stop under the unanimous membership rule. This is one of the earliest rigorous works regarding the stable structure of trading blocs when forming RTAs is endogenously determined. Another contribution of this paper is that it provides a basic framework for analysing the stability issue of RTAs. It may necessarily require two models to answer the stability question. The analysis should begin with a static trade model to clarify the welfare effects of RTAs by solving the equilibrium welfare for each structure of trading blocs, then it is required to model the process of trade liberalisation as a negotiation game. By solving the equilibrium of the game, we can find the stable structure of trading blocs and the path(s) to reach this. In the example of Yi (1996), world trade is modelled within an N-country intra-industry trade framework, and both production and consumption are considered. Each country is assumed to produce a numeraire good with a constant marginal cost, and the representative consumer in each country has a quasilinear-quadratic form of utility function. In this framework, various trading equilibria can be solved for different coalition structures, 
and the relationship between structures of CUs and social welfare for each country can be derived. Then, the process of formation of CUs is modelled as two coalition formation games with different rules. By using the relationship obtained in the trade equilibria, the equilibrium outcomes of each coalition formation game can be obtained to characterise the stable structures of CUs.

McLaren (2002) constructs another coalition formation game, which is close to the unanimous membership model by Yi (1996) and also finds that an RTA between two countries can be the equilibrium outcome of trade negotiation. He ascribes this outcome to sector-specific sunk investments in production and costs occurring in the trade negotiation process. It is explained that if there is an expectation of future RTA, investments will be allocated to ensure that potential bloc members specialise more towards each other, and less specialisation between member and non-member. Thus, this specialisation undermines the further motivation to achieve MFT.

Instead of considering trading blocs in the form of CUs, Levy (1997) and Krishna (1998) analyse the case of FTAs and support the argument that RTAs can be "stumbling blocks". Levy (1997) explores a Hecksher-Ohlin model and a monopolistic competition model in which trade regimes are determined by the median voters. His first finding is that the option of bilateral FTAs can never make initially infeasible MFT become feasible. Then, he shows that in the monopolistic competition framework, a bilateral FTA, especially between two countries with similar capital-labour ratio, can provide disproportionately large gains for the median voters, making their payoffs even higher then under MFT. Thus, previously feasible MFT will be blocked by the option of an FTA. Krishna (1998) presents another political economy framework in which trade policy is driven by the producers. The result suggests that such 
a political economy is more likely to support a trade-diverting FTA, and producers can benefit more from an FTA than MFT. Thus, previously feasible MFT again can be rendered infeasible.

A contrary argument is made by Ornelas (2005), who suggests that the formation of FTAs can support further multilateral trade liberalisation because this diminishes the role of politics in the determination of trade regimes. The significant contrast between this study and previous works may be partly a result of the endogeneity of external tariffs when FTAs are formed. He finds that the formation of an FTA will reduce the external tariffs against non-members and that the extent of reduction increases with the size of the FTA and the relative concern of each government about political contributions. This outcome is consistent with what is obtained by Richardson (1993) and Bagwell and Staiger (1999) and it is further realised that the tariff complementarity effect is reinforced in the political economy. Ornelas (2005) explains that there are two effects of the tariff on the domestic market. First, imposing tariffs on imports will shift domestic consumption from imports to domestic products, which increases the profits of local producers. This is called strategic effect. It will also shift domestic surplus from consumers to producers, which is referred to as the distributive effect. However, the effectiveness of an external tariff to achieve these two targets is reduced with an FTA. Consequently, the FTA will reduce the incentive of member governments to keep a high external tariff. Meanwhile, the political economy reinforces both the strategic and distributive motives of each government for protection. Therefore, the reduction in external tariffs by FTA member countries becomes deeper. The formation of an FTA and the reduction of external tariffs will decrease the profits of producers, and therefore induce less political contributions to 
the local government. From another point of view, this result leads the objective of the government closer to the welfare-maximising level. Thus, the motivation to achieve MFT becomes larger.

Mukunoki (2005) also examines the dynamic time-path issue of FTAs and obtains an ambiguous result. It is found that under some conditions only the MTA can achieve MFT, while under some other conditions only FTAs can achieve MFT. More interestingly, when the parameters are located in a region, countries have no incentive to achieve an MTA while they have the incentive to form a single FTA and are not willing to move further. The result in this case implies that although MFT cannot be achieved, the option of an FTA can still raise global welfare.

In addition to the studies on the expansion of CUs and FTAs by accepting new members, other works consider the case when trading blocs are expanded through overlapping FTAs. Mukunoki and Tachi (2006) may be the first paper to investigate the dynamic motivations of forming a "hub-and-spoke" system and the effects on feasibility of MFT. They explore a symmetric three-country oligopoly model with homogenous goods and exogenous tariffs. By comparing the welfare for each country under different structures of trading blocs, they provide a possible dynamic time-path expansion. As shown in Figure 2.1, they find that compared to the circumstance with no trade agreement, an FTA can make both member countries better off at the expense of the non-member country. Moreover, the gains from the FTA for members can be even larger than under MFT when the initial MFN tariffs are low. This outcome seems to stop further trade liberalisation. Nevertheless, the option of the "hub-and-spoke" system makes an additional FTA feasible. It is found that being a hub is better than any other position and being a spoke is better than being outside an 


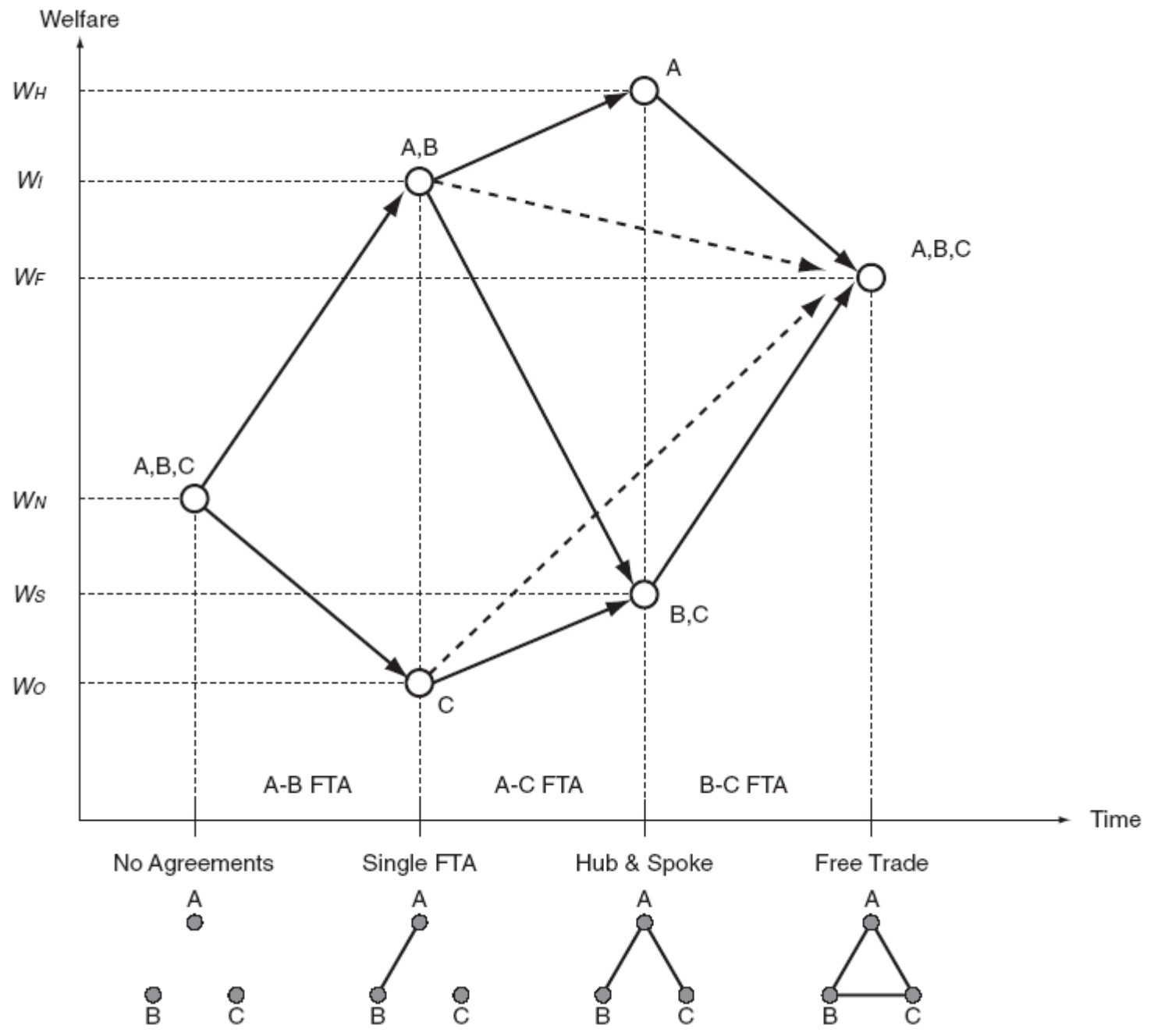

Figure 2.1: Welfare Ranking 
FTA. Thus, when an FTA has already been formed, there is incentive to approve an additional FTA to achieve a "hub-and-spoke" system. Nevertheless, such a system is not stable either because the two spokes are willing to form another FTA, and therefore MFT is achieved through three overlapping FTAs. They further construct a sequential expansion game to model the process of trade negotiation and suggest that MFT is always an equilibrium outcome and under some conditions it is a unique equilibrium outcome.

The dynamic time-path analysis of RTAs is further developed when each country is allowed to endogenously choose the path of bloc formation. Aghion, Antràs, and Helpman (2007) construct a world in which utility is transferable among nations. They model the process of trade negotiation as a dynamic bargaining game in which a leading country endogenously determines whether to propose an MTA or to sequentially offer RTAs to each other country. They confirm that MFT cannot be achieved when the political concern is sufficiently large. However, they provide very limited insight about whether RTAs are "stumbling blocks" or "building blocks" towards MFT.

The issue of how endowment asymmetry across countries influences the formation of RTAs is addressed by Riezman (1999), who simulates two different world economies that differ by their endowment pattern. It is found that in the first world economy including one large trading bloc and two small ones, RTAs can be stepping stones towards MFT. On the contrary, in the second world economy with more even distribution of endowment, the formation of RTAs blocks the potentially feasible MFT through an MTA.

Based on Riezman's (1999) framework, Melatos and Woodland (2007) generalise 
the asymmetric characteristics across countries and extend the paths of bloc formation into more options. Countries are allowed to choose among unilateral tariff reduction, joining an FTA, a CU, and an MTA. Regarding the process of trade negotiation, cooperative game theory is applied and the core is used to define a stable coalition structure. With the assistance of simulation, they find that MFT can be achieved when all countries are similar. When the world becomes asymmetric, trade negotiation may end up with CUs between countries with similar consumer preferences and similar endowment in the export sector of each country.

Saggi and Yildiz (2009) apply an asymmetric three-country and three-good "competingexporters trade model" based on Bagwell and Staiger (1999) and a simultaneous bilateral FTA formation game between these countries to examine the equilibrium outcome of trade negotiation. Instead of allowing countries to endogenously decide whether to negotiate through multilateral or bilateral trade liberalisation, Saggi and Yildiz (2009) assume that countries are only allowed simultaneously choose whether or not they want to form bilateral FTAs with their trading partners in the negotiation game. After deriving the coalition proof (stable) Nash equilibria of the game, they compare the results with the case in which countries adopt a purely multilateral approach to trade liberalisation to investigate how the option of FTAs affects the likelihood of achieving MFT. They also find asymmetry across countries is an important determinant of the potential outcome of trade liberalisation. When countries have symmetric endowments, MFT is the only stable equilibrium outcome regardless of whether countries can pursue bilateral FTAs or not. When endowments become asymmetric across countries, there exist circumstances in which only FTAs can achieve MFT, supporting the "building block" argument. In contrast, there are also circumstances where the 
option of bilateral FTAs undermines global free trade although it can lower the likelihood of achieving no agreement. Applying the same trade framework, Saggi (2009) shows that MFN leads to higher aggregate world welfare than tariff discrimination. He further models multilateral tariff cooperation as a self-enforcing process and finds that MFN punishments are more likely to sustain MFT than discriminatory ones.

Limao (2007) considers RTAs that are motivated by capturing non-trade benefits from partners, and assumes that there is a public good in each country that can induce regional spillovers. In this framework, it is shown that such RTAs reduce the motivation of multilateral trade liberalisation. It is explained that multilateral trade liberalisation can weaken the threat that can be used in RTAs, so that the benefits from RTAs will be extracted by multilateral trade liberalisation. Thus, this work provides further support for the "stumbling block" literature.

Instead of addressing the debate between regionalism and multilateralism, Baldwin (2006) focuses on the final steps of trade liberalisation, searching for the forces which can lead the world to achieve MFT when there have already existed a motley assortment of unilateral, bilateral and multilateral trade agreements. It is predicted that the world in 2010 will comprise three fuzzy and leaky trading blocs. Moving these trading blocs to global free trade requires a multilateralisation of the existing regionalism and the WTO should play a constructive role in this process. In addition, political economy forces created by the "spaghetti bowls as building blocs" mechanism can encourage the multilateralisation of regionalism. 


\subsection{Conclusion}

This chapter reviews the theoretical contributions to the literature about RTAs. Since Viner (1950) articulated the principal concepts of trade creation and trade diversion, the main concern of the studies has developed from the original static welfare issue to the dynamic time-path issue. Nevertheless, the ambiguous welfare effects of RTAs have never varied, although more and more economists have gradually agreed on the significant gains from RTAs for member countries since the proliferation of the new regionalism. On the other hand, dramatic disagreements have arisen regarding the dynamic time-path issue, and the debate on whether the formation of RTAs is a "building block" or a "stumbling block" for global trade liberalisation has never stopped. Some studies have concluded that RTAs are a crucial intermediate step towards further global trade liberalisation (e.g., Baldwin 1995; Ethier 1998; Mukunoki and Tachi 2006; Ornelas 2005). These "building block" arguments strongly support the gains from trading blocs for member countries, and therefore member countries are motivated to expand the blocs while non-members are encouraged to seek entry. They suggest that this process will continue until MFT is achieved. In contrast, others believe that RTAs are likely to destroy multilateral trade liberalisation in spite of the gains from RTAs (e.g., Bhagwati 1995; Bond and Syropoulos 1996; Levy 1997; Krishna 1998; McLaren 2002). Their essential argument is that, because of this discriminatory trade policy, the gains from RTAs, especially for the member countries, can be even larger than from multilateral trade liberalisation. Thus, trade liberalisation may stop before MFT is achieved. As well as these two types of controversial arguments, there exists literature lying in between, suggesting that the outcome of regional trade liberalisation is dependent on the rule of RTAs (for example, Yi 1996). However, 
on the basis of the current knowledge regarding this debate, we have clarified very few general conditions under which the formation of RTAs can become the stepping stone or "stumbling block" towards MFT. In our view, this vague result is ascribed to the complexity of the dynamic time-path issue itself. The essential concern of this issue is indeed the continuation of motivation for member countries to expand trading blocs and for non-members to seek entry until MFT is reached. However, such motivation differs dramatically across countries and may vary with the expansion of RTAs, especially in an asymmetric world. Therefore, it is hard to find a general conclusion which can cover all cases successfully and further research should continue to focus on a few specific aspects to search for the sorts of RTAs likely to encourage further multilateral trade liberalisation. 


\section{Chapter 3}

\section{Trade Agreements in a Welfare-Maximising World}

\subsection{Introduction}

As we have mentioned previously, the proliferation of RTAs has raised two essential debates. One debate concerns the direct welfare effects of RTAs, focusing on whether RTAs lead to higher or lower welfare for their members and non-members. The other deals with the stability of RTAs and their effects on the global trade system. In this chapter, we aim to provide insights for both debates, especially the latter one, in a symmetric welfare-maximising framework. We examine the welfare effects of different trade agreements when all countries are welfare maximising, and further investigate the equilibrium outcome(s) of trade negotiation if the objective of each government is national welfare. Our study follows the analytical framework established by Yi (1996), which is one of the earliest works regarding the stable structures of trading blocs. However, we consider RTAs in the form of overlapping bilateral FTAs instead of CUs. We apply the three-country and three-good "competing-exporters model" developed by Bagwell and Staiger (1999) as our basic trade framework. By comparing 
the equilibrium welfare of each country under different structures of trading blocs, we can clarify the welfare impacts of each trade agreement. Then we model the process of trade negotiation as a trade negotiation game, in which each country endogenously decides whether to negotiate through multilateral or bilateral trade liberalisation. By solving the equilibrium of the game, the stable structure of trading blocs and the path(s) to reach this can be found.

In this framework, we find that at the early stage of trade negotiation, an FTA is Pareto welfare improving, mainly because the FTA members reduce their external tariffs against the non-member. Moreover, although being the hub is still the best position, a spoke position is even worse than being outside a single FTA. This directly leads to the result that a "hub-and-spoke" structure cannot be achieved and the unique equilibrium outcome of trade negotiation is given by MFT through an MTA.

This chapter is organised as follows. Section 2 presents the basic trade framework suggested by Bagwell and Staiger (1999) and discusses some properties in the static equilibrium before any trade agreement is achieved. Section 3 compares the social welfare of each country under different structures of trading blocs. Our sequential negotiation game is introduced in section 4 to investigate the equilibrium outcome of trade negotiation. The final section summarises the results.

\subsection{The Static Trade Model}

\subsubsection{Basic Framework}

We examine trade policies in a world with three symmetric countries. We apply the three-country and three-good "competing exporter" trade model originally developed 
by Bagwell and Staiger (1999) as our basic analytical framework. Consider a world with three countries $\mathrm{A}, \mathrm{B}$ and $\mathrm{C}$, with three goods a, b and c. Let $N=\{A, B, C\}$ be the set of countries and $n=\{a, b, c\}$ denote the set of goods. The population size of each country is 1 . For convenience, we use $i \in n$ to represent the good corresponding to the lower case value of $I \in N$ (e.g., if $\mathrm{I}=\mathrm{A}$, then $\mathrm{i}=\mathrm{a}$ ). We assume that for each country $I \in N$, it is endowed with zero units of good i and $3 / 2$ units of each good in the set $n \backslash i$. However, all three goods are demanded in this country. The demand for good $j \in n$ in country I is given by $D_{j}^{I}\left(p_{j}^{I}\right)=\alpha-\beta p_{j}^{I}$, where $p_{j}^{I}$ denotes the price of $\mathrm{j}$ in country I. The endowment difference generates different autarky prices across countries, which makes country I import good i from either of the other two countries. We let $\tau_{i}^{\bar{I}}$ be the specific tariff of country I imposed on imports of good i from country $\bar{I} \in N \backslash I$, which is assumed to be non-prohibitive, and $\mathrm{T}$ be the tariff vector $\left(\tau_{a}^{B}, \tau_{a}^{C}, \tau_{b}^{A}, \tau_{b}^{C}, \tau_{c}^{A}, \tau_{c}^{B}\right)$. In addition, trade deflection is assumed to be impossible in our framework. Thus, the trade pattern can be illustrated by Figure 3.1.

\subsubsection{Trade Equilibrium}

We begin to examine the perfectly competitive trade equilibrium, given initial tariffs. We first consider the equilibrium in the market of good a. The arbitrage condition requires that the tariff imposed by A must equal the margin between its local price in $\mathrm{A}$ and the foreign price, so we have:

$$
p_{a}^{A}=p_{a}^{B}+\tau_{a}^{B}=p_{a}^{C}+\tau_{a}^{C}
$$

For each country $I \in N$, its imports and exports can be expressed as $I M_{i}\left(p_{i}^{I}\right)=$ $D_{i}^{I}\left(p_{i}^{I}\right)$ and $E X_{\bar{i}}^{I}\left(p_{\bar{i}}^{I}\right)=3 / 2-D_{\bar{i}}^{I}\left(p_{\bar{i}}^{I}\right)$ respectively, where $\bar{i} \in n \backslash i$ represents that good 


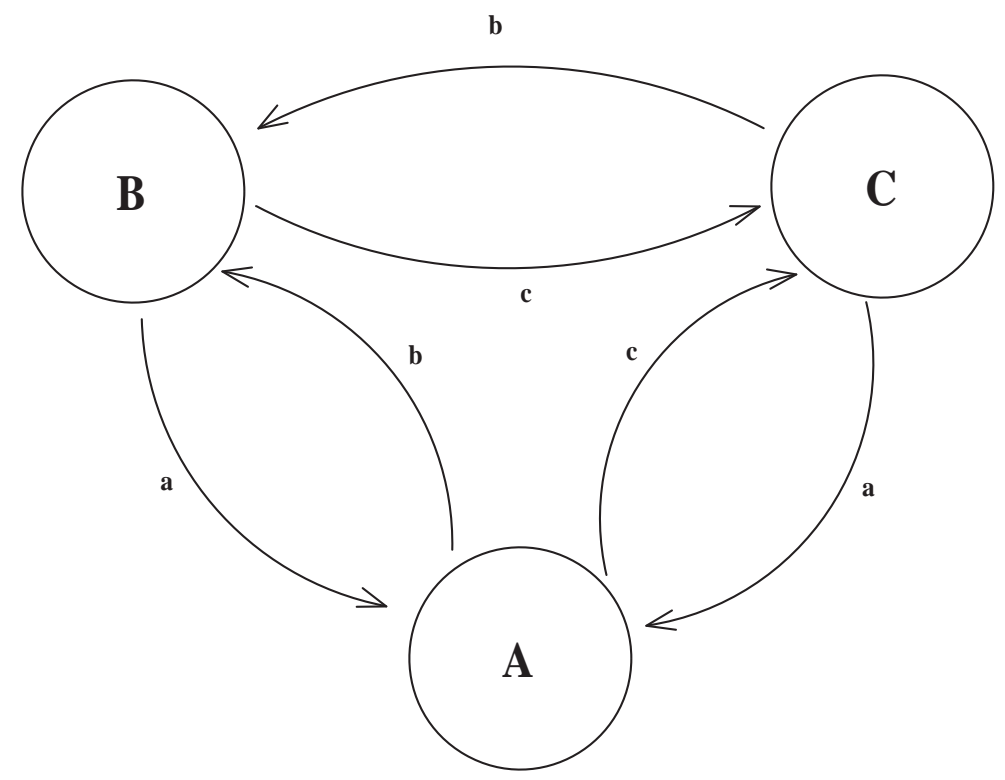

Figure 3.1: Trade Pattern

$\bar{i}$ is exported to country $\bar{I} \in N \backslash I$. Finally, we have the market-clearing condition, given by:

$$
I_{a}\left(p_{a}^{A}\right)=E X_{a}^{B}\left(p_{a}^{B}\right)+E X_{a}^{C}\left(p_{a}^{C}\right) .
$$

Then the equilibrium prices for good a can be solved from equations (3.1) and (3.2). We obtain that

$$
\begin{aligned}
& \hat{p}_{a}^{A}=\frac{\alpha-1}{\beta}+\frac{\tau_{a}^{B}+\tau_{a}^{C}}{3} ; \\
& \hat{p}_{a}^{B}=\frac{\alpha-1}{\beta}+\frac{\tau_{a}^{C}-2 \tau_{a}^{B}}{3} ; \\
& \hat{p}_{a}^{C}=\frac{\alpha-1}{\beta}+\frac{\tau_{a}^{B}-2 \tau_{a}^{C}}{3} .
\end{aligned}
$$


Similarly, we can solve the equilibrium prices for b and c. It is indicated that equilibrium prices are dependent on tariffs chosen by each country. Moreover, we notice that $\partial \hat{p}_{i}^{I} / \partial \tau_{i}^{\bar{I}}>0$, implying that the domestic price of the import good in each country increases in the tariff imposed on its trading partners. We also observe that $\partial\left(\hat{p}_{\bar{i}}^{I} / \hat{p}_{i}^{\bar{I}}\right) / \partial \tau_{i}^{\bar{I}}>0$, implying that a country's terms of trade improve when a higher tariff is imposed. In terms of export goods, we have $\partial \hat{p}_{b}^{A} / \partial \tau_{b}^{A}<0$ and $\partial \hat{p}_{b}^{A} / \partial \tau_{b}^{C}>0$, which implies that the export price in each country is decreasing in the tariff it faces and increasing in the tariff imposed on its export rival.

By substituting equilibrium prices into import and export functions, we can describe the equilibrium trade volumes in terms of a set of tariffs. For instance, in country A,

$$
\begin{aligned}
& I \hat{M}_{a}\left(\hat{p}_{a}^{A}\right)=D\left(\hat{p}_{a}^{A}\right)=1-\frac{\beta\left(\tau_{a}^{B}+\tau_{a}^{C}\right)}{3} ; \\
& \hat{E X_{b}^{A}}\left(\hat{p}_{b}^{A}\right)=3 / 2-D\left(\hat{p}_{b}^{A}\right)=1 / 2+\frac{\beta\left(\tau_{b}^{C}-2 \tau_{b}^{A}\right)}{3} ; \\
& \hat{E X}_{c}^{A}\left(\hat{p}_{c}^{A}\right)=3 / 2-D\left(\hat{p}_{c}^{A}\right)=1 / 2+\frac{\beta\left(\tau_{c}^{B}-2 \tau_{c}^{A}\right)}{3} .
\end{aligned}
$$

As we would expect, a country's import volume decreases in its import tariff. Its export volume also decreases in the tariff it faces and increases in the tariff imposed on its export rival. Finally, according to (3.6), (3.7) and (3.8), we obtain constraints that $\tau_{a}^{B}+\tau_{a}^{C}<3 / \beta, 2 \tau_{b}^{A}-\tau_{b}^{C}<3 / 2 \beta$ and $2 \tau_{c}^{A}-\tau_{c}^{B}<3 / 2 \beta$, which ensure that tariffs are non-prohibitive. Similar results about the equilibrium trade volumes and constraints for non-prohibitive tariffs can be obtained for country B and C. 


\subsubsection{Social Welfare, Government Objective and Optimal Tar- iffs}

Next, we solve the tariff vector in the trade equilibrium. In this chapter, we assume that the objective of each government is to maximise the social welfare of its own country, which is defined as the sum of its consumer surplus, producer surplus, and tariff revenue, given by:

$$
W^{I}=\sum_{j \in n} \int_{p_{j}^{I}}^{\alpha / \beta} D\left(p_{j}^{I}\right) d p_{j}^{I}+\frac{3}{2} \sum_{\bar{i} \in n \backslash i} p_{i}^{I}+\sum_{\bar{I} \in N \backslash I} \tau_{i}^{\bar{I}} E X_{i}^{\bar{I}},
$$

where the first term characterises the sum of the consumer surplus, the second term is producer surplus and the last term represents tariff revenue. In the trade equilibrium, the social welfare of each country can be described as a function of equilibrium prices, and further expressed as a set of tariffs. For instance, country A's social welfare in equilibrium becomes

$$
\begin{aligned}
\hat{W}^{A}(T)= & \frac{1}{2}\left(\frac{\alpha}{\beta}-\hat{p}_{a}^{A}\right)\left(\alpha-\beta \hat{p}_{a}^{A}\right)+\frac{1}{2}\left(\frac{\alpha}{\beta}-\hat{p}_{b}^{A}\right)\left(\alpha-\beta \hat{p}_{b}^{A}\right)+\frac{1}{2}\left(\frac{\alpha}{\beta}-\hat{p}_{c}^{A}\right)\left(\alpha-\beta \hat{p}_{c}^{A}\right) \\
& +\frac{3}{2} \hat{p}_{b}^{A}+\frac{3}{2} \hat{p}_{c}^{A}+\tau_{a}^{B}\left(3 / 2-\left(\alpha-\beta \hat{p}_{a}^{B}\right)\right)+\tau_{a}^{C}\left(3 / 2-\left(\alpha-\beta \hat{p}_{a}^{C}\right)\right) .
\end{aligned}
$$

We can then solve the welfare-maximising problem subject to the non-prohibitive tariff constraint to find the optimal tariffs of country A. The first-order conditions are given by $\partial \hat{W}^{A} / \partial \tau_{a}^{B}=0$ and $\partial \hat{W}^{A} / \partial \tau_{a}^{C}=0$, which yield the solution: $\tau_{a}^{B}=\tau_{a}^{C}=\frac{3}{8 \beta}$. Given the symmetry of the model, the same results apply for country B and C. In summary, the tariff bundle $\tau_{i}^{\bar{I}}=\frac{3}{8 \beta}$, for any $i \in n$, is the unique Nash equilibrium, while such a tariff pair chosen by each country is its dominant strategy in this static game.

There are several interesting implications from our results. First, the optimal tariffs chosen by each country are independent of the tariffs chosen by its trading 
partners. Second, the optimal tariffs of each country satisfy the MFN principle in the WTO framework, which requires that member countries are not permitted to discriminate in their tariff policy across members. Intuitively, this result can be partly ascribed to the symmetric setup of our model and the other reason may be that the option of RTAs has not been introduced yet. Furthermore, since the optimal tariff bundle is the unique Nash equilibrium, starting from the optimal tariff bundle, no country has the incentive to offer either non-reciprocal trade preferences or unilaterally non-discriminatory tariff reduction to its trading partners. However, we observe that the welfare of each country will increase if all countries reduce tariffs by the same proportion simultaneously. Therefore, multilateral trade cooperation can make all countries better off, while the "free-rider problem" gives rise to this "prisoner's dilemma" Nash equilibrium outcome.

\subsection{Trade Liberalisation through Bilateral FTAs or an MTA}

In this section, we identify all the possible types of trading bloc structures when trade liberalisation occurs either through bilateral FTAs or an MTA. Then we compare the one-shot welfare of each country under different structures and examine whether countries have the incentive to form such trading blocs or not.

If the countries are allowed to form trading blocs through bilateral FTAs or an MTA, there are eight possible structures, which can be divided into four categories. As shown in Figure 3.2, a link between any two countries means tariffs between them are eliminated. Figure 3.2(a) describes the circumstance in which 


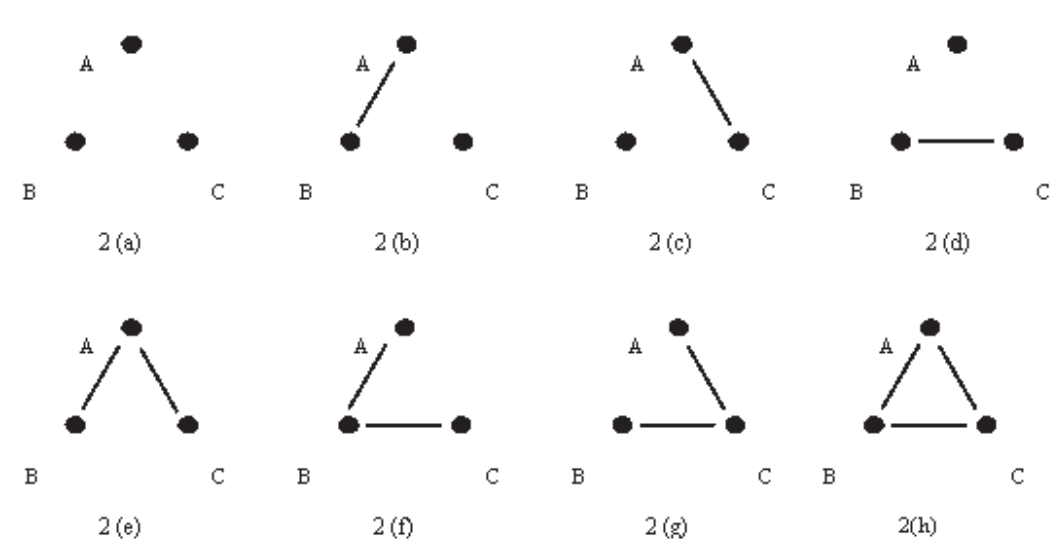

Figure 3.2: Possible Structures of Trading Blocs

no trade agreement is reached between countries. In this case, each country identically sets the MFN tariff at the Nash equilibrium level, as obtained previously. We denote it here as $\hat{\tau}_{n o n}=\frac{3}{8 \beta}$, and the tariff vector in this equilibrium becomes $\hat{T}_{\text {non }}=\left(\hat{\tau}_{\text {non }}, \hat{\tau}_{\text {non }}, \hat{\tau}_{\text {non }}, \hat{\tau}_{\text {non }}, \hat{\tau}_{\text {non }}, \hat{\tau}_{\text {non }}\right)$. By substituting $\hat{T}_{\text {non }}$ into equation (3.10), we can obtain the equilibrium social welfare for country A. Owing to the symmetry of the world, the equilibrium welfare should be equal across countries. We denote it as $\hat{W}_{n o n}$. Thus, we conclude that in the equilibrium before any bilateral or multilateral tariff cooperation, $\hat{W}^{A}\left(T_{\text {non }}\right)=\hat{W}^{B}\left(T_{\text {non }}\right)=\hat{W}^{C}\left(T_{\text {non }}\right)=\hat{W}_{\text {non }}$.

Figure 3.2(b), (c) and (d) depict the situations when two countries form a bilateral FTA, leaving the third country outside. The agreement eliminates tariffs between the two member countries. However, members can still independently impose tariffs on the non-member. For instance, in structure 3.2(b), an FTA is achieved between A and $\mathrm{B}$. In this case, $\tau_{a}^{B}$ and $\tau_{b}^{A}$ are removed while $\mathrm{A}$ and $\mathrm{B}$ can still impose tariffs on C. In our framework, we assume that tariffs are endogenised for each stage of trade liberalisation. In other words, after the formation of an FTA, each member 
country can change its original tariffs on the non-member and the non-member can also change tariffs on members to maximise their respective social welfare as given by (3.9). Thus, in the case of 3.2(b), the objective function for each country becomes $\hat{W}^{I}\left(0, \tau_{a}^{C}, 0, \tau_{b}^{C}, \tau_{c}^{A}, \tau_{c}^{B}\right)$, where $I \in N$. By solving the optimisation problem similarly as we did in section 3.2.2, we obtain that in equilibrium, $\tau_{a}^{B}=\tau_{b}^{A}=0 ; \tau_{a}^{C}=\tau_{b}^{C}=$ $\frac{3}{22 \beta}<\hat{\tau}_{\text {non }}$ and $\tau_{c}^{A}=\tau_{c}^{B}=\frac{3}{8 \beta}=\hat{\tau}_{\text {non }}$. Owing to the symmetric setup of our model, we can generally show that when a bilateral FTA is achieved, the equilibrium tariff imposed by an inside-FTA country is $\hat{\tau}_{\text {in }}=\frac{3}{22 \beta}<\hat{\tau}_{\text {non }}$, and $\hat{\tau}_{\text {out }}=\frac{3}{8 \beta}=\hat{\tau}_{\text {non }}$ by an outside-FTA country.

The result implies that an FTA leads member countries to voluntarily liberalise their external tariffs against the non-member country. Bagwell and Staiger (1999) describe this outcome as the tariff complementarity effect of an FTA, and therefore suggest that forming FTAs can be a good complement to multilateral tariff cooperation. Bagwell and Staiger (1999) did not detail why this effect arises and our explanation is that the formation of an FTA reduces the effectiveness of external tariffs for member countries in improving the terms of trade and increasing tariff revenue. This finding is consistent with the observation made by Richardson (1993), who attributes it to competition for tariff revenue by member countries.

In what follows, we compare circumstances before and after the formation of a bilateral FTA to examine the welfare impacts of an FTA on both member and nonmember countries, and investigate whether countries have any incentive to form an FTA. The following proposition can simply be derived to answer these questions.

Proposition 1 Compared to the circumstance without any trade agreement, a bilateral FTA improves the welfare of all countries, and member countries benefit more 
than the non-member.

Proof Without the loss of generality, suppose an FTA is formed between A and B. In equilibrium, the welfare of each country is given by $\hat{W}^{I}\left(0, \hat{\tau}_{\text {in }}, 0, \hat{\tau}_{\text {in }}, \hat{\tau}_{\text {out }}, \hat{\tau}_{\text {out }}\right)$, where $I \in N$. By substituting the value of $\hat{\tau}_{\text {in }}, \hat{\tau}_{\text {out }}$ and $\hat{\tau}_{\text {non }}$ into the welfare function of each country respectively, it is straightforward to show that

$$
\begin{gathered}
\hat{W}^{A}\left(0, \hat{\tau}_{\text {in }}, 0, \hat{\tau}_{\text {in }}, \hat{\tau}_{\text {out }}, \hat{\tau}_{\text {out }}\right)-\hat{W}^{A}\left(\hat{T}_{\text {non }}\right)>0 ; \\
\hat{W}^{B}\left(0, \hat{\tau}_{\text {in }}, 0, \hat{\tau}_{\text {in }}, \hat{\tau}_{\text {out }}, \hat{\tau}_{\text {out }}\right)-\hat{W}^{B}\left(\hat{T}_{\text {non }}\right)>0 ; \\
\hat{W}^{C}\left(0, \hat{\tau}_{\text {in }}, 0, \hat{\tau}_{\text {in }}, \hat{\tau}_{\text {out }}, \hat{\tau}_{\text {out }}\right)-\hat{W}^{C}\left(\hat{T}_{\text {non }}\right)>0 ; \\
\hat{W}^{A}\left(0, \hat{\tau}_{\text {in }}, 0, \hat{\tau}_{\text {in }}, \hat{\tau}_{\text {out }}, \hat{\tau}_{\text {out }}\right)=\hat{W}^{B}\left(0, \hat{\tau}_{\text {in }}, 0, \hat{\tau}_{\text {in }}, \hat{\tau}_{\text {out }}, \hat{\tau}_{\text {out }}\right)>\hat{W}^{C}\left(0, \hat{\tau}_{\text {in }}, 0, \hat{\tau}_{\text {in }}, \hat{\tau}_{\text {out }}, \hat{\tau}_{\text {out }}\right) .
\end{gathered}
$$

Using more general notations, if we denote $\hat{W}_{\text {in }}$ and $\hat{W}_{\text {out }}$ the equilibrium welfare of an FTA member and non-member respectively, we have $\hat{W}_{\text {in }}>\hat{W}_{\text {out }}>\hat{W}_{\text {non }}$, as was to be shown.

In contrast to the results of Mukunoki and Tachi (2006), suggesting that an FTA improves the welfare of member countries at the expense of the rest of the world, we notice that all the countries benefit from the formation of a bilateral FTA, although member countries gain more than the non-member. A different outcome arises here mainly because the FTA members reduce their external tariffs against the non-member.

Member countries benefit because the elimination of internal tariffs induces more competition within the FTA, thereby increasing the efficiency of the market. On the contrary, such a discriminatory trade liberalisation makes the non-member suffer because of a shift of the source of imports from a non-member to a member country, but 
meanwhile the reduction of external tariffs from the tariff complementarity effect provides the outside country easier access to the market of member countries. Our result shows that for a non-member country, the benefit due to the latter is strong enough to outweigh the negative effect from the former and ensures that the non-member country overall is better off. In addition, since each country is welfare motivated, the result also implies that each should have the incentive to form a bilateral FTA.

We have finished comparing circumstances before and after the formation of a bilateral FTA. Nevertheless, trade negotiation in the world may not end up with a single FTA. For instance, each member of the existing FTA may further develop an additional bilateral FTA with the non-member. This action does not require the approval of the other member, and the non-member can also actively originate a bilateral agreement with one of the members instead of joining the existing bloc. If such an extra agreement is completed on the basis of 3.2(b), (c) or (d), the world will turn out to have a structure with two overlapping bilateral FTAs, as shown in 3.2(e), (f) or (g). The term "hub-and-spoke" system is employed in the literature to characterise this structure. A "hub-and-spoke" system is different from another type of sequential liberalisation in which a bilateral FTA is expanded by accepting a new member. To form a "hub-and-spoke" system, each member of an existing FTA simply needs to negotiate with the non-member individually without the consent of the other member. When such an additional bilateral FTA is concluded, the previous member involved in the new agreement becomes the hub, and the other previous member and the non-member become spokes. Moreover, since a "hub-and-spoke" system is the overlapping result of two bilateral FTAs, it is also distinct from a CU. Here, instead of setting common external tariffs, each country involved in the "hub-and-spoke" 
system still sets its tariff independently. In addition, such a system only works in the presence of the rules of origin, which can at least avoid direct trade deflection. Otherwise, in our framework it would be the same as MFT.

Next, we extend our welfare and incentive analysis by incorporating the "hub-andspoke" system. We analogously proceed to assess the social welfare of each country in this system and compare it with the results obtained previously. In a "hub-andspoke" system, the market access between the hub and each spoke is duty free, but it is not duty free between the two spokes. In other words, tariffs only apply to trade between the two spokes. In a similar way to our previous analysis, we obtain that the equilibrium tariff level between the two spokes is given by $\hat{\tau}_{\text {spoke }}=\frac{3}{22 \beta}$. It is found that $\hat{\tau}_{\text {spoke }}=\hat{\tau}_{\text {in }}<\hat{\tau}_{\text {out }}$, implying that the tariff complementarity effect also occurs here. By substituting $\hat{\tau}_{\text {spoke }}$ into the welfare function, we can obtain the equilibrium welfare of each country in a "hub-and-spoke" system. Then we can compare it with previous circumstances, and derive the following proposition.

Proposition 2 Compared to the circumstance with a bilateral FTA, a "hub-andspoke" system makes the hub better off and both spokes worse off.

Proof If we denote $\hat{W}_{\text {hub }}$ and $\hat{W}_{\text {spoke }}$ the equilibrium welfare of the hub and a spoke respectively, it is straightforward to obtain that $\hat{W}_{\text {hub }}>\hat{W}_{\text {in }}>\hat{W}_{\text {out }}>\hat{W}_{\text {spoke }}>\hat{W}_{\text {non }}$, as was to be shown.

This proposition shows that in terms of social welfare, the hub is the most preferred position among those we have discussed so far. The rationale is quite simple. As a hub, the profit of the import-competing sector and tariff revenue decrease because of the complete elimination of its tariffs. However, consumer surplus increases because 
domestic consumers benefit from lower prices. Moreover, both of its two export sectors now have free access to other countries, which brings about more profit. In addition, since trade barriers still apply between the two spokes, each export firm in the hub country has an advantage in its overseas market, because a tariff is imposed on its export competitor from another spoke country. Our result shows that gains dominate losses. Thus, each member of a bilateral FTA has the incentive to establish an additional bilateral FTA with the non-member to become the hub.

On the contrary, the spoke position turns out to be extremely undesirable, and is even worse than that of the non-member in the circumstance with a bilateral FTA. This outcome is different from the one obtained by Mukunoki and Tachi (2006), suggesting that the spoke position is better than that of the non-member. This difference arises also because in our framework the FTA members reduce their external tariffs against the non-member when the first FTA is formed, bringing about significant benefit to the non-member.

Compared to being outside a bilateral FTA, it is easier for a spoke's exports to access the market of the hub. However, the benefit from this access is very limited, because its competitor from the other spoke also has free access. On the other hand, consumers in the spoke may benefit from eliminating tariffs on exports from the hub, but trade diversion caused by this discriminatory tariff arrangement can to some extent offset this positive effect. ${ }^{1}$ Furthermore, the reduction in the tariff revenue and loss in profit in the import-competing sector also makes the spoke country worse off. Our result shows that the negative effects outweigh the benefits. Therefore, in the circumstance with a single FTA, the non-member has no incentive to approve

\footnotetext{
${ }^{1}$ In this model, trade diversion is defined as a shift of the source of imports from a more efficient country to a less efficient country induced by an RTA.
} 
another bilateral FTA with either of the members and a "hub-and-spoke" system may not be established.

Finally, we complete this section by discussing the last possible circumstance on the path of trade liberalisation, i.e., MFT, in which all tariffs in the world are eliminated, as shown in 3.2(h). In our framework, this can be achieved through two alternative channels. On the one hand, it can be realised through three overlapping bilateral FTAs. For instance, on the basis of a "hub-and-spoke" system, as shown in 3.2(e), if another bilateral FTA is formed between the two spokes, it will lead to MFT. On the other hand, it can be concluded by an MTA through multilateral trade liberalisation (e.g., in the WTO framework) at any stage of trade negotiation. In this regime, all countries agree to eliminate their tariffs simultaneously. We can similarly derive the social welfare for each country under MFT and compare it with other scenarios. Since MFT is usually viewed as the optimum in trade negotiation by most trade theories, we provide more analysis. First, we examine whether MFT is the optimal outcome in terms of the social welfare of the world; second, we identify the welfare effects of MFT on each country at different stages of trade liberalisation, and third, we investigate whether countries are motivated to move towards MFT. The following two propositions elucidate these analyses.

Proposition 3 In terms of the total social welfare of the whole world, MFT is the unique optimal outcome.

Proof Let $\hat{W}$ be the total social welfare of the world in the trade equilibrium. Then we have

$$
\hat{W}=\hat{W}^{A}(T)+\hat{W}^{B}(T)+\hat{W}^{C}(T) .
$$


Thus, $\hat{W}$ is described as a function of T. By solving the optimisation problem of the function $\hat{W}(T)$, we obtain that the optimal tariff vector is $(0,0,0,0,0,0)$, as was to be shown.

This proposition confirms that MFT can lead the world to achieve maximal welfare, but it does not necessarily mean that MFT is the optimal outcome for every country. Therefore, our next proposition is to identify the welfare effects of MFT on each country and to examine whether the welfare of every country is improved. Since MFT can be achieved at any stage of trade negotiation, we need to compare the equilibrium welfare of each country under MFT with all other possible circumstances on the path of trade liberalisation.

Proposition 4 (i) Compared to the circumstance without any trade agreement, MFT improves the welfare for every country. (ii) If a bilateral FTA is already achieved, MFT still makes all countries better off. (iii) If a "hub-and-spoke" system is established, MFT makes the hub worse off and both spokes better off.

Proof If we denote $\hat{W}_{m f t}$ as the equilibrium welfare of each country under MFT, we can simply obtain that

$$
\begin{aligned}
& \hat{W}_{\text {hub }}-\hat{W}_{m f t}=\frac{23}{484 \beta}>0 ; \\
& \hat{W}_{m f t}-\hat{W}_{\text {in }}=\frac{303}{15488 \beta}>0 ; \\
& \hat{W}_{\text {in }}>\hat{W}_{\text {out }}=\frac{9}{15488 \beta}>0 ; \\
& \hat{W}_{\text {out }}>\hat{W}_{\text {spoke }}=\frac{19}{1936 \beta}>0 ; \\
& \hat{W}_{\text {spoke }}-\hat{W}_{\text {non }}=\frac{131}{7744 \beta}>0 .
\end{aligned}
$$

Thus, we have $\hat{W}_{\text {hub }}>\hat{W}_{m f t}>\hat{W}_{\text {in }}>\hat{W}_{\text {out }}>\hat{W}_{\text {spoke }}>\hat{W}_{\text {non }}$, as was to be shown. 


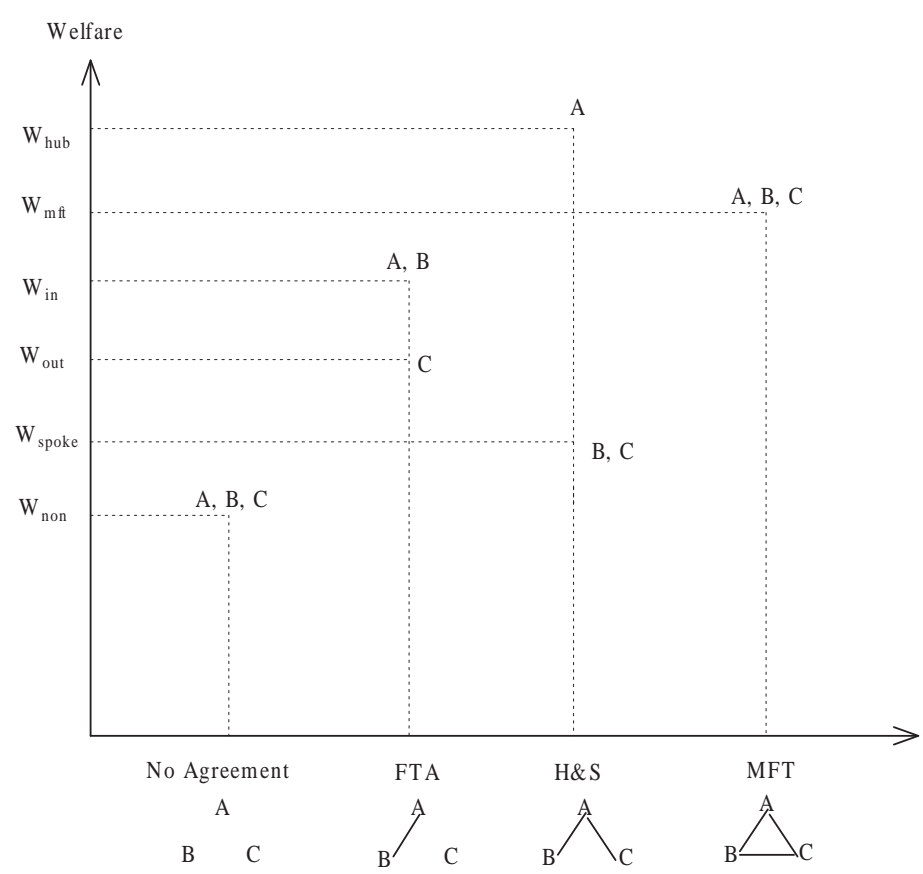

Figure 3.3: Welfare Ranking

In Mukunoki and Tachi (2006), the relationship between $\hat{W}_{m f t}$ and $\hat{W}_{i n}$ is uncertain, depending on initial tariffs. By endogenising tariffs, we obtain unambiguous welfare effects of all the trade agreements. In particular, $\hat{W}_{m f t}>\hat{W}_{i n}$ always hold, which is consistent with the case of Mukunoki and Tachi (2006) when initial tariffs are close to the Nash equilibrium level.

Our result also suggests that in regards to the welfare of an individual country, the position of hub is the best position within all structures of trading blocs, and MFT can lead to a better outcome than any other position except the hub. Thus, countries in most circumstances have the incentive to achieve MFT while the hub is unwilling to do so. Here, the strong position of the hub is illustrated again, which is proven to be even better than MFT. As explained earlier, this is because there is an advantage for exporters from the hub to compete in a spoke market with exporters 
from the other spoke. Having analysed the social welfare for all possible positions, we can rank it in a diagram, represented by Figure 3.3.

\subsection{Dynamic Negotiation Game}

\subsubsection{Setup of the Game}

After discussing the welfare effects and motivations of forming trade agreements, in this section we analyse the stability issue of trade negotiation. We investigate the nature of the stable structure of trading blocs when the formation of trade agreements is endogenously determined, and assess the dynamic process(es) to reach this. We introduce a sequential negotiation game between the three countries described in our basic framework with a finite horizon. In general, there are three periods in this game and three stages within each period. We assume that no trade agreement is achieved between them initially, and that countries set their tariffs at the levels of what we obtain in the equilibrium, respectively. Each country acts in turn as a leader and can either propose a trade liberalisation agreement, or do nothing, at the beginning of each period. If an agreement is offered, then the remaining two countries, as the followers, decide sequentially whether to accept or reject it at the next two stages of this period. When a leader makes an offer, it can decide whether to enter multilateral or bilateral negotiation, and if it decides to participate in the bilateral negotiation, it can choose to either offer a single bilateral FTA to one of the other countries, or two overlapping FTAs to both other countries simultaneously. The leader is not allowed to offer an existing agreement that has been approved already, but it can still offer an agreement that was rejected previously. In a bilateral negotiation process, an FTA is formed as 
long as the follower involved accepts the offer, while in a multilateral negotiation, an MTA is achieved only if both of the followers accept it. In other words, any rejection in a multilateral framework will end the negotiation in this period and the current structure of trading blocs will remain in place. As soon as an agreement is reached, countries will lead to a new equilibrium, and the corresponding equilibrium tariff vector solved in section 3.3 will be chosen. In addition, the game ends immediately when MFT is achieved, even though this three-period negotiating procedure has not been completed. It is also assumed that country A offers in the first period, and $\mathrm{B}$ and $\mathrm{C}$ are the leader for the second and third periods, respectively. Also, if an offer suggested by the leader involves both followers, then the sequence of their decisions complies with the rule that $\mathrm{A}$ moves prior to $\mathrm{B}, \mathrm{B}$ prior to $\mathrm{C}$, and $\mathrm{A}$ prior to $\mathrm{C}$. This assumption makes it more convenient to clarify whether there is a first-mover advantage in this game.

We formalise the notations of this game precisely as follows. Let $N=\{A, B, C\}$ denote the set of countries involved in this negotiation game. The set of history and terminal history are denoted $H$ and $Z$, respectively. $P(h)$ is the player function, and $D(h)$ is the action set at the history $h$, where $h \in H \backslash Z$. At the starting point of this game, where $h=\phi$, it is assumed that $P(\phi)=A$ and $D(\phi)=2^{N \backslash A} \bigcup N$. In this event, the action set consists of five elements: $\phi,\{B\},\{C\},\{B, C\}$ and $N$, which depict the feasible options of $\mathrm{A}$ at the initial history. Here, $\phi$ represents no action. At this particular history where leader A moves, it also means that the leader does not propose any sort of trade agreement. In contrast, the other four actions in $D(\phi)$ correspond to the possible choices when $A$ intends to offer a trade agreement, in which $\{B\}$ and $\{C\}$ characterise the action to offer a single bilateral FTA to B 
and $\mathrm{C}$, respectively, $\{B, C\}$ means to offer two overlapping FTAs to both $\mathrm{B}$ and $\mathrm{C}$ simultaneously, and the action $N$ represents the decision to participate in multilateral negotiation, suggesting that all countries eliminate tariffs in the world.

The set of history at the stage after the move by $\mathrm{A}$ is $H_{11}=\left\{h_{11}: h_{11}=\right.$ $(\phi, d(\phi)), d(\phi) \in D(\phi)\}$. We have $P\left(h_{11}\right)=B, \forall h_{11} \in H_{11}$ with the action set

$$
D\left(h_{11}\right)= \begin{cases}\phi & \text { if } d(\phi) \in\{\phi,\{C\}\} \\ \{a, r\} & \text { otherwise. }\end{cases}
$$

As a follower, its action $\phi$ also stands for no action, which indicates that $\mathrm{B}$ does not respond to A. By our definition, this event can occur in two circumstances. One is the case in which $\mathrm{A}$ does not propose any trade agreement at all (i.e., $d(\phi)=\phi)$ and the other is when B is not involved in the proposal suggested by A. Otherwise, B is to decide whether to accept or reject the offer.

After the response of $\mathrm{B}$, the history set can be expressed as

$$
H_{12}=\left\{h_{12}: h_{12}=\left(\phi, d(\phi), d\left(h_{11}\right)\right), d\left(h_{11}\right) \in D\left(h_{11}\right)\right\}
$$

It then becomes the turn of $\mathrm{C}$ to react $\left(P\left(h_{12}\right)=C, \forall h_{12} \in H_{12}\right)$, and its action set is similar to the one of $\mathrm{B}$ earlier, given by

$$
D\left(h_{12}\right)= \begin{cases}\phi & \text { if } d(\phi) \in\{\phi,\{B\}\} \text { or } d(\phi)=N \text { and } d\left(h_{11}\right)=r \\ \{a, r\} & \text { otherwise. }\end{cases}
$$

The action of $\mathrm{C}$ must be $\phi$ if it is not involved in the offer or if $\mathrm{B}$ rejects an offer prior to $\mathrm{C}$ in the multilateral negotiation.

The action of $\mathrm{C}$ at this stage completes the first period of our negotiation game, in which $\mathrm{A}$ is the leading country, while B and $\mathrm{C}$ follow sequentially, as described in Figure 3.4. We notice that all four types of trading blocs structures are likely to be reached in the first period and some of them can be achieved through different paths. 


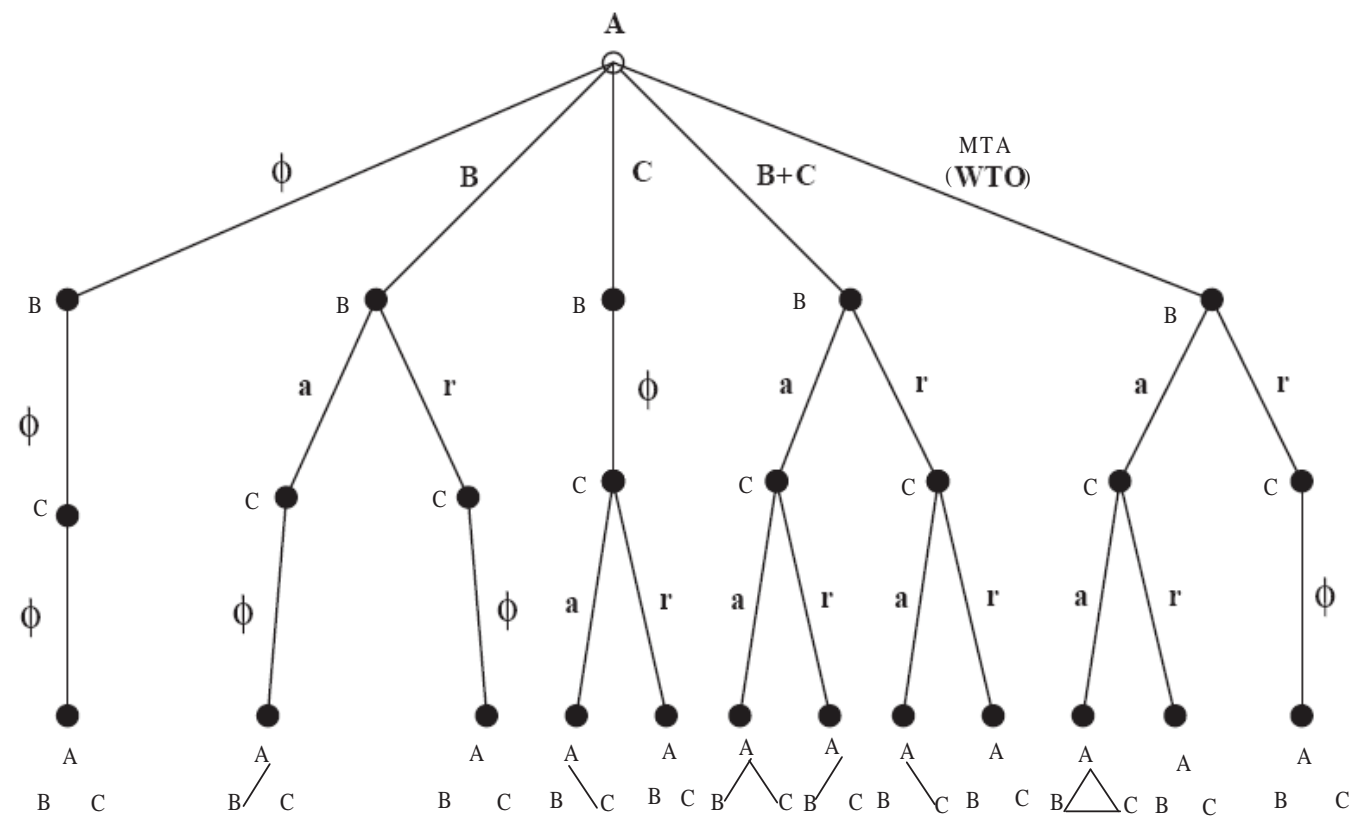

Figure 3.4: The First Period of the Game

The negotiation process in the remaining two periods is similar to the first one except for the changes in the role played by each country. B becomes the leader to make an offer in the second period, then A reacts followed by the response of C. In the last period, $\mathrm{C}$ leads the negotiation and $\mathrm{A}$ reacts prior to $\mathrm{B}$. Moreover, owing to the progress made in negotiation, the action set of the leader in a later period may become smaller, becoming a subset of $D(\phi)$. In our setup, it depends on which history this leader is at. For instance, suppose B is to move as a leader at the history $h_{2}$ where a bilateral FTA is already achieved between A and B (i.e., $h_{2}=(\phi,\{B\}, a, \phi)$ or $\left.\left.(\phi,\{B, C\}, a, r)\right\}\right)$ or a "hub-and-spoke system", with A as a hub, is already established (i.e., $\left.h_{2}=(\phi,\{B, C\}, a, a)\right)$ in the first period, then B only has the options between offering nothing $(\phi)$, a single FTA to $\mathrm{C}(\{C\})$ and an MTA $(N)$, and its action set thereby becomes $\{\phi,\{C\}, N\}$. Similarly, if MFT is achieved 
in the first period, negotiation ends before $\mathrm{B}$ can offer, so B is not active at all. To make our notations consistent, we assume the action set of $\mathrm{B}$ in this case is $\phi$. This may also be the case for $\mathrm{C}$, when $\mathrm{C}$ becomes the leader.

The one-shot payoff of a player $I \in N$ in period $t \in\{1,2,3\} \hat{W}_{t}^{I}$ is the value obtained from the welfare function of this country in the equilibrium given the trading blocs structure formed at the end of this period. Thus, it depends on the progress in negotiation and the position of the country in this structure of trading blocs. Moreover, the total payoff of the player in the game is its continuation payoff in all periods, expressed as $\hat{W}_{1}^{I}+\hat{W}_{2}^{I}+\hat{W}_{3}^{I}$, and each player is to maximise it.

\subsubsection{Equilibrium Outcome(s)}

In this section, we characterise the subgame perfect Nash equilibrium outcome(s) of this dynamic negotiation game to discuss the following questions: can MFT eventually be achieved through trade negotiation? If it can, is it achieved through the multilateral path or the bilateral path? If not, what will be the stable structure(s) of trading blocs? Moreover, which country can get the highest payoff and is there any first-mover advantage? The equilibrium outcome is derived by backward induction.

Proposition 5 MFT is the unique subgame perfect Nash equilibrium outcome of the trade negotiation game, and the outcome is achieved through an MTA in the first period.

Proof As we have shown previously, the welfare ranking between different positions is given by $\hat{W}_{\text {hub }}>\hat{W}_{\text {mft }}>\hat{W}_{\text {in }}>\hat{W}_{\text {out }}>\hat{W}_{\text {spoke }}>\hat{W}_{\text {non }}$. Thus, compared with 
MFT, there is only one superior position, that is the hub. But we suggest that a "huband-spoke" system can never be formed because no country is willing to become the spoke $\left(\hat{W}_{\text {out }}>\hat{W}_{\text {spoke }}\right)$. Thus, it is impossible for any country to achieve the level of welfare as a hub. Since MFT then becomes the best feasible position, every country is willing to achieve it as soon as possible. Therefore, in the first period of trade negotiation, MFT will be achieved through an MTA . The result can be confirmed in detail by backward induction as follows.

We at first consider the last period. According to the setup of the game, all the eight trading blocs structures shown in Figure 3.2 are possible at the end of the second period. If a "hub-and-spoke" structure in which $\mathrm{C}$ is the hub (shown by 3.2 (g)) or MFT (shown by $3.2(\mathrm{~h})$ ) has been achieved in the second period, it will also be maintained in the third period. For the remaining cases, MFT will be achieved in the third period.

Then, we consider the second period. Five outcomes are possible at the end of the first period, as shown in figure 3.2(a), (b), (c), (e), and (h). Similarly, if MFT has been achieved in the first period, it will be maintained in the second period. For the other cases, by taking into account the outcomes derived in the third period, we find that MFT will always be achieved in the second period.

We finally consider the first period. By taking into account the outcomes derived for the second and third periods, we find the outcome in the first period will be MFT through an MTA. In summary, MFT is the unique equilibrium outcome and it will be achieved through the following path: in the first period, A offers an MTA to B and $\mathrm{C}$, and both of them accept it. Thus, MFT is reached by an MTA at the end of the first period. 
This proposition reveals that if each country is to maximise its own welfare, trade negotiations will achieve MFT through the multilateral framework while bilateral trade agreements cannot be found on the equilibrium path. Our explanation is that although countries have the incentive to approve bilateral FTAs and being a hub is preferred even to MFT, a spoke position turns out to be extremely undesirable, and is even worse than being outside an existing bilateral FTA. Thus, a "hub-and-spoke" structure can never be formed and no country can become the hub. Then, every country will agree on its best feasible position-MFT through an MTA. We also find that the outcome makes the social welfare equal for each country, and therefore there is no first-mover advantage in the trade negotiation.

\subsection{Conclusion}

In this chapter, we apply the three-country and three-good "competing exporter trade model" originally developed by Bagwell and Staiger (1999) to study the welfare effects of different trade agreements and investigate the equilibrium outcome(s) of trade negotiation when each country is welfare motivated. The main contribution of this chapter is to provide new insights for the welfare and stability issues of trade liberalisation, especially the debate between multilateralism and regionalism, in a welfare-maximising framework. Our work shows that at the early stage of trade negotiation, a bilateral FTA becomes Pareto welfare improving owing to the tariff complementarity effect. Moreover, the hub is the best position for a country among all structures of trading blocs and is superior to MFT. However, the spoke position turns out to be extremely undesirable, and is worse than being outside an existing bilateral FTA. Thus, a "hub-and-spoke" system cannot be achieved and MFT through 
an MTA becomes the unique equilibrium outcome of trade negotiation.

The study in this chapter is limited to a world in which all countries are welfare maximising. However, politics plays a crucial role in trade liberalisation in the real world. Thus, in the following chapters, we extend our analysis into several frameworks in which each country is politically motivated. We investigate whether the welfare effects of trade agreements, the incentive of forming trading blocs and the equilibrium outcome of trade negotiation will change when each government has political concerns. In Chapter 4 we consider a circumstance in which the political pressures are only from the import-competing sector, and in Chapter 5 we allow all sectors to lobby the local government. We finally discuss an asymmetric world including two big countries and one small country in Chapter 6. 


\section{Chapter 4}

\section{Trade Agreements under the Political Pressures from the Import-Competing Sector}

\subsection{Introduction}

In the previous chapter we studied the welfare effects of different trade agreements and investigated the equilibrium outcome(s) of trade negotiation when each country is welfare motivated. Since politics plays a crucial role in trade liberalisation in the real world, we extend our analysis into frameworks in which each country is politically motivated. We aim to examine the welfare effects of trade agreements, the incentive to form trading blocs and the equilibrium outcome(s) of trade negotiation in several political economy frameworks. In the current chapter, we consider a circumstance in which the political pressures are only from the import competing sector.

We construct our trade framework on the basis of the three-country and threegood "competing exporter trade model" used in the previous chapter. The political structure we use is similar to Ornelas (2005), which follows the basic framework developed by Grossman and Helpman (1995), emphasising the interaction between lobby 
groups representing the special interest of one industry and the government in their home country. We find that the welfare effects of most trade agreements are analogous to what was obtained in the previous welfare-maximising framework except that the welfare ranking between a country outside a bilateral FTA and a spoke becomes ambiguous. In particular, when the political concerns are sufficiently large, a spoke is better off than an outside country. Moreover, since the objective of each government tends to include not only the national welfare but also political contributions, the motivation of forming a trade agreement becomes more complex. We show that the forces of the political economy reduce the chance to form a trade agreement. Moreover, the equilibrium outcome of trade negotiation in this case depends on the following two parameters. One is the relative concern to each government about political contributions and the other is the relative bargaining power of each government against the lobby group. As long as either of these parameters is small enough, MFT can be achieved. The path to achieving this outcome mainly depends on whether the "outside country" has the incentive to endorse an additional FTA to become a spoke. If this motivation exists, MFT will be achieved through overlapping FTAs. Otherwise, it will usually be achieved through an MTA. As the value of these two parameters increases, it is likely that a single FTA is the equilibrium outcome. If both of them become sufficiently large, no agreement will be achieved. In addition, we find that the option of bilateral FTAs does not make an initially infeasible MFT become feasible, while the previously feasible MFT is likely to be blocked by the option of an FTA. Thus, it supports the argument that RTAs can be "stumbling blocks". What is more interesting, for a particular range of parameter values, countries have no incentive to achieve an MTA. They do form a single FTA but are not willing to move 
further. The FTA improves the welfare for all countries, although MFT cannot be achieved.

The structure of this chapter is similar to Chapter 3. Section 2 presents the trade framework and discusses some properties in the political equilibrium before any trade agreement is achieved. Section 3 compares the social welfare and government payoff of each country under different structures of trading blocs. We further assess the welfare effects of each trade agreement and whether countries have an incentive to approve this agreement. An analogous trade negotiation game is introduced in section 4 to investigate the equilibrium outcome(s) of trade negotiation. The final section summarises the results.

\subsection{The Static Trade Model}

\subsubsection{Basic Framework}

We examine trade policies in a world with three symmetric countries. In the previous chapter, we assume that each of the three countries is endowed with zero units of one good and 3/2 units of each of other two goods. This setup gives rise to the result that there is no import competing sector for any country, so it is unlikely to bring about any lobbying activity representing such a sector. Since our work in the current chapter aims to incorporate the effect of the political economy, we improve the trade model used previously. We instead assume that each country is endowed with all of these three goods, while the endowment of one of the goods is relatively smaller than the other two. This assumption ensures that the sector with smaller endowment has to compete with the same importing good in the domestic market, so lobby groups 
may be formed to pursue protection from their domestic government.

Again, consider a world with three countries A, B and C, with three goods a, b and c. All the basic setups still apply except that in the current circumstance we assume that each country $I \in N$ is endowed with $k$ units of good $\mathrm{i}$ and $x k$ units of each good in the set $n \backslash i$, where $k>0$ and $x>1$. The endowment difference also generates different autarky prices across countries, which makes country I import good i from either of the other two countries. Thus, the trade pattern is the same as illustrated by Figure 3.1.

The political structure follows the basic framework developed by Grossman and Helpman (1995), which emphasises the interaction between lobby groups representing the special interest of one industry and the government in their home country. The owners of capital in a certain sector are able to organise a lobby group to make political contributions (PC) contingent on the trade policy taken by the government. Since production is not considered in our framework, we assume that the owners of endowment can form a lobby group. Moreover, in this chapter, only the owners in the import competing sector are highly concentrated, and these constitute a negligible fraction of the total population. Therefore, only they are able to solve the free rider problem to organise a lobby group. Also, since they only capture a negligible fraction of consumer surplus and tariff revenue, their objective becomes the producer surplus minus the contributions given to the government. Their objective can be expressed as:

$$
V_{i}^{I}(T, P C)=\Pi_{i}^{I}(T)-P C^{I}
$$

On the other hand, the objective of the government is a weighted average of aggregate social welfare and political contributions from the lobby group. For country 
I, that is

$$
G^{I}(T, P C)=W^{I}(T)+\gamma P C^{I},
$$

where $W^{I}$ is the total social welfare for country I, which is defined in a similar way as in Chapter 3. This assumption implies that the government cares about both social welfare and political contributions, where the non-negative parameter $\gamma$ reflects the relative weight of the government on political contributions. As explained by Grossman and Helpman (1995), this is because political contributions can be used to finance campaign spending and provide other benefits to the officeholders while social welfare becomes crucial if voters see it as an important indicator of the performance of the government in the election. In particular, when $\gamma=0$, we have the special case in which the government is welfare maximising.

To simplify our analysis of the lobbying process between the owners in the import competing sector and the local government, we model the political game as a Nash bargaining game, as suggested by Maggi and Rodriguez-Clare (1998), in which $\sigma$ and $1-\sigma(\sigma \in[0,1])$ denote the bargaining power of the government and the lobby group, respectively. Although in much of the literature, including the seminal work by Grossman and Helpman (1995), the bargaining process is constructed as an extensive form game, we instead model it as a cooperative game for two reasons. First, the bargaining procedure between the lobby group and the government is not explicit in practice. For instance, it is not clear which party moves first in this political game. Nash's bargaining model can avoid the vagueness of the lobbying process. Second, it is more straightforward for us to solve the equilibrium contribution value by using this approach. This solution is crucial if we aim to further examine the equilibrium outcome of the dynamic negotiation game between countries. 


\subsubsection{Trade Equilibrium}

We still start by examining the perfectly competitive trade equilibrium given initial tariffs, and the method used here is the same as in Chapter 3. Nevertheless, under the current setup, for each country $I \in N$, its imports and exports become $I M_{i}\left(p_{i}^{I}\right)=$ $D_{i}^{I}\left(p_{i}^{I}\right)-k$ and $E X_{\bar{i}}^{I}\left(p_{\bar{i}}^{I}\right)=x k-D_{\bar{i}}^{I}\left(p_{\bar{i}}^{I}\right)$ respectively, where $\bar{i} \in n \backslash i$ represents that good $\bar{i}$ is exported to country $\bar{I} \in N \backslash I$. Following the procedure we used in the previous chapter, we obtain the result that the equilibrium prices for good a in the three countries are given by

$$
\begin{aligned}
& \hat{p}_{a}^{A}=\frac{\alpha}{\beta}-\frac{k+2 x k}{3 \beta}+\frac{\tau_{a}^{B}+\tau_{a}^{C}}{3} ; \\
& \hat{p}_{a}^{B}=\frac{\alpha}{\beta}-\frac{k+2 x k}{3 \beta}+\frac{\tau_{a}^{C}-2 \tau_{a}^{B}}{3} ; \\
& \hat{p}_{a}^{C}=\frac{\alpha}{\beta}-\frac{k+2 x k}{3 \beta}+\frac{\tau_{a}^{B}-2 \tau_{a}^{C}}{3} .
\end{aligned}
$$

Similarly, we can solve the equilibrium prices for b and c. By substituting equilibrium prices into import and export functions, we can describe the equilibrium trade volumes in terms of a set of tariffs. For instance, in country A,

$$
\begin{aligned}
& I \hat{M}_{a}\left(\hat{p}_{a}^{A}\right)=D\left(\hat{p}_{a}^{A}\right)-k=\frac{2(x k-k)-\beta\left(\tau_{a}^{B}+\tau_{a}^{C}\right)}{3} ; \\
& \hat{E X_{b}^{A}}\left(\hat{p}_{b}^{A}\right)=x k-D\left(\hat{p}_{b}^{A}\right)=\frac{x k-k+\beta\left(\tau_{b}^{C}-2 \tau_{b}^{A}\right)}{3} \\
& \hat{E X_{c}^{A}}\left(\hat{p}_{c}^{A}\right)=x k-D\left(\hat{p}_{c}^{A}\right)=\frac{x k-k+\beta\left(\tau_{c}^{B}-2 \tau_{c}^{A}\right)}{3} .
\end{aligned}
$$


As we would expect, all the properties regarding tariffs we had in section 3.2.2 hold here. Finally, according to (4.6), (4.7) and (4.8), we obtain constraints that $\tau_{a}^{B}+\tau_{a}^{C}<2(x k-k) / \beta, 2 \tau_{b}^{A}-\tau_{b}^{C}<(x k-k) / \beta$ and $2 \tau_{c}^{A}-\tau_{c}^{B}<(x k-k) / \beta$, which ensure that tariffs are non-prohibitive. Similar results about the equilibrium trade volumes and constraints for non-prohibitive tariffs can be obtained for country B and C.

\subsubsection{Equilibrium Tariffs and Political Contributions in the Presence of Political Pressures}

Next, we solve the equilibrium tariffs and political contributions with the presence of political pressures. In our framework, they are the equilibrium outcome of the Nash bargaining game mentioned previously. For country $I \in N$, the threat point of this bargaining problem is the situation without any lobbying activity, in which $P C^{I}=0$ and its tariffs $\tau_{i}^{\bar{I}}$ are set to maximise the social welfare of this country, denoted by $\tau_{i}^{\bar{I}^{*}}$. In such a circumstance, the payoffs of the government and the import competing sector are given by $W^{I^{*}}$ and $\Pi_{i}^{I^{*}}$, respectively. Furthermore, it is straightforward to show that if the lobbying activity occurs, the efficient bargaining outcome is obtained when the tariffs are set to maximise $W^{I}+\gamma \Pi_{i}^{I}$, that is

$$
\tau_{i}^{\bar{I}}{ }^{p} \in \arg \max _{\tau_{i}^{\bar{I}}}\left(W^{I}+\gamma \Pi_{i}^{I}\right)
$$

We call them the optimal political tariffs, respectively.

By solving this optimisation problem, the optimal level of political tariff of each 
country is given by

$$
\tau_{i}^{p}=\frac{x k+3 \gamma k-k}{4 \beta}
$$

In the case where each government is only concerned with its social welfare $(\gamma=0)$, the optimal social welfare-maximising tariff is $\tau_{i}^{\bar{I}^{*}}=\frac{x k-k}{4 \beta}$. Here, we also add the restriction that $\gamma<x-1$ to ensure that the optimal political tariff is non-prohibitive. Since $k>0, \beta>0$ and $x>1$, we can then state the following proposition.

Proposition 6 The optimal tariffs imposed by each government are strictly increasing in its relative concern about political contributions $(\gamma)$.

This result is not surprising and implies that the optimal political tariff should be higher than the optimal one set to maximise the national welfare. The explanation for that is quite straightforward. When a government has political concerns about a sector, there has to be a preferred policy used to protect it. Here, imposing a higher tariff is to protect the import competing sector. In addition, greater concerns about this sector should lead to higher protection being provided. Thus, the optimal political tariff will increase as the relative weight of the political concerns to social welfare $(\gamma)$ becomes larger.

We complete this section by solving the equilibrium level of political contributions. As we have mentioned previously, the approach applied here can guarantee that the bargaining result is efficient. However, the distribution of the bargaining surplus is dependent on the bargaining power between the lobby group and the government. In country $I \in N$, to convince the government to implement politically pressured tariffs, the lobby group must at least contribute:

$$
P C_{\min }^{I}=\frac{W^{I^{*}}-W^{I^{p}}}{\gamma},
$$


where $W^{I^{p}}$ denotes the social welfare if the politically pressured tariffs are adopted. Otherwise, the government will ignore the political contributions and set the welfaremaximising tariffs $\tau_{i}^{\bar{I}^{*}}$. When $P C^{I}$ reaches the minimal value, the import competing sector captures the whole bargaining surplus while the government obtains nothing. On the other hand, the maximal value of the contributions is given by

$$
P C^{I}{ }_{\max }=\Pi_{i}^{I^{p}}-\Pi_{i}^{I^{*}}
$$

where $\Pi_{i}^{I^{p}}$ denotes the profit in the import-competing sector if the politically pressured tariffs are adopted. If the contributions exceed this value, the payoff for this sector will be higher without any contributions. When $P C^{I}$ reaches this upper bound, the government obtains the whole bargaining surplus. Since we have assigned $\sigma$ and $1-\sigma$ the bargaining power of the government and lobby group, respectively, the equilibrium contributions in each country is given by:

$$
\hat{P C}^{I}=\sigma P C_{\text {max }}^{I}+(1-\sigma) P C^{I}{ }_{\text {min }} .
$$

\subsection{Trade Liberalisation in the Presence of Politi- cal Pressures}

In Chapter 3, we identified all the possible types of trading blocs structures when trade liberalisation occurs either through bilateral FTAs or an MTA, as shown in Figure 3.2. In this section, we still compare the one-shot welfare of each country under different structures and examine whether countries have the incentive to form such trading blocs or not. We now consider these questions in the political framework. Since the government objective of a country may diverge from its social welfare, our 
analysis is more complex than that in Chapter 3.

Figure 3.2(a) describes the circumstance in which no trade agreement is reached between countries. In our current framework, each country identically sets the MFN tariff at the optimal political tariff level, as given by equation (4.10). We denote it here as $\hat{\tau}_{\text {non }}^{p}$ and the tariff vector in this equilibrium becomes $\hat{T}_{\text {non }}^{p}=\left(\hat{\tau}_{\text {non }}^{p}, \hat{\tau}_{\text {non }}^{p}, \hat{\tau}_{\text {non }}^{p}, \hat{\tau}_{\text {non }}^{p}, \hat{\tau}_{\text {non }}^{p}, \hat{\tau}_{\text {non }}^{p}\right)$. By substituting $\hat{T}_{n o n}^{p}$ into each country's welfare function, we can obtain the social welfare for each country in the political equilibrium. Because of the symmetry of the world, the equilibrium welfare should be equal across countries. Thus, we can use $\hat{W}_{n o n}^{p}$ to denote the level of social welfare for each country in the political equilibrium before any bilateral or multilateral tariff cooperation, where $\hat{W}_{n o n}^{p}=\hat{W}^{A}\left(T_{n o n}^{p}\right)=$ $\hat{W}^{B}\left(T_{n o n}^{p}\right)=\hat{W}^{C}\left(T_{n o n}^{p}\right)$. Furthermore, we can solve the level of political contributions in this equilibrium $\hat{P C_{n o n}}$ by substituting $\tau_{i}^{\bar{I}^{*}}$ and $\tau_{i}^{\bar{I}^{p}}$ into (4.11), (4.12) and (4.13), and we have $\hat{P C_{n o n}}=\frac{(1+\sigma) \gamma k^{2}}{4 \beta}$.

Figure 3.2(b) depicts the situation in which two countries, A and B, form a bilateral FTA. In this case, $\tau_{a}^{B}$ and $\tau_{b}^{A}$ are removed while A and B can still impose tariffs on C. Thus, the objective function for each government becomes $G^{I}\left(0, \tau_{a}^{C}, 0, \tau_{b}^{C}, \tau_{c}^{A}, \tau_{c}^{B}\right)$, where $I \in N$. By solving the optimisation problem, we obtain that in equilibrium, $\tau_{a}^{B}=\tau_{b}^{A}=0, \tau_{a}^{C}=\tau_{b}^{C}=\frac{x k+3 \gamma k-k}{11 \beta}<\hat{\tau}_{n o n}^{p}$, and $\tau_{c}^{A}=\tau_{c}^{B}=\frac{x k+3 \gamma k-k}{4 \beta}=\hat{\tau}_{\text {non. }}^{p}$. In general, the optimal political tariff imposed by an inside-FTA country is $\hat{\tau}_{i n}^{p}=\frac{x k+3 \gamma k-k}{11 \beta}<$ $\hat{\tau}_{\text {non }}^{p}$, and $\hat{\tau}_{\text {out }}^{p}=\frac{x k+3 \gamma k-k}{4 \beta}=\hat{\tau}_{\text {non }}^{p}$ by an outside-FTA country.

This result is consistent with what was observed in the previous chapter. Here, we confirm that the tariff complementarity effect of an FTA occurs even in the presence of political pressures. Moreover, we find that the extent of the external tariff reduction $\left(\hat{\tau}_{i n}^{p}-\hat{\tau}_{n o n}^{p}\right)$ is strictly increasing in $\gamma$, which implies that the tariff complementarity 
effect is reinforced when the political economy is introduced. Ornelas (2005) explains that there are two effects of tariffs on the domestic market. First, imposing tariffs on imports will shift domestic consumption from imports to domestic products, which increases the profits of local producers. This is called the strategic effect. It will also shift domestic surplus from consumers to producers, named the distributive effect. However, because the effectiveness of the external tariff to achieve these two targets is reduced with an FTA, the formation of an FTA will weaken the incentive of member governments to keep a high external tariff. Meanwhile, the political economy reinforces both the strategic and the distributive motives of each government for protection. Therefore, the reduction in external tariffs by FTA member countries becomes deeper.

In what follows, we again compare structure 3.2(a) and (b) to examine the welfare impacts of an FTA on both member and non-member countries in this political economy framework, and investigate whether countries have any incentive to form an FTA. The following two propositions can simply be derived to answer these two questions.

Proposition 7 Compared to the circumstance without any trade agreement, a bilateral FTA improves the welfare of all countries, and member countries benefit more than the non-member. Furthermore, the extent of welfare improvement for each member is increasing in its relative concern about the political contributions $(\gamma)$.

Proof Without the loss of generality, suppose an FTA is formed between A and B. In the political equilibrium, the welfare of each country is given by $\hat{W}^{I}\left(0, \hat{\tau}_{\text {in }}^{p}, 0, \hat{\tau}_{\text {in }}^{p}, \hat{\tau}_{\text {out }}^{p}, \hat{\tau}_{\text {out }}^{p}\right)$, where $I \in N$. By substituting the value of $\hat{\tau}_{i n}^{p}, \hat{\tau}_{\text {out }}^{p}$ and $\hat{\tau}_{\text {non }}^{p}$ into the welfare function 
of each country, respectively, we obtain that

$$
\begin{gathered}
\hat{W}^{A}\left(0, \hat{\tau}_{\text {in }}^{p}, 0, \hat{\tau}_{\text {in }}^{p}, \hat{\tau}_{\text {out }}^{p}, \hat{\tau}_{\text {out }}^{p}\right)-\hat{W}^{A}\left(\hat{T}_{\text {non }}^{p}\right)=\frac{k^{2}(x+3 \gamma-1)(47 x+229 \gamma-47)}{3872 \beta} ; \\
\hat{W}^{B}\left(0, \hat{\tau}_{\text {in }}^{p}, 0, \hat{\tau}_{\text {in }}^{p}, \hat{\tau}_{\text {out }}^{p}, \hat{\tau}_{\text {out }}^{p}\right)-\hat{W}^{B}\left(\hat{T}_{\text {non }}^{p}\right)=\frac{k^{2}(x+3 \gamma-1)(47 x+229 \gamma-47)}{3872 \beta} ; \\
\hat{W}^{C}\left(0, \hat{\tau}_{\text {in }}^{p}, 0, \hat{\tau}_{\text {in }}^{p}, \hat{\tau}_{\text {out }}^{p}, \hat{\tau}_{\text {out }}^{p}\right)-\hat{W}^{C}\left(\hat{T}_{\text {non }}^{p}\right)=\frac{k^{2}(x+3 \gamma-1)(23 x-19 \gamma-23)}{1936 \beta} ; \\
\hat{W}^{A}\left(0, \hat{\tau}_{\text {in }}^{p}, 0, \hat{\tau}_{\text {in }}^{p}, \hat{\tau}_{\text {out }}^{p}, \hat{\tau}_{\text {out }}^{p}\right)-\hat{W}^{C}\left(0, \hat{\tau}_{\text {in }}^{p}, 0, \hat{\tau}_{\text {in }}^{p}, \hat{\tau}_{\text {out }}^{p}, \hat{\tau}_{\text {out }}^{p}\right)=\frac{k^{2}(x+3 \gamma-1)(x+267 \gamma-1)}{3872 \beta} ; \\
\hat{W}^{B}\left(0, \hat{\tau}_{\text {in }}^{p}, 0, \hat{\tau}_{\text {in }}^{p}, \hat{\tau}_{\text {out }}^{p}, \hat{\tau}_{\text {out }}^{p}\right)-\hat{W}^{C}\left(0, \hat{\tau}_{\text {in }}^{p}, 0, \hat{\tau}_{\text {in }}^{p}, \hat{\tau}_{\text {out }}^{p}, \hat{\tau}_{\text {out }}^{p}\right)=\frac{k^{2}(x+3 \gamma-1)(x+267 \gamma-1)}{3872 \beta} .
\end{gathered}
$$

Since $k>0, \beta>0, x>1$ and $0 \leq \gamma<x-1$, it is straightforward to show that

$$
\begin{gathered}
\hat{W}^{A}\left(0, \hat{\tau}_{\text {in }}^{p}, 0, \hat{\tau}_{\text {in }}^{p}, \hat{\tau}_{\text {out }}^{p}, \hat{\tau}_{\text {out }}^{p}\right)>\hat{W}^{A}\left(\hat{T}_{\text {non }}^{p}\right) ; \\
\hat{W}^{B}\left(0, \hat{\tau}_{\text {in }}^{p}, 0, \hat{\tau}_{\text {in }}^{p}, \hat{\tau}_{\text {out }}^{p}, \hat{\tau}_{\text {out }}^{p}\right)>\hat{W}^{B}\left(\hat{T}_{\text {non }}^{p}\right) ; \\
\hat{W}^{C}\left(0, \hat{\tau}_{\text {in }}^{p}, 0, \hat{\tau}_{\text {in }}^{p}, \hat{\tau}_{\text {out }}^{p}, \hat{\tau}_{\text {out }}^{p}\right)>\hat{W}^{C}\left(\hat{T}_{\text {non }}^{p}\right) ; \\
\hat{W}^{A}\left(0, \hat{\tau}_{\text {in }}^{p}, 0, \hat{\tau}_{\text {in }}^{p}, \hat{\tau}_{\text {out }}^{p}, \hat{\tau}_{\text {out }}^{p}\right)=\hat{W}^{B}\left(0, \hat{\tau}_{\text {in }}^{p}, 0, \hat{\tau}_{\text {in }}^{p}, \hat{\tau}_{\text {out }}^{p}, \hat{\tau}_{\text {out }}^{p}\right)>\hat{W}^{C}\left(0, \hat{\tau}_{\text {in }}^{p}, 0, \hat{\tau}_{\text {in }}^{p}, \hat{\tau}_{\text {out }}^{p}, \hat{\tau}_{\text {out }}^{p}\right) .
\end{gathered}
$$

It is also obvious that $\hat{W}^{A}\left(0, \hat{\tau}_{\text {in }}^{p}, 0, \hat{\tau}_{\text {in }}^{p}, \hat{\tau}_{\text {out }}^{p}, \hat{\tau}_{\text {out }}^{p}\right)-\hat{W}^{A}\left(\hat{T}_{\text {non }}^{p}\right)$ and $\hat{W}^{B}\left(0, \hat{\tau}_{\text {in }}^{p}, 0, \hat{\tau}_{\text {in }}^{p}, \hat{\tau}_{\text {out }}^{p}, \hat{\tau}_{\text {out }}^{p}\right)-\hat{W}^{B}\left(\hat{T}_{\text {non }}^{p}\right)$ increase in $\gamma$.

Using more general notations, if we denote $\hat{W}_{i n}^{p}$ and $\hat{W}_{\text {out }}^{p}$ the welfare of an FTA member and non-member in the political equilibrium, respectively, we have $\hat{W}_{i n}^{p}>$ $\hat{W}_{\text {out }}^{p}>\hat{W}_{\text {non }}^{p}$, and $\hat{W}_{\text {in }}^{p}-\hat{W}_{\text {non }}^{p}$ increases in $\gamma$, as was to be shown.

The proposition shows that the fact that all countries benefit from a bilateral FTA also applies in this political economy framework. Moreover, we notice that the political economy leads to a greater welfare improvement for member countries than a purely welfare-motivated government. This result can be explained by the 
deeper reduction in both internal and external tariffs for FTA members in the political economy. When no trade agreement is formed, higher tariffs imposed in the political economy would make the welfare of each country lower than the social optimal level. Thus, when an FTA is achieved, the welfare improvement for member countries can be greater in the political economy than that in a welfare-maximising world.

The proposition also indicates that if countries are purely welfare motivated, they should be willing to approve the FTA. However, in our current framework, since each country cares about not only national welfare but also political contributions, we are yet to clarify whether countries have the incentive to form an FTA or not. Thus, we now turn to examine the conditions under which politically motivated countries have the incentive to do so. Here, we assume that a country is motivated to implement an FTA if and only if the government payoff after the formation of the FTA is greater than before based on the objective function given by (4.2), i.e., $\hat{G}_{i n}>\hat{G}_{n o n}$. If we substitute the equilibrium tariffs with a bilateral FTA into equations (4.11), (4.12) and (4.13), we obtain that the political contributions for a member and non-member are given by $\hat{P C_{i n}}=\frac{(1+\sigma) \gamma k^{2}}{22 \beta}$ and $\hat{P C_{\text {out }}}=\frac{(1+\sigma) \gamma k^{2}}{4 \beta}$, respectively. We find that $\hat{P C_{i n}} \leq \hat{P C_{n o n}}$, where they are equal when $\gamma=0$, and $\hat{P C_{\text {out }}}=\hat{P C_{\text {non }}}$. This result implies that when two countries form an FTA, the effect on their government payoff is uncertain, while the government payoff for the outside country definitely increases. Thus, it is still ambiguous whether countries have the incentive to form an FTA. Nevertheless, one fact clarified here is that in this political framework, no country will implement a welfare-reducing FTA, while it may prevent a welfare-improving one, as suggested by Ornelas (2005). The following proposition allows us to assess the incentive of forming an FTA in more detail. 
Proposition 8 In the circumstance originally without any trade agreement, political economy forces reduce the likelihood of forming a bilateral FTA. In particular, each country has the incentive to approve an FTA if and only if $\sigma<\sigma_{0}$, where

$$
\sigma_{0}=\frac{47(x-1)^{2}+370(x-1) \gamma-105 \gamma^{2}}{792 \gamma^{2}} .
$$

Proof If we substitute the combination of $\hat{W}_{i n}^{p}$ and $\hat{P C_{i n}}$ and the combination of $\hat{W}_{n o n}^{p}$ and $\hat{P C_{n o n}}$ into (4.2), we obtain that the payoff difference between an FTA member and a country before the formation of any trade agreement is

$$
\hat{G}_{\text {in }}-\hat{G}_{\text {non }}=\frac{47(x-1)^{2} k^{2}+370(x-1) \gamma k^{2}-105 \gamma^{2} k^{2}-792 \sigma \gamma^{2} k^{2}}{3872 \beta} .
$$

In the case without any political pressure, $(\gamma=0)$, we have $\hat{G}_{i n}>\hat{G}_{n o n}$, which confirms that countries have the incentive to form an FTA if each government is purely welfare motivated. Alternatively, if $\gamma>0$, we obtain that $\hat{G}_{i n}>\hat{G}_{\text {non }}$ if $\sigma<\sigma_{0}$ and $\hat{G}_{i n} \leq \hat{G}_{n o n}$ otherwise, as was to be shown.

This proposition implies that political pressures reduce the possibility of forming an FTA that is welfare improving for all countries. Since $\sigma_{0}$ is decreasing and convex in $\gamma$, to ensure countries have the incentive to form an FTA requires that $\sigma$ or $\gamma$ is small enough. Figure 4.1 illustrates an example when $\mathrm{x}=2$. In this case, if $\sigma$ and $\gamma$ are located above the curve, the motivation of forming a welfare-improving FTA will be blocked by political pressures. In this area, any combination of these two parameters leads to $\hat{G}_{i n}<\hat{G}_{n o n}$. In other words, everything else being constant, there is less possibility to form an FTA when the value of $\gamma$ or $\sigma$ gets larger. The intuition behind $\gamma$ is quite straightforward. The lobby group intends to prevent the local government from forming an FTA because of the reduction in their surplus when 


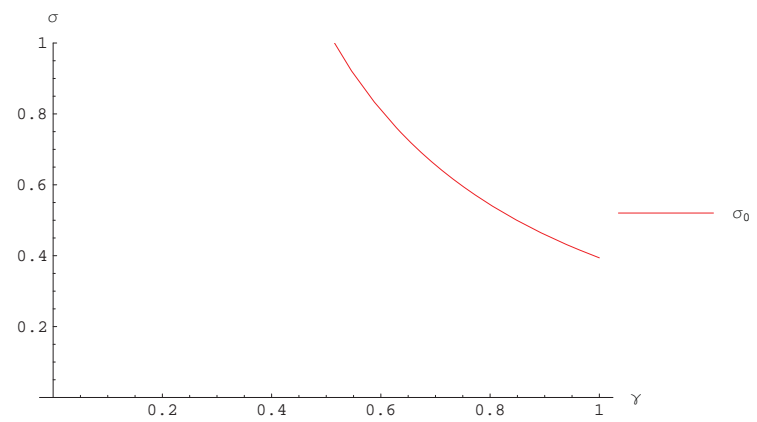

Figure 4.1: The Motivation of Forming an FTA

an FTA is achieved, so they will commit to contributing more as compensation if an FTA can be blocked. However, from the perspective of the government, stopping the FTA will result in lower social welfare. A larger value of $\gamma$ means that the government is concerned relatively more with the compensation from the lobby group than the welfare loss, then we can imagine that there is a greater chance for the government to follow the preference of the lobby group and block the welfare-improving FTA. On the other hand, the result from $\sigma$ is somehow paradoxical, implying that a weaker government with less bargaining power against the lobby group is more likely to approve an FTA. Indeed, this result is in accordance with the result of Maggi and Rodriguez-Clare (1998). The explanation is that with less bargaining power(i.e., $\sigma$ is small) and everything else is constant, a government will capture fewer contributions from the lobby group. Thus, if the rent gained from blocking the FTA is less than the welfare lost from not implementing it, the government is unwilling to block it.

Next, we extend our welfare and incentive analysis by incorporating the "huband-spoke" system. We analogously proceed to assess the equilibrium social welfare and government payoff in this system and compare them with the results obtained 
in previous structures. We can imagine that there should be no political contributions from the lobby group in the hub country because the import-competing sector is no longer protected. In a similar way to our previous analysis, we find that in the political equilibrium the tariff level between the two spokes is given by $\hat{\tau}_{\text {spoke }}^{p}=\frac{x k+3 \gamma k-k}{11 \beta}=\hat{\tau}_{\text {in }}^{p}<\hat{\tau}_{\text {out }}^{p}$, implying that the tariff complementarity effect also occurs here. Moreover, the level of political contributions in a spoke country is given by $\hat{P C} C_{\text {spoke }}=\frac{(1+\sigma) \gamma k^{2}}{22 \beta}=\hat{P C_{i n}}$. Thus, the spoke that was the non-member of the previous FTA receives fewer political contributions, while there is no change in contributions for the other spoke that was a member of the previous FTA. If these results are also substituted into the welfare and government payoff function of each country, we can derive the following two propositions, by comparing a "hub-and-spoke" system with previous circumstances.

Proposition 9 Compared to the circumstance with a bilateral FTA, a "hub-andspoke" system makes the hub better off $\left(\hat{W}_{h u b}^{p}>\hat{W}_{i n}^{p}\right)$, the spoke that was a member of the previous FTA worse off $\left(\hat{W}_{\text {spoke }}^{p}<\hat{W}_{i n}^{p}\right)$, and the welfare effect on the other spoke that was the non-member of the previous FTA is ambiguous. Moreover, the hub is always a better position than both spokes $\left(\hat{W}_{h u b}^{p}>\hat{W}_{\text {spoke }}^{p}\right)$ and being a spoke is always better than a position without any agreement $\left(\hat{W}_{\text {spoke }}^{p}>\hat{W}_{\text {non }}^{p}\right)$.

Proof It is straightforward to show that

$$
\begin{aligned}
& \hat{W}_{h u b}^{p}-\hat{W}_{i n}^{p}=\frac{k^{2}(x+3 \gamma-1)(1039 x+213 \gamma-1039)}{34848 \beta}>0 ; \\
& \hat{W}_{\text {spoke }}^{p}-\hat{W}_{i n}^{p}=-\frac{k^{2}(x+3 \gamma-1)(161 x+219 \gamma-161)}{34848 \beta}<0 ; \\
& \hat{W}_{\text {spoke }}^{p}-\hat{W}_{\text {non }}^{p}=\frac{k^{2}(x+3 \gamma-1)(131 x+921 \gamma-131)}{17424 \beta}>0 .
\end{aligned}
$$


Thus, we have confirmed that $\hat{W}_{h u b}^{p}>\hat{W}_{i n}^{p}>\hat{W}_{s p o k e}^{p}>\hat{W}_{n o n}^{p}$. However, we obtain

$$
\hat{W}_{\text {spoke }}^{p}-\hat{W}_{\text {out }}^{p}=\frac{k^{2}(x+3 \gamma-1)(-19 x+273 \gamma+19)}{4356 \beta}>0,
$$

if $\gamma>\frac{19(x-1)}{273}$, and $\hat{W}_{\text {spoke }}^{p}-\hat{W}_{\text {out }}^{p} \leq 0$, otherwise. Therefore, it is uncertain whether a "hub-and-spoke" system makes the spoke that was the non-member of the previous FTA better off or not.

This proposition again illustrates the strong position of the hub. As explained in the previous chapter, there is an advantage for exporters from the hub to compete in a spoke market. Moreover, in the political economy framework, it becomes likely that a spoke is better off than the non-member in the circumstance with a bilateral FTA, especially when $\gamma$ is relatively large. As explained earlier in this section, this is because the political economy can lead to greater welfare improvement for member countries of an FTA than a purely welfare-motivated government owing to the deeper reduction in both internal and external tariffs in the political economy.

Proposition 10 In the circumstance with a bilateral FTA, each member country has the incentive to conclude a new FTA with the non-member country to become the hub. In contrast, the motivation of the non-member is ambiguous. It has the incentive to endorse the new FTA if and only if $\sigma<\sigma_{1}$, where

$$
\sigma_{1}=\frac{-19(x-1)^{2}+216(x-1) \gamma-72 \gamma^{2}}{891 \gamma^{2}}
$$

Proof In analogy with the approach applied previously, we can simply obtain that the government payoff difference between a hub and an FTA member is

$$
\hat{G}_{h u b}-\hat{G}_{i n}=\frac{1039(x-1)^{2} k^{2}+3330(x-1) \gamma k^{2}-945 \gamma^{2} k^{2}-1584 \sigma \gamma^{2} k^{2}}{34848 \beta} .
$$


Since $k>0, \beta>0, x>1,0 \leq \gamma<x-1$, and $0 \leq \sigma \leq 1$, we have $\hat{G}_{h u b}>\hat{G}_{i n}$.

On the other hand, the government payoff difference between a spoke and a nonmember is

$$
\hat{G}_{\text {spoke }}-\hat{G}_{\text {out }}=\frac{-19(x-1)^{2} k^{2}+216(x-1) \gamma k^{2}-72 \gamma^{2} k^{2}-891 \sigma \gamma^{2} k^{2}}{4356 \beta} .
$$

We find $\hat{G}_{\text {spoke }}>\hat{G}_{\text {out }}$ if $\sigma<\sigma_{1}$ and $\hat{G}_{\text {spoke }} \leq \hat{G}_{\text {out }}$, otherwise, as was to be shown.

Finally, we complete this section by discussing the last possible circumstance on the path of trade liberalisation, i.e., MFT. As observed in the previous chapter, MFT can lead the world to achieve the maximal welfare, but it does not guarantee that MFT is the optimal outcome for every country. Thus, we intend to identify the welfare effects of MFT on each country at different stages of trade liberalisation in the political economy framework. Moreover, we aim to investigate whether countries are motivated to achieve MFT.

Proposition 11 In terms of social welfare of a country, being the hub is the best position, while MFT leads to a better outcome than any other position except the hub.

Proof Let $\hat{W}_{m f t}$ be the social welfare for each country under MFT, then we can simply obtain that

$$
\begin{aligned}
& \hat{W}_{h u b}^{p}-\hat{W}_{m f t}=\frac{k^{2}(x+3 \gamma-1)(23 x+3 \gamma-23)}{1089 \beta}>0 ; \\
& \hat{W}_{m f t}-\hat{W}_{i n}^{p}=\frac{k^{2}(x+3 \gamma-1)(101 x+39 \gamma-101)}{11616 \beta}>0 ;
\end{aligned}
$$

Thus, we have $\hat{W}_{h u b}^{p}>\hat{W}_{m f t}>\hat{W}_{\text {in }}^{p}>\hat{W}_{\text {spoke }}^{p}>\hat{W}_{\text {non }}^{p}$.

This proposition suggests that, except for the hub, MFT makes countries at all other positions better off. We can compare the social welfare results in the political 


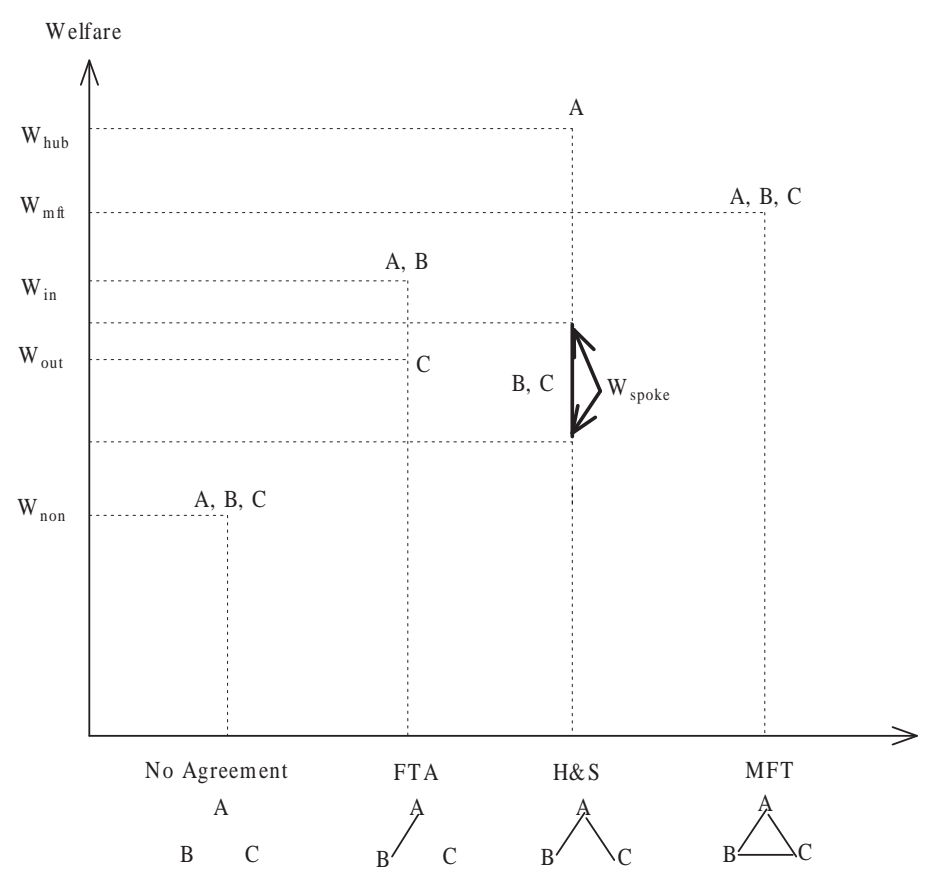

Figure 4.2: Welfare Ranking

equilibrium for all possible positions in Figure 4.2. We find that the welfare ranking here is analogous to what is obtained in the previous welfare-maximising framework. However, the ranking between an outside country of a bilateral FTA and a spoke in the current framework becomes ambiguous. In particular, when political pressures are sufficiently large, a spoke can be better off than an outside country. Our next proposition is to examine whether governments under political pressures have the motivation to support MFT. As we can expect, each government under MFT will receive no political contributions from the lobby group, so the government payoff of a country is the same as its social welfare. Moreover, since MFT is likely to be achieved at any stage of trade negotiation, we need to compare the government payoff of each country in the equilibrium under MFT with all other circumstances on the path of trade liberalisation. 
Proposition 12 (i) In the circumstance without any trade agreement, countries have the incentive to achieve MFT if and only if $\sigma<\sigma_{2}$, where

$$
\sigma_{2}=\frac{(x-1)^{2}+6(x-1) \gamma-3 \gamma^{2}}{12 \gamma^{2}}
$$

If a bilateral FTA is already achieved, each member has the incentive to achieve MFT if and only if $\sigma<\sigma_{3}$ and the non-member has the incentive if and only if $\sigma<\sigma_{4}$, where

$$
\begin{aligned}
\sigma_{3} & =\frac{101(x-1)^{2}+342(x-1) \gamma-411 \gamma^{2}}{528 \gamma^{2}} \\
\sigma_{4} & =\frac{13(x-1)^{2}+144(x-1) \gamma-48 \gamma^{2}}{363 \gamma^{2}}
\end{aligned}
$$

(iii) If a "hub-and-spoke"system is established, each spoke government has the incentive to achieve MFT while the hub does not.

Proof In analogy with the earlier analysis, we can simply derive the government payoff difference for a country under MFT and in other circumstances. We have

$$
\begin{aligned}
& \hat{G}_{m f t}-\hat{G}_{n o n}=\frac{(x-1)^{2} k^{2}+6(x-1) \gamma k^{2}-3 \gamma^{2} k^{2}-12 \sigma \gamma^{2} k^{2}}{48 \beta} \\
& \hat{G}_{m f t}-\hat{G}_{i n}=\frac{101(x-1)^{2} k^{2}+342(x-1) \gamma k^{2}-411 \gamma^{2} k^{2}-528 \sigma \gamma^{2} k^{2}}{11616 \beta} \\
& \hat{G}_{m f t}-\hat{G}_{\text {out }}=\frac{13(x-1)^{2} k^{2}+144(x-1) \gamma k^{2}-48 \gamma^{2} k^{2}-363 \sigma \gamma^{2} k^{2}}{1452 \beta} \\
& \hat{G}_{m f t}-\hat{G}_{h u b}=\hat{W}_{m f t}^{p}-\hat{W}_{h u b}^{p}=-\frac{k^{2}(x+3 \gamma-1)(23 x+3 \gamma-23)}{1089 \beta} \\
& \hat{G}_{m f t}-\hat{G}_{\text {spoke }}=\frac{29(x-1)^{2} k^{2}+108(x-1) \gamma k^{2}-36 \gamma^{2} k^{2}-99 \sigma \gamma^{2} k^{2}}{2178 \beta}
\end{aligned}
$$

Since $k>0, \beta>0, x>1,0 \leq \gamma<x-1$, and $0 \leq \sigma \leq 1$, we have $\hat{G}_{m f t}>\hat{G}_{n o n}$ if and only if $\sigma<\sigma_{2} ; \hat{G}_{m f t}>\hat{G}_{i n}$ if and only if $\sigma<\sigma_{3} ; \hat{G}_{m f t}>\hat{G}_{\text {out }}$ if and only if $\sigma<\sigma_{4}$. Also, we have $\hat{G}_{h u b}>\hat{G}_{m f t}$ and $\hat{G}_{m f t}>\hat{G}_{\text {spoke }}$ always hold, as was to be shown. 
This proposition implies that the political economy also reduces the possibility of achieving MFT through an MTA. We find that all of $\sigma_{2}, \sigma_{3}$ and $\sigma_{4}$ are decreasing and convex in $\gamma$. Thus, in the circumstance without any trade agreement and with a bilateral FTA, to ensure all countries have the incentive to approve an MTA requires that $\sigma$ or $\gamma$ is small enough. This result is very similar to what is obtained when we analyse the motivation of forming an FTA, and the intuition behind the result is the same. Moreover, the proposition suggests that in the circumstance of a "hub-andspoke" system, it is unlikely that MFT would be reached through an MTA because the hub country does not support it. However, it can be achieved through an additional FTA between the two spokes. They are motivated to make an additional FTA because in a spoke country, the political contributions received by the government are not sufficient to cover the gain of social welfare when it adopts MFT. Therefore, the political economy cannot prevent the spokes from achieving MFT.

\subsection{Dynamic Negotiation Game}

\subsubsection{Setup of the Game}

After we have discussed the welfare effects and motivations of forming trade agreements in the political economy framework, we turn to analyse the stability of trade negotiation. We investigate the nature of the stable structure of trading blocs when the formation of trade agreements is endogenously determined, and assess the dynamic process(es) to reach it. We apply a similar sequential negotiation game as used in the previous chapter, although the payoff of each player in the current case is in relation to the government payoff instead of the social welfare of the country. In 
more detail, the one-shot payoff of a player $I \in N$ in period $t \in\{1,2,3\} \hat{G}_{t}^{I}$ is the value obtained from (4.2) in the political equilibrium given the trading blocs structure formed at the end of this period, and the total payoff of the player in the game is expressed as $\hat{G}_{1}^{I}+\hat{G}_{2}^{I}+\hat{G}_{3}^{I}$.

\subsubsection{Equilibrium Outcome(s)}

In this section, we characterise the subgame perfect Nash equilibrium outcome(s) of this dynamic negotiation game to discuss the same questions as in the previous chapter: can MFT eventually be achieved through trade negotiation? If it can, is it achieved through the multilateral path or the bilateral path? If not, what will be the stable structure(s) of trading blocs? Moreover, which country can get the highest payoff and is there any first-mover advantage? The equilibrium outcome is derived by backward induction.

Proposition 13 The subgame perfect Nash equilibrium outcome of the trade negotiation game depends on the relationship between $\gamma$ and $\sigma$. (i) If $\sigma<\sigma_{1}, M F T$ is the unique equilibrium outcome and it will be achieved through overlapping FTAs at the end of the second period. (ii) If $\sigma_{1}<\sigma<\min \left\{\sigma_{2}, \sigma_{3}\right\}, M F T$ is the unique equilibrium outcome and it will be achieved through an MTA. (iii) If $\max \left\{\sigma_{1}, \sigma_{3}\right\}<\sigma<\sigma_{4}$, MFT is the unique equilibrium outcome and it will be achieved through overlapping FTAs at the end of the last period. (iv) If $\max \left\{\sigma_{3}, \sigma_{4}\right\}<\sigma<\sigma_{0}$, the equilibrium outcome is given by a bilateral FTA. (v) If $\sigma>\max \left\{\sigma_{0}, \sigma_{2}\right\}$, the unique equilibrium outcome is no trade agreement.

Proof See Appendix 
The proposition reveals that in our current political economy framework, the equilibrium outcome of trade negotiation depends on the relationship between $\gamma$ and $\sigma$. The example when $x=2$ is illustrated in Figures 4.3 and 4.4. The two-dimensional space of $\gamma$ and $\sigma$ is divided by the curves into several regions. When these two parameters are located in the black, yellow or blue region in Figure 4.4, MFT will be achieved. If they are in the green region, the equilibrium outcome is given by a bilateral FTA. Who will become the members of the FTA depends on the relationship between $\hat{G}_{\text {in }}$ and $\hat{G}_{\text {out }}$. If $\hat{G}_{\text {in }}>\hat{G}_{\text {out }}$, an FTA between A and B and an FTA between A and $\mathrm{C}$ are the equilibrium outcomes. If $\hat{G}_{i n} \leq \hat{G}_{\text {out }}$, an FTA between B and C can also be sustained as an equilibrium outcome. If they are in the red region, no trade agreement will be achieved. This result shows that the first-mover advantage only occurs in the first case when the two parameters are located in the black region.

The result also implies that achieving MFT requires that $\sigma$ or $\gamma$ is small enough, and it confirms that the political economy reduces the possibility of achieving MFT. As explained previously, the lobby group intends to prevent the local government from trade liberalisation because of the reduction in their surplus when MFT is achieved, so they will commit to contributing more as compensation if trade liberalisation can be prevented. However, from the perspective of the government, stopping trade liberalisation will generate a trade distortion, which results in a lower social welfare. A smaller value of $\gamma$ means that the government is concerned relatively less with the compensation from the lobby group than with the welfare loss, so we can imagine that there is a greater chance for the government to ignore the preference of the lobby group and support MFT. On the other hand, with less bargaining power (i.e., $\sigma$ is small) and everything else being constant, a government will capture fewer contributions 


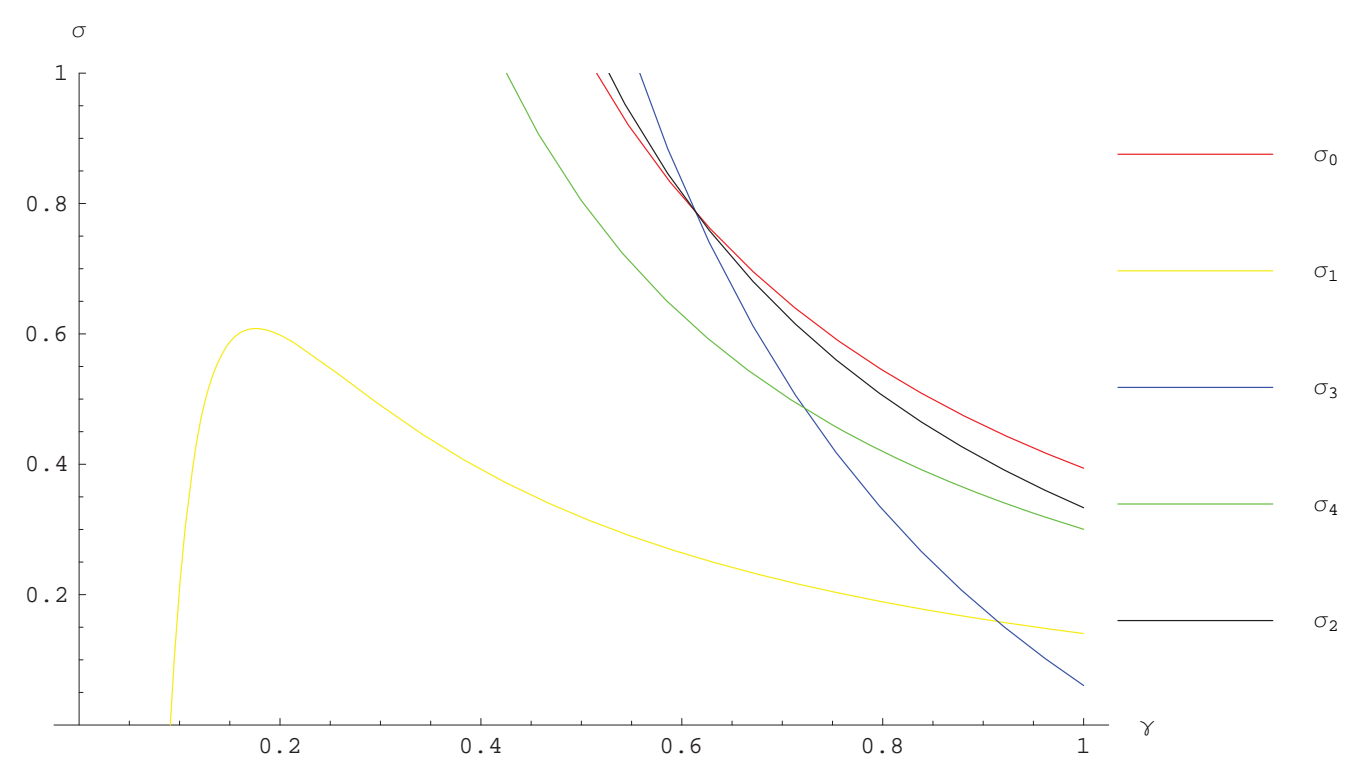

Figure 4.3: Curves Determining the Equilibrium Outcome

from the lobby group. Thus, if the rent from stopping a trade agreement is too little to dominate the welfare loss from trade distortion without it, the government is unwilling to stop trade liberalisation.

Another interesting finding from the proposition is that MFT can be achieved through different paths, mainly depending on whether the outside country of a bilateral FTA has the incentive to endorse an additional FTA to become a spoke. If this motivation exists ( $\sigma<\sigma_{1}$ as illustrated by the black region in Figure 4.4), MFT will be achieved through overlapping FTAs. Otherwise, it will usually be achieved through an MTA (if $\sigma_{1}<\sigma<\min \left\{\sigma_{2}, \sigma_{3}\right\}$ as illustrated by the yellow region). However, there is a special case in which MFT will be achieved through overlapping FTAs even if the outside country does not have the incentive to become a spoke. In particular, if $\max \left\{\sigma_{1}, \sigma_{3}\right\}<\sigma<\sigma_{4}$ (the blue region), MFT will be achieved through overlapping FTAs in the third period. The reason is that in this case, a bilateral FTA is formed 


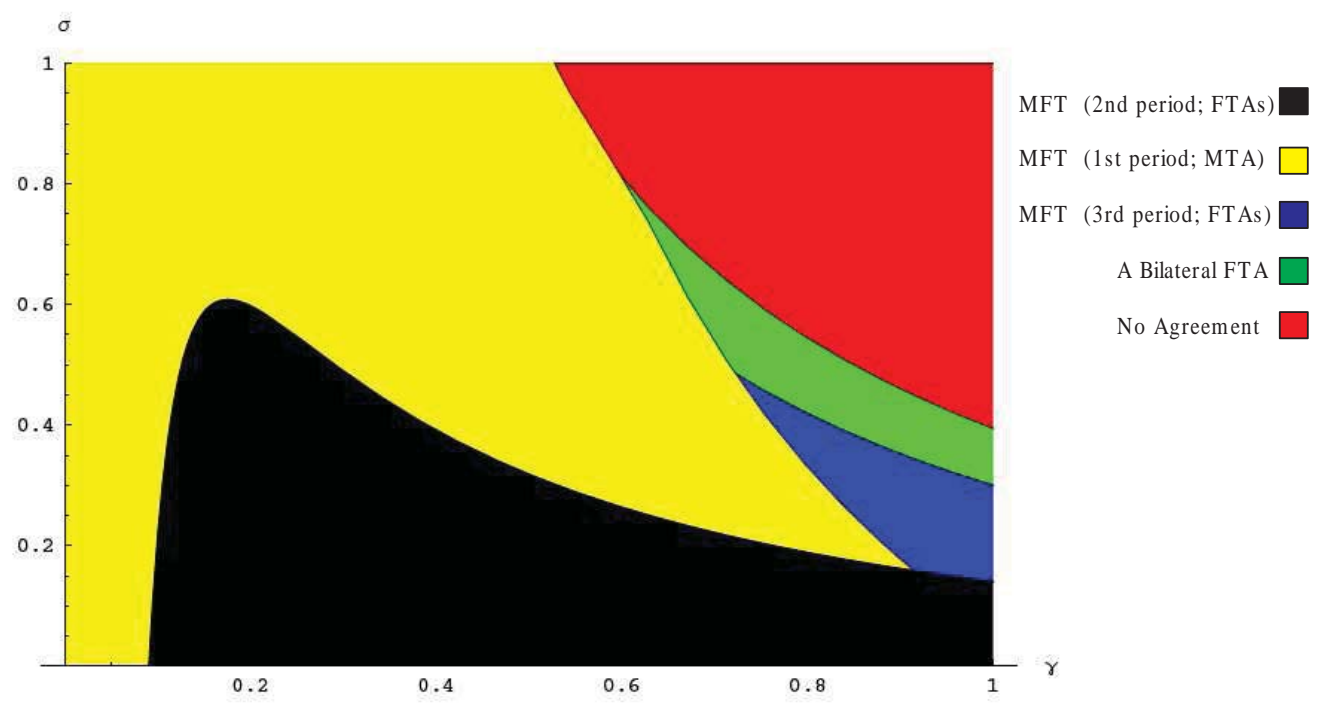

Figure 4.4: The Equilibrium Outcome of Trade Negotiation

between $\mathrm{A}$ and $\mathrm{B}$ at the end of the second period, and $\mathrm{C}$ prefers to achieve MFT in the third period. However, C cannot propose an MTA because C knows that A and $\mathrm{B}$ will reject it. On the contrary, if the outside country $\mathrm{C}$ offers two overlapping FTAs, both A and B will accept it. Thus, a "hub-and-spoke" system only appears temporarily at one stage in the third period, and eventually all countries obtain the payoff under MFT rather than as a spoke.

Our result also suggests that the option of bilateral FTAs does not make an initially infeasible MFT become feasible, while the previously feasible MFT is likely to be blocked by the option of an FTA (if $\max \left\{\sigma_{3}, \sigma_{4}\right\}<\sigma<\sigma_{2}$ ). Thus, the result supports the argument that RTAs can be "stumbling blocks". What is more interesting, when the parameters are located in a region $\left(\sigma_{2}<\sigma<\sigma_{0}\right)$, countries have no incentive to achieve an MTA while they form a single FTA and are not willing to move further. The result in this case implies that although MFT cannot be achieved, the option of FTAs can still raise global welfare. This outcome is consistent with that 
obtained by Mukunoki (2005).

\subsection{Conclusion}

In this chapter, we extend our previous welfare-maximising analysis into a framework in which each country is politically motivated. We consider a circumstance where the political pressures are only from the import competing sector. We find that the welfare effects of most trade agreements are analogous to what was obtained in the previous welfare-maximising framework except that the welfare ranking between an outside country of a single FTA and a spoke becomes ambiguous. In particular, when the political concerns are sufficiently large, a spoke is better off than an outside country. Since the objective of each government tends to include not only the national welfare but also political contributions, the motivation of forming a trade agreement becomes more complex. We find that the political economy reduces the chance to form a trade agreement. Moreover, the equilibrium outcome of trade negotiation in this case depends on the following two parameters. One is the relative concern to each government of political contributions and the other is the relative bargaining power of each government against the lobby group. As long as either of them is small enough, MFT can be achieved. The path to achieving this outcome mainly depends on whether the outside country of a bilateral FTA has the incentive to endorse an additional FTA to become a spoke. If this motivation exists, MFT will be achieved through overlapping FTAs. Otherwise, it will usually be achieved through an MTA. As the value of these two parameters increases, it is likely that a single FTA is the equilibrium outcome. If both of them become sufficiently large, no agreement will be achieved. In addition, our result suggests that the option of bilateral FTAs does not 
make an initially infeasible MFT become feasible, while the previously feasible MFT is likely to be blocked by the option of an FTA. Thus, it supports the argument that RTAs can be "stumbling blocks". What is more interesting, when the parameters are located in a particular range, countries have no incentive to achieve an MTA while they form a single FTA and are not willing to move further. Nevertheless, the FTA option can still improve global welfare.

The study in this chapter is limited to a symmetric world in which the political pressures are only from the the import-competing sector. In the next two chapters, we will further generalise our analytical framework. We will allow all sectors to lobby the local government in Chapter 5 and will finally discuss an asymmetric world including two big countries and a small country in Chapter 6 . 


\section{Chapter 5}

\section{Trade Agreements under Political Pressures from All Sectors}

\subsection{Introduction}

In the previous chapter, we extend our analysis of trade agreements into a framework in which each country is politically motivated. However, the political pressures are only from the import-competing sector. In the current chapter, we generalise the political framework to a case in which all sectors can lobby the local government. In this new political environment, we still aim to examine the welfare effects of trade agreements, the incentive to form trading blocs and the equilibrium outcome of trade negotiation.

The setup of our trade model and political structure follows that used in the previous chapter. However, to take into account the interaction between the lobbying actions from export sectors and the respective government policies, we allow each government to provide export subsidies, and both tariffs and export subsidies are endogenous. Moreover, we assume that trade negotiation only concerns removing tariffs. In other words, when a trading bloc is formed, tariffs within this area must be 
eliminated, but each country can still on its own choose export subsidies. We allow export subsidies to exist during the process of trade liberalisation mainly because in practice export subsidies in many countries are difficult to remove. Under this new assumption, we find that the welfare effects of both FTAs and an MTA are ambiguous, and MFT (i.e., all tariffs in the world are eliminated) leads to the optimal outcome regarding the total welfare of the world if and only if all export subsidies are removed. In addition, we show that the equilibrium outcome of trade negotiation in this case can either be MFT through an MTA or without any agreement, while regional trade liberalisation does not appear as an equilibrium path at all. The result depends on the following parameters. One is the relative concern about political contributions to each government and the other is the endowment ratio between different sectors in each country. Given the endowment of each country, MFT is achieved through an MTA if the political concern is relatively small, and it improves the welfare of all countries. In contrast, when the political concern is sufficiently large, no trade agreement can be achieved.

The structure of this chapter is similar to the previous two chapters. Section 2 presents the trade framework and discusses some properties in the political equilibrium before any trade agreement is achieved. Section 3 compares the social welfare and government payoff of each country under different structures of trading blocs. We further assess the welfare effects of each trade agreement and whether countries have the incentive to approve this agreement. A trade negotiation game is introduced in section 4 to investigate the equilibrium outcome of trade negotiation. The final section summarises the results. 


\subsection{The Static Trade Model}

\subsubsection{Basic Framework}

Consider a symmetric world, again with three countries A, B and C, with three goods a, b and c. The setup of the trade model in Chapter 4 applies here except that in the current circumstance, we allow each government not only to impose import tariffs but also to provide export subsidies. Introducing export subsidies will not change the trade pattern between these countries and therefore it can also be illustrated by Figure 3.1. We still let $\tau_{i}^{\bar{I}}$ be the specific tariff of country $I$ imposed on imports of good $i$ from country $\bar{I} \in N \backslash I$, and $T$ be the tariff vector $\left(\tau_{a}^{B}, \tau_{a}^{C}, \tau_{b}^{A}, \tau_{b}^{C}, \tau_{c}^{A}, \tau_{c}^{B}\right) . S_{i}^{\bar{I}}$ is used to represent the government subsidy from country $\bar{I}$ on its exports to country $I$ and the subsidy vector $S$ is defined as $\left(S_{a}^{B}, S_{a}^{C}, S_{b}^{A}, S_{b}^{C}, S_{c}^{A}, S_{c}^{B}\right)$.

The political structure here is similar to that in Chapter 4. However, in the current chapter, we assume that the owners of endowments in both import-competing sector and export sectors are highly concentrated. Therefore, all the owners of endowments as a whole are able to organise a lobby group to represent their general interest. Their objective becomes the sum of producer surplus in all sectors minus the contributions given to the government. For country I, it can be expressed as:

$$
V^{I}(T, S, P C)=\sum_{j \in n} \Pi_{j}^{I}(T, S)-P C^{I}
$$

On the other hand, the objective of the government is a weighted average of aggregate social welfare and political contributions from the lobby group. For country I, that is

$$
G^{I}(T, S, P C)=W^{I}(T, S)+\gamma P C^{I}
$$


Since the cost of export subsidies should be deducted when we measure social welfare, country I's total social welfare becomes the sum of its consumer surplus, producer surplus and tariff revenue, minus its export subsidy, given by:

$$
W^{I}=\sum_{j \in n} \int_{p_{j}^{I}}^{\alpha / \beta} D\left(p_{j}^{I}\right) d p_{j}^{I}+x k \sum_{\bar{i} \in n \backslash i} p_{\bar{i}}^{I}+k p_{i}^{I}+\sum_{\bar{I} \in N \backslash I} \tau_{i}^{\bar{I}} \hat{E X_{i}^{\bar{I}}}-\sum_{\bar{i} \in n \backslash i} S_{\bar{i}}^{I} \hat{E} X_{\bar{i}}^{I}
$$

The lobbying process between the owners of endowment and the local government is still modelled as a Nash bargaining game, as used in Chapter 4. Since the bargaining power of this game is not the main concern of the current chapter, we add the assumption that these two parties have equal bargaining powers $(\sigma=0.5)$, so they evenly divide the bargaining surplus.

\subsubsection{Trade Equilibrium}

We still start by examining the perfectly competitive trade equilibrium given initial tariffs and export subsidies. We first consider the equilibrium in the market of good a. The arbitrage condition here requires that the tariff imposed by A minus the government subsidy from each exporting country must equal the margin between its local price in A and foreign price, so we have

$$
p_{a}^{A}=p_{a}^{B}+\tau_{a}^{B}-S_{a}^{B}=p_{a}^{C}+\tau_{a}^{C}-S_{a}^{C}
$$

Following the procedure we used in the previous chapter, we obtain the result that the equilibrium prices for good a in the three countries are given by

$$
\begin{aligned}
& \hat{p}_{a}^{A}=\frac{\alpha}{\beta}-\frac{k+2 x k}{3 \beta}+\frac{\tau_{a}^{B}+\tau_{a}^{C}-S_{a}^{B}-S_{a}^{C}}{3} ; \\
& \hat{p}_{a}^{B}=\frac{\alpha}{\beta}-\frac{k+2 x k}{3 \beta}+\frac{\tau_{a}^{C}-S_{a}^{C}-2\left(\tau_{a}^{B}-S_{a}^{B}\right)}{3} ;
\end{aligned}
$$




$$
\hat{p}_{a}^{C}=\frac{\alpha}{\beta}-\frac{k+2 x k}{3 \beta}+\frac{\tau_{a}^{B}-S_{a}^{B}-2\left(\tau_{a}^{C}-S_{a}^{C}\right)}{3} .
$$

Similarly, we can solve the equilibrium prices for b and c. By substituting equilibrium prices into import and export functions, we can describe the equilibrium trade volumes in terms of a set of tariffs and export subsidies. For instance, in country A,

$$
\begin{aligned}
& I \hat{M}_{a}\left(\hat{p}_{a}^{A}\right)=D\left(\hat{p}_{a}^{A}\right)-k=\frac{2(x k-k)-\beta\left(\tau_{a}^{B}+\tau_{a}^{C}-S_{a}^{B}-S_{a}^{C}\right)}{3} ; \\
& \hat{E X_{b}^{A}}\left(\hat{p}_{b}^{A}\right)=x k-D\left(\hat{p}_{b}^{A}\right)=\frac{x k-k+\beta\left(\tau_{b}^{C}-S_{b}^{C}-2\left(\tau_{b}^{A}-S_{b}^{A}\right)\right)}{3} ; \\
& \hat{E X}_{c}^{A}\left(\hat{p}_{c}^{A}\right)=x k-D\left(\hat{p}_{c}^{A}\right)=\frac{x k-k+\beta\left(\tau_{c}^{B}-S_{c}^{B}-2\left(\tau_{c}^{A}-S_{c}^{A}\right)\right)}{3} .
\end{aligned}
$$

As we would expect, all the properties regarding tariffs we had in section 3.2.2 still hold here. In addition, we find that a country's import volume increases in subsidies provided by the other two export countries. On the other hand, its export volume increases in the subsidy from the local government but decreases in the subsidy to its competing exporters from another country. Finally, according to (5.8), (5.9) and (5.10), we obtain the constraints that $\tau_{a}^{B}+\tau_{a}^{C}-S_{a}^{B}-S_{a}^{C}<2(x k-k) / \beta$, $2\left(\tau_{b}^{A}-S_{b}^{A}\right)-\left(\tau_{b}^{C}-S_{b}^{C}\right)<(x k-k) / \beta$ and $2\left(\tau_{c}^{A}-S_{c}^{A}\right)-\left(\tau_{c}^{B}-S_{c}^{B}\right)<(x k-k) / \beta$, which ensure that tariffs are non-prohibitive. Similar results about the equilibrium trade volumes and the constraints for non-prohibitive tariffs can be obtained for country B and C. 


\subsubsection{Equilibrium Tariffs and Political Contributions in the New Political Framework}

Next, we solve the equilibrium tariffs and political contributions in the presence of political pressures. In the current framework, they are the equilibrium outcome of a Nash bargaining game similar to the one in Chapter 4. For country $I \in N$, the threat point of this bargaining problem is still the situation without any lobbying activity, in which $P C^{I}=0$. In this case, the government sets tariffs $\tau_{i}^{\bar{I}}$ and export subsidies $S_{\bar{i}}^{I}$ to maximise the social welfare of this country, denoted by $\tau_{i}^{\bar{I}^{*}}$ and $S_{\bar{i}}^{I^{*}}$. In such a circumstance, the payoff of the government and the owners of endowment in a sector $j \in n$ are given by $W^{I^{*}}$ and $\Pi_{j}^{I^{*}}$, respectively. Furthermore, it is straightforward to show that if the lobbying activity occurs, the efficient bargaining outcome is obtained when the tariffs and subsidies are set to maximise $W^{I}+\gamma \sum_{j \in n} \Pi_{j}^{I}$, that is

$$
\left(\tau_{i}^{\bar{I}^{p}}, S_{\bar{i}}^{I}\right) \in \arg \max _{\tau_{i}^{\bar{I}}, S_{\bar{i}}^{I}}\left(W^{I}+\gamma \sum_{j \in n} \Pi_{j}^{I}\right)
$$

We call them the optimal political tariffs and subsidies, respectively.

By solving this optimisation problem, the optimal level of political tariff and subsidy of each country is given by

$$
\begin{gathered}
{\tau_{i}^{\bar{I}}}^{p}=\frac{2 x k-2 k+2 \gamma x k+7 \gamma k}{9 \beta} ; \\
S_{\bar{i}}^{I^{p}}=\frac{k-x k+8 \gamma x k+\gamma k}{9 \beta} .
\end{gathered}
$$


In the case where all countries are concerned only about their own social welfare $(\gamma=0)$, the optimal social welfare-maximising tariff and subsidy are $\tau_{i}^{\bar{I}^{*}}=\frac{2 x k-2 k}{9 \beta}$ and $S_{\bar{i}}^{I^{*}}=\frac{k-x k}{9 \beta}$. Since $k>0, \beta>0$ and $x>1$, then $S_{\bar{i}}^{I^{*}}$ must be negative, indicating that each welfare-maximising government should impose a tax instead of a subsidy on its exports. The reason for this is that both tariff and export tax can indeed improve the terms of trade of this country, and the benefit from this can outweigh the loss from the distortion caused by imposing taxes. In other words, this result confirms that export subsidy can only be explained by political motivations. We can further state the following proposition.

Proposition 14 The optimal level of tariff and export subsidy chosen by each government is strictly increasing in its relative concern about political contributions $(\gamma)$.

The result regarding the tariff is consistent with that in Chapter 4, and we find a similar result regarding the export subsidy. As we explained in the previous chapter, when a government has a political concern about a sector, there has to be a preferred policy to protect it, and imposing a higher tariff can be used to protect the import competing sector. Similarly, export subsidies are provided to encourage the export sectors. Thus, the greater the political concern about export sectors, the higher the level of subsidy that will be provided.

We complete this section by solving the equilibrium level of political contributions. As in the previous chapter, in country $I \in N$, to convince the government to implement tariffs and export subsidies, the lobby group must at least contribute:

$$
P C_{\text {min }}^{I}=\frac{W^{I^{*}}-W^{I^{p}}}{\gamma},
$$

where $W^{I^{p}}$ denotes the social welfare if the politically pressured tariffs and subsidies 
are adopted by the government. Otherwise, it will ignore the political contributions and set the welfare-maximising tariffs and subsidies. When $P C^{I}$ reaches the minimum value, the owners of endowments capture the whole bargaining surplus while the government obtains nothing. On the other hand, the maximum value of the contributions is given by

$$
P C^{I}{ }_{\max }=\sum_{j \in n} \Pi_{j}^{I^{p}}-\sum_{j \in n} \Pi_{j}^{I^{*}}
$$

where $\Pi_{j}^{I^{p}}$ denotes the profit in the sector $j \in n$ if the politically pressured tariffs are adopted. If the contributions exceed this value, the payoff of the owners of the endowment will be higher without contributions. When $P C^{I}$ reaches this upper bound, the government obtains the whole bargaining surplus. Since the bargaining power between the government and the lobby group is assumed to be equal in this chapter, the equilibrium level of contributions in each country is given by:

$$
\hat{P} C^{I}=\frac{P C^{I}{ }_{\max }+P C^{I}{ }_{\text {min }}}{2} .
$$

\subsection{Trade Liberalisation in the New Political Frame- work}

In this section, we still compare the one-shot welfare effect on each country under different structures and examine whether countries have the incentive to form trading blocs or not. We consider these questions in a new political environment.

When no trade agreement is reached between countries, each country identically sets the MFN tariffs and export subsidies at the optimal political level, as given by (5.12) and (5.13). We denote them here as $\hat{\tau}_{N}^{p}$ and $\hat{S}_{N}^{p}$, respectively. By substituting 
them into (5.3), we can obtain the equilibrium social welfare for each country in this new political economy framework, denoted as $\hat{W}_{N}^{p}$. Following a similar procedure as used in Chapter 4, we can solve the level of political contributions in the equilibrium, given by $\hat{P C_{N}}=\frac{3\left(2 x^{2}+1\right) \gamma k^{2}}{8 \beta}$.

When two countries (e.g., A and B) form a bilateral FTA, tariffs between them will be eliminated, i.e., $\tau_{a}^{B}=\tau_{b}^{A}=0$. However, they can still independently impose tariffs on the non-member country C, and provide subsidies on their exports. Here, the objective function for each government becomes $G^{I}\left(\left(0, \tau_{a}^{C}, 0, \tau_{b}^{C}, \tau_{c}^{A}, \tau_{c}^{B}\right), S\right)$. By solving the optimisation problem as we did previously, we obtain that $\tau_{a}^{B}=\tau_{b}^{A}=0$, $\tau_{a}^{C}=\tau_{b}^{C}=\frac{2 x k-2 k+2 \gamma x k+7 \gamma k}{22 \beta}<\hat{\tau}_{N}^{p}$ and $\tau_{c}^{A}=\tau_{c}^{B}=\frac{2 x k-2 k+2 \gamma x k+7 \gamma k}{9 \beta}=\hat{\tau}_{N}^{p}$. In terms of subsidies, we have $S_{a}^{B}=S_{b}^{A}=\frac{5 k-5 x k+28 \gamma x k-\gamma k}{33 \beta}<\hat{S}_{N}^{p}, S_{c}^{A}=S_{c}^{B}=\frac{k-x k+8 \gamma x k+\gamma k}{9 \beta}=\hat{S}_{N}^{p}$ and $S_{a}^{C}=S_{b}^{C}=\frac{8 k-8 x k+58 \gamma x k+5 \gamma k}{66 \beta}<\hat{S}_{N}^{p}$.

In general, the optimal political tariff imposed by an inside-FTA country is $\hat{\tau}_{I}^{p}=$ $\frac{2 x k-2 k+2 \gamma x k+7 \gamma k}{22 \beta}<\hat{\tau}_{N}^{p}$, and $\hat{\tau}_{O}^{p}=\frac{2 x k-2 k+2 \gamma x k+7 \gamma k}{9 \beta}=\hat{\tau}_{N}^{p}$ by an outside-FTA country. On the other hand, the optimal subsidy provided by a member country for an export to the other member is $\hat{S}_{I I}^{p}=\frac{5 k-5 x k+28 \gamma x k-\gamma k}{33 \beta}<\hat{S}_{N}$, for that to the non-member is $\hat{S}_{I O}^{p}=\frac{k-x k+8 \gamma x k+\gamma k}{9 \beta}=\hat{S}_{N}^{p}$, and the subsidy from the non-member country is $\hat{S}_{O}^{p}=$ $\frac{8 k-8 x k+58 \gamma x k+5 \gamma k}{66 \beta}<\hat{S}_{N}^{p}$.

Once more, it is found that an FTA leads member countries to voluntarily liberalise their external tariffs against the non-member country. Also, $\left(\hat{\tau}_{I}^{p}-\hat{\tau}_{N}^{p}\right)$ is strictly increasing in $\gamma$, which implies that the tariff complementarity effect is reinforced when the political economy is introduced. Both of these properties are consistent with the observation made in our previous chapters. Thus, these findings are generalised in this new political environment. Moreover, we notice that both the export subsidy 
within the FTA and that from the non-member are decreased, while the subsidy from a member government on exports to the non-member does not change. This can be the consequence of the change in tariff by each importing country. If an importing country lowers the tariff, it is no longer necessary for the exporting country to offer a high level of subsidy to keep its goods competitive in the overseas market. Thus, we would expect that the exporting country reduces the subsidy as the importing country reduces the tariff. In addition, we find these export subsidies are negative when $\gamma=0$, which again confirms our previous argument that export subsidy can only be explained by political motivations.

In what follows, we compare circumstances before and after the formation of a bilateral FTA to examine the welfare impacts of an FTA on both member and nonmember countries, and investigate whether countries have any incentive to form an FTA. The following two propositions can simply be derived to answer these two questions.

Proposition 15 Compared to the circumstance without any trade agreement, a bilateral FTA has ambiguous welfare impacts on both member and non-member countries. The result depends on the relative concern about the political contributions $(\gamma)$ and the endowment ratio between different sectors $(x)$ in each country.

Proof We substitute the equilibrium tariff and subsidy vector when a bilateral FTA is formed into the welfare function of each country, and obtain that

$$
\begin{aligned}
& \hat{W}_{I}^{p}-\hat{W}_{N}^{p}=\frac{k^{2}(7 x-7-29 \gamma x+20 \gamma)(2 x-2+2 \gamma x+7 \gamma)}{891 \beta} \\
& \hat{W}_{O}^{p}-\hat{W}_{N}^{p}=\frac{2 k^{2}(46 x-46-53 \gamma x-37 \gamma)(2 x-2+2 \gamma x+7 \gamma)}{9801 \beta},
\end{aligned}
$$


where $\hat{W}_{I}^{p}$ and $\hat{W}_{O}^{p}$ denote the welfare in the political equilibrium for a member country and non-member country, respectively.

Since $k>0, x>1 \beta>0$ and $\gamma \geq 0$, it is uncertain whether $\hat{W}_{I}^{p}$ and $\hat{W}_{O}^{p}$ are larger than $\hat{W}_{N}^{p}$. In detail, $\hat{W}_{I}^{p}>\hat{W}_{N}^{p}$ iff $\gamma<\frac{7(x-1)}{29 x-20} ; \hat{W}_{O}^{p}>\hat{W}_{N}^{p}$ iff $\gamma<\frac{46(x-1)}{53 x+37}$.

Our proposition is consistent with the widely accepted theoretical result about the ambiguous welfare effects of RTAs. As Viner (1950) first suggested, they may be welfare improving or welfare reducing, depending on the specific features in each case. In our framework, we notice that the welfare impacts of an FTA can be affected by $\gamma$ and $x$. Given the endowment of each country ( $x$ is fixed), the FTA is Pareto welfare improving when the extent of political concern is low $\left(\gamma<\min \left\{\frac{7(x-1)}{29 x-20}, \frac{46(x-1)}{53 x+37}\right\}\right)$. On the other hand, all the countries are worse off owing to the formation of the FTA when the weight on political contributions is large $\left(\gamma>\max \left\{\frac{7(x-1)}{29 x-20}, \frac{46(x-1)}{53 x+37}\right\}\right)$.

Our result regarding the welfare impacts of an FTA here is also consistent with the observation made in Chapter 3 that if each government is purely welfare motivated, then an FTA improves the welfare of all countries. However, it contradicts the result in Chapter 4 that an FTA always improves the welfare of all countries even in a political economy framework. This inconsistency can be ascribed to the existence of export subsidies in the current case, which give rise to more distortion of the allocation of resources. Especially when the political concern is large enough, the distortion resulting from politics and export subsidies can significantly offset the gains from the preferential tariff elimination. Thus, an FTA becomes welfare reducing.

We now turn to the discussion of the motivation of forming an FTA. Since an FTA is welfare improving when $\gamma=0$, i.e., each government is a welfare maximiser, then each country should be willing to form an FTA. However, in the presence of 
political pressures $(\gamma>0)$, each government tends to care about not only national welfare but also political contributions. Since the welfare impacts of an FTA are ambiguous, the motivation to form an FTA may also be uncertain. If we substitute the equilibrium tariff and subsidy vector with a bilateral FTA into equations (5.14), (5.15) and (5.16) we obtain that the political contributions for a member and nonmember are given by $\hat{P C_{I}}=\frac{3\left(11 x^{2}+1\right) \gamma k^{2}}{44 \beta}$ and $\hat{P C_{O}}=\frac{3\left(2 x^{2}+1\right) \gamma k^{2}}{8 \beta}$, respectively. We find that $\hat{P C_{I}} \leq \hat{P C_{N}}$, where the equality holds when $\gamma=0$, and $\hat{P C} C_{O}=\hat{P C}{ }_{N}$ always holds. Therefore, when an FTA is formed, each member country receives fewer political contributions than before while the contributions received by the nonmember are not changed. This result, consistent with that in Chapter 4, clarifies that in this political framework, no country will implement a welfare-reducing FTA, while it may prevent a welfare-improving one. The following proposition allows us to assess the incentive to form an FTA in more detail.

Proposition 16 In a circumstance without any trade agreement, political economy forces reduce the likelihood of forming a bilateral FTA. In particular, each country has the incentive to approve an FTA if and only if $\gamma<\gamma_{0}$, where

$$
\gamma_{0}=\frac{4\left(-44 x^{2}+133 x+9 \sqrt{2} \sqrt{32 x^{4}-56 x^{3}+111 x^{2}-182 x+95}-89\right)}{464 x^{2}+1304 x+1067} .
$$

Proof If we substitute the combination of $\hat{W}_{I}^{p}$ and $\hat{P C_{I}}$ and $\hat{W}_{N}^{p}$ and $\hat{P C} C_{N}$ into (5.2), we obtain that the payoff difference between an FTA member and a country before the formation of any trade agreement is

$$
\hat{G}_{I}-\hat{G}_{N}=\frac{k^{2}\left(112(x-1)^{2}-8(44 x-89) \gamma(x-1)-(8 x(58 x+163)+1067) \gamma^{2}\right)}{7128 \beta} .
$$

In the case without any political pressure $(\gamma=0)$, we have $\hat{G}_{I}>\hat{G}_{N}$, which confirms that countries have the incentive to form an FTA if each government is purely welfare 


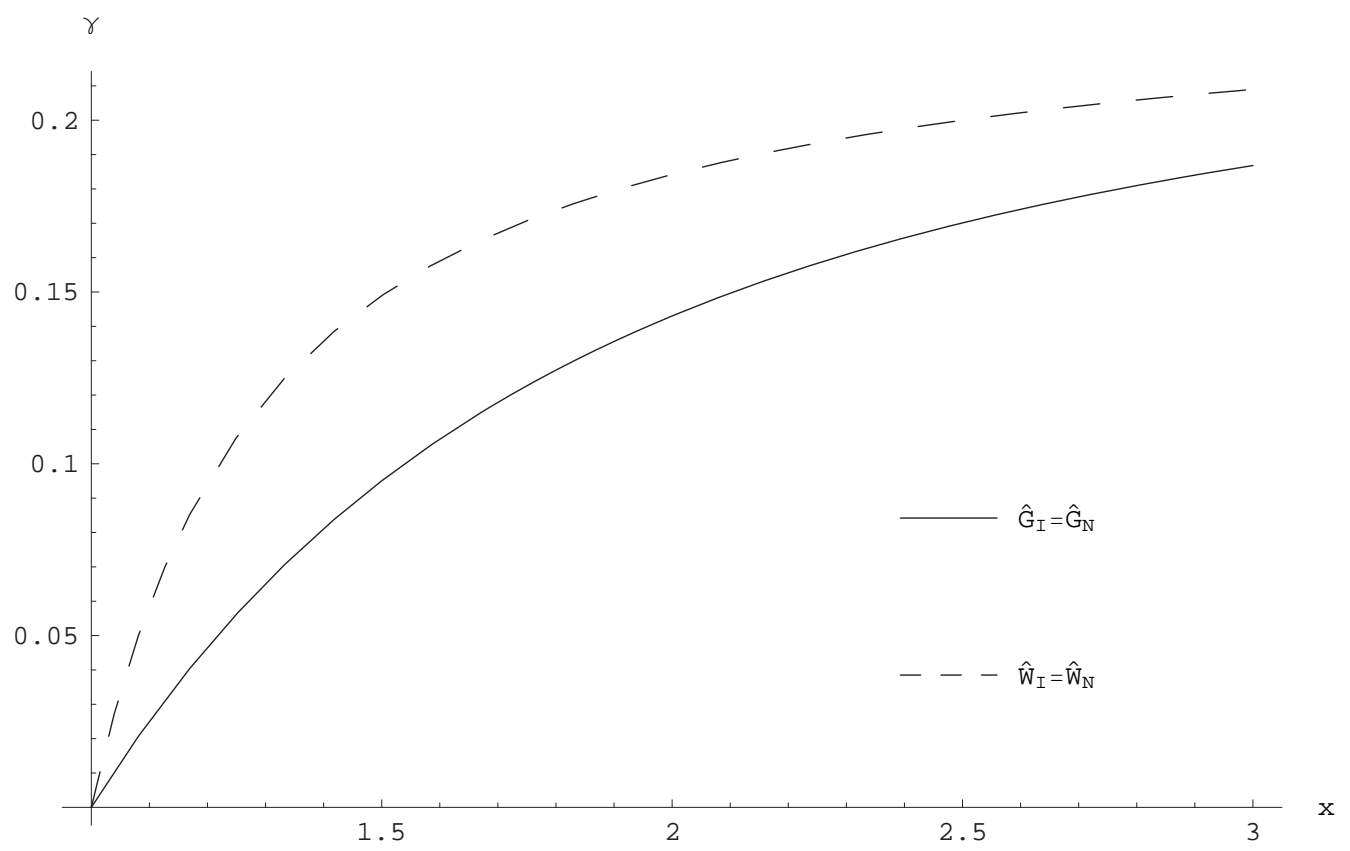

Figure 5.1: The Welfare Effect and Motivation of Forming an FTA

motivated. Alternatively, if $\gamma>0$, we obtain that $\hat{G}_{I}>\hat{G}_{N}$ if $\gamma<\gamma_{0}$ and $\hat{G}_{I} \leq \hat{G}_{N}$ otherwise, as was to be shown.

Like the result obtained in Chapter 4, this proposition also implies that political pressures reduce the possibility of forming an FTA that can be welfare improving. In the current political framework, the motivation of forming an FTA depends on the relationship between $x$ and $\gamma$. As shown in Figure 5.1, the solid curve, representing the circumstances when $\hat{G}_{I}=\hat{G}_{N}$, is located below the dashed curve representing $\hat{W}_{I}^{p}=\hat{W}_{N}^{p}$. This is because, when an FTA is formed, each member country receives fewer political contributions $\left(\hat{P C_{I}} \leq \hat{P C_{N}}\right)$. The figure indicates that if $x$ and $\gamma$ are located in the area below the solid curve, a welfare-improving FTA will be approved. If they are above the dashed curve, a welfare-reducing FTA will be prevented. If they 
are between these two curves, which guarantees $\hat{G}_{I}<\hat{G}_{N}$ and $\hat{W}_{I}^{p}>\hat{W}_{N}^{p}$, a welfareimproving FTA will be blocked by political pressures. In this case, the political contributions lost by a government from implementing an FTA are relatively more significant than the increase in social welfare, and thus the government is willing to block it.

Moreover, since $\gamma_{0}$ is an increasing function of $x$, an increase in the value of $x$ will increase the range of $\gamma$ in which countries have an incentive to form an FTA. On the contrary, an increase in $\gamma$ will reduce the range of $x$ in which an FTA can be approved. In other words, holding everything else constant, there is a large possibility to form an FTA when the value of $\gamma$ is relatively small and $x$ is large. Part of the explanation for this result related to $\gamma$ is the same as that in the previous chapter. The lobby group intends to prevent the local government from forming an FTA because of the reduction in their surplus when an FTA is achieved, so they will commit to contributing more as compensation if an FTA can be blocked. However, from the perspective of the government, stopping the FTA may result in lower social welfare. A larger value of $\gamma$ means that the government is relatively more concerned with the compensation from the lobby group than the welfare loss. It is then likely that there is a greater chance for the government to follow the preference of the lobby group and block the welfare-improving FTA. Additionally, in the current framework, when $\gamma$ becomes sufficiently large, an FTA will reduce the welfare of member countries, and therefore no country will support the welfare-reducing FTA. The intuition behind $x$ is quite straightforward. In our framework, the parameter $x$ measures the comparative advantage of each country through international trade. With a larger value of $x$, the benefit for each country from trade liberalisation is greater, which brings about a 
greater chance to form an FTA.

Next, we extend our welfare and incentive analysis by incorporating the "huband-spoke" system. We analogously proceed to assess the equilibrium social welfare and government payoff in this system and compare these with the results obtained in previous structures. As mentioned in earlier chapters, in a "hub-and-spoke" system, tariffs only apply to trade between the two spokes. However, in the current framework, each country can still provide government subsidies on its exports. In a similar way to our previous analysis, we find that in the political equilibrium the tariff level between two spokes is given by $\hat{\tau}_{S}^{p}=\frac{2 x k-2 k+2 \gamma x k+7 \gamma k}{22 \beta}=\hat{\tau}_{I}^{p}<\hat{\tau}_{O}^{p}$, implying that the tariff complementarity effect also occurs here. In terms of subsidies, the hub offers $\hat{S}_{H}^{p}=\frac{5 k-5 x k+28 \gamma x k-\gamma k}{33 \beta}=\hat{S}_{I I}^{p}$, while each spoke provides $\hat{S}_{S S}^{p}=\frac{8 k-8 x k+58 \gamma x k+5 \gamma k}{66 \beta}=$ $\hat{S}_{O}^{p}$ for exports to the other spoke, and $\hat{S}_{S H}^{p}=\frac{k-x k+6 \gamma x k}{7 \beta}<\hat{S}_{O}^{p}$ for exports to the hub. We can further obtain that the level of political contributions in a hub and a spoke are given by $\hat{P C_{H}}=\frac{3 x^{2} \gamma k^{2}}{4 \beta} \leq \hat{P C_{I}}$ and $\hat{P C_{S}}=\frac{3\left(11 x^{2}+1\right) \gamma k^{2}}{44 \beta}=\hat{P C_{I}} \leq \hat{P C_{O}}$, respectively. Thus, the hub and the spoke that was the non-member of the previous FTA receive fewer political contributions, while there is no change in contributions for the other spoke that was a member of the previous FTA. If these results are also substituted into the welfare and government payoff function of each country, we can derive the following proposition, by comparing a "hub-and-spoke" system with previous circumstances.

Proposition 17 In a circumstance of a bilateral FTA, a "hub-and-spoke" system makes the spoke that was a member of the previous FTA worse off $\left(\hat{W}_{S}^{p}<\hat{W}_{I}^{p}\right)$, and the welfare effects on the hub and the other spoke that was the non-member of the previous FTA are ambiguous. However, the non-member of the previous FTA has no 
incentive to approve another FTA to achieve a "hub-and-spoke"system ( $\left.\hat{G}_{S}<\hat{G}_{O}\right)$.

Proof Suppose that originally there is a bilateral FTA between A and B. If A and $\mathrm{C}$ decide to form an additional FTA, it will make $\mathrm{A}$ become a hub, and $\mathrm{B}$ and $\mathrm{C}$ become spokes. Thus, the welfare change for $\mathrm{A}$ is given by

$$
\hat{W}_{H}^{p}-\hat{W}_{I}^{p}=\frac{k^{2}(2 x-2+2 \gamma x+7 \gamma)(8383 x-8383-11021 \gamma x-112 \gamma)}{480249 \beta} .
$$

Similarly, the welfare effect on $B$ and $C$ are respectively given by

$$
\begin{aligned}
& \hat{W}_{S}^{p}-\hat{W}_{I}^{p}=-\frac{k^{2}(2 x-2+2 \gamma x+7 \gamma)(194 x-194+887 \gamma x+2065 \gamma)}{480249 \beta} \\
& \hat{W}_{S}^{p}-\hat{W}_{O}^{p}=-\frac{k^{2}(2 x-2+2 \gamma x+7 \gamma)(929 x-929+11324 \gamma x-12341 \gamma)}{480249 \beta} .
\end{aligned}
$$

Since $k>0, x>1 \beta>0$ and $\gamma \geq 0$, it is straightforward to show that the welfare of country B decreases $\left(\hat{W}_{S}^{p}<\hat{W}_{I}^{p}\right)$, while the welfare effects on A and $\mathrm{C}$ are uncertain, depending on the relationship between $\gamma$ and $x$. However, in regard to the government payoff of C, we obtain $\hat{G}_{S}-\hat{G}_{O}<0$, which confirms that the non-member of the previous FTA has no incentive to form a new FTA.

This proposition supports our arguments in previous chapters suggesting the strong position of the hub in terms of social welfare, especially when $\gamma$ is relatively small. The spoke, on the other hand, is not very likely to become a desirable position in terms of social welfare. Our outcome shows that there is the possibility for $\hat{W}_{S}^{p}$ to be larger than $\hat{W}_{O}^{p}$ only if $x<\frac{12341}{11324}$. Even if this condition is satisfied, it still requires $\gamma>\frac{929 x-929}{12341-11324 x}$. In addition, from the perspective of the government of the non-member country, even when $\hat{W}_{S}^{p}$ is larger than $\hat{W}_{O}^{p}$, the increase in social welfare is never sufficient to compensate the loss in political contributions from the lobby 
goup. Thus, the non-member country has no incentive to approve an additional FTA to achieve a "hub-and-spoke" system.

Finally, we complete this section by discussing the last possible circumstance on the path of trade liberalisation, i.e., MFT, in which all tariffs in the world are eliminated while export subsidies are still allowed. Owing to the existence of export subsidies, removing all tariffs may not lead the world to achieve maximal welfare. Our next proposition searches for the condition under which MFT is still the optimal outcome of trade liberalisation.

Proposition 18 In terms of the total social welfare of the whole world, MFT (when $T=0)$ is the optimal outcome if and only if export subsidies are removed $(S=0)$.

Proof When all tariffs in the world are eliminated, the equilibrium total social welfare in the world is given by

$$
\begin{aligned}
\hat{W}^{A}+\hat{W}^{B}+\hat{W}^{C}= & \frac{(2 x k+k)(6 \alpha-2 x k-k)}{2 \beta} \\
& -\frac{\beta\left(S_{a}^{B^{2}}-S_{a}^{B} S_{a}^{C}+S_{a}^{C^{2}}\right)}{3} \\
& -\frac{\beta\left(S_{b}^{A^{2}}-S_{b}^{A} S_{b}^{C}+S_{b}^{C^{2}}\right)}{3} \\
& -\frac{\beta\left(S_{c}^{A^{2}}-S_{c}^{A} S_{c}^{B}+S_{c}^{B^{2}}\right)}{3} .
\end{aligned}
$$

By solving the optimisation problem of this equation, we can obtain $S_{a}^{B}=S_{a}^{C}=$ $S_{b}^{A}=S_{b}^{C}=S_{c}^{A}=S_{c}^{B}=0$, as was to be shown.

This proposition indicates that if trade liberalisation focuses only on the issue of reduction in tariffs, it may not necessarily lead to the optimal outcome. It explains why export subsidies are strictly forbidden in the WTO framework. Nevertheless, 
MFT may still improve social welfare with the existence of export subsidies. Furthermore, when all tariffs are removed, the subsidy of each country in the political equilibrium is set at the level of $\hat{S}_{F}^{p}=\frac{k-x k+6 \gamma x k}{7 \beta}=\hat{S}_{S H}^{p}$, which increases in $\gamma$ and may not be 0 . Therefore, our next proposition will discuss the welfare effects of MFT and investigate the conditions under which social welfare is improved.

Proposition 19 In a circumstance without any trade agreement, the welfare impacts of MFT on each country are ambiguous. The result depends on the relative concern about the political contributions $(\gamma)$ and the endowment ratio between different sectors $(x)$ in each country.

Proof Let $\hat{W}_{F}^{p}$ be the social welfare for each country under MFT, then we obtain that

$$
\hat{W}_{F}^{p}-\hat{W}_{N}^{p}=\frac{4 k^{2}(2 x-2+2 \gamma x+7 \gamma)(5 x-5-16 \gamma x+7 \gamma)}{1323 \beta},
$$

of which the sign is uncertain. In more detail, $\hat{W}_{F}^{p}>\hat{W}_{N}^{p}$ if and only if $\gamma<\frac{5(x-1)}{16 x-7}$.

This proposition suggests that if countries are allowed to provide export subsidies under political pressures, not only the welfare effects of discriminatory trade liberalisation (i.e., FTA) are ambiguous, but the effects of multilateral trade liberalisation are also ambiguous. In both frameworks, achieving a welfare-improving agreement requires $\gamma$ to be relatively small. In addition, the level of political contributions received under MFT is $\hat{P C}_{F}=\frac{3 x^{2} \gamma k^{2}}{4 \beta} \leq \hat{P C_{N}}$. Thus, in analogy with our earlier analysis about the FTA, we find that in the circumstance without any trade agreement no country will support a welfare-reducing MTA, and may prevent a welfare-improving one. The next proposition provides us with more ideas about the motivation of forming an MTA under political pressures. 
Proposition 20 Without any trade agreement, political economy forces reduce the likelihood of forming an MTA. In particular, each country has the incentive to approve an MTA if and only if $\gamma<\gamma_{1}$, where

$$
\gamma_{1}=\frac{8\left(-44 x^{2}+142 x+21 \sqrt{16 x^{4}-16 x^{3}+33 x^{2}-82 x+49}-98\right)}{1024 x^{2}+3136 x+2401}
$$

Proof If we substitute the combination of $\hat{W}_{F}^{p}$ and $\hat{P C_{F}}$, and $\hat{W}_{N}^{p}$ and $\hat{P C_{N}}$ into (5.2), we obtain that the payoff difference for a country under an MTA and before the formation of any trade agreement is

$$
\hat{G}_{F}-\hat{G}_{N}=\frac{k^{2}\left(320(x-1)^{2}-32(22 x-49) \gamma(x-1)-(32 x+49)^{2} \gamma^{2}\right)}{10584 \beta} .
$$

In the case without any political pressure $(\gamma=0)$, we have $\hat{G}_{F}>\hat{G}_{N}$, which confirms that countries have the incentive to approve an MTA, if each government is purely welfare motivated. Alternatively, if $\gamma>0$, we obtain that $\hat{G}_{F}>\hat{G}_{N}$ if $\gamma<\gamma_{1}$ and $\hat{G}_{F} \leq \hat{G}_{N}$ otherwise, as was to be shown.

Following the welfare and incentive analysis of forming an FTA, we find very similar results regarding forming an MTA. First, the welfare effects of an MTA are ambiguous, depending on the relationship between $\gamma$ and $x$. Second, a government does not support a welfare-reducing MTA, but it may block a welfare-improving one. In addition, the incentive to form an MTA also depends on $\gamma$ and $x$.

\subsection{Dynamic Negotiation Game}

In this section, we analyse the stability issue of trade negotiation in this new political environment. We apply a similar sequential negotiation game as used in previous chapters. However, because of the change in the political framework, the one-shot 
payoff of a player $I \in N$ in period $t \in\{1,2,3\} \hat{G}_{t}^{I}$ becomes the value obtained from (5.2) in the political equilibrium given the trading blocs structure formed at the end of this period, and the total payoff of the player in the game is still its continuation payoff in all periods, expressed as $\hat{G}_{1}^{I}+\hat{G}_{2}^{I}+\hat{G}_{3}^{I}$.

We still examine the subgame perfect Nash equilibrium outcome(s) of this dynamic negotiation game to focus on similar questions as discussed in previous chapters. The equilibrium outcome is derived by backward induction.

Proposition 21 The subgame perfect Nash equilibrium outcome of the trade negotiation game depends on the relationship between $\gamma$ and $x$. If $\gamma<\gamma_{1}$, MFT is the unique equilibrium outcome and will be achieved through an MTA at the end of the first period. If $\gamma>\gamma_{1}$, the unique equilibrium outcome is no trade agreement.

Proof When $\gamma<\gamma_{1}$, it guarantees not only that $\hat{G}_{F}>\hat{G}_{N}$, but also that $\hat{G}_{F}>\hat{G}_{I}$, $\hat{G}_{F}>\hat{G}_{S}, \hat{G}_{H}>\hat{G}_{I}$, and $\hat{G}_{H}>\hat{G}_{G}$. Compared to MFT, there are only two superior positions: one is the non-member of a bilateral FTA, and the other is the hub. In the former case, the two member countries should prefer MFT to a bilateral FTA $\left(\hat{G}_{F}>\hat{G}_{I}\right)$, so either of them would propose an MTA in the first place instead of a bilateral FTA, and the other two countries should not reject it $\left(\hat{G}_{F}>\hat{G}_{N}\right)$. In the latter case, we claim that a "hub-and-spoke" can never be formed because no country is willing to become the spoke $\left(\hat{G}_{O}>\hat{G}_{S}\right)$. Therefore, as long as $\hat{G}_{F}>\hat{G}_{N}$ is satisfied, MFT can be achieved through the multilateral framework in the first period.

On the contrary, if $\gamma>\gamma_{1}$, it not only causes $\hat{G}_{N}>\hat{G}_{F}$ but also makes $\hat{G}_{O}>\hat{G}_{F}$ and $\hat{G}_{N}>\hat{G}_{I}$ hold, so no country is interested in forming a bilateral FTA or an MTA. Moreover, owing to the undesirable position of a spoke, a "hub-and-spoke" cannot be formed. Therefore, no agreement will be achieved. Both of these results can be 


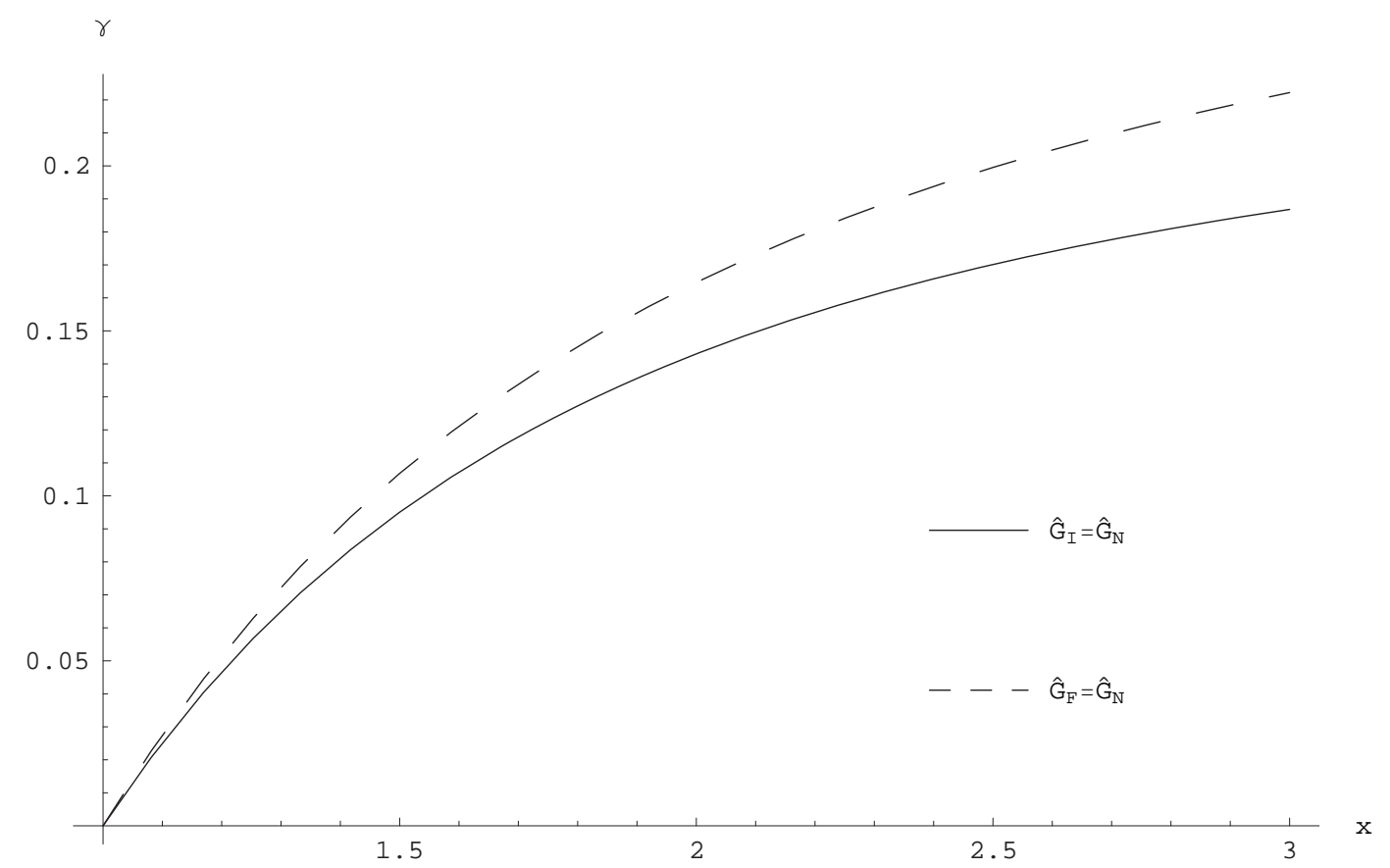

Figure 5.2: The Equilibrium Outcome of Trade Negotiation

confirmed in detail by backward induction.

The equilibrium outcomes of trade negotiation can be illustrated by Figure 5.2. When these two parameters are located below the dashed curve, MFT will be achieved through an MTA. In contrast, when they are located above, no trade agreement will be achieved. One implication from this proposition is that, given the endowment of each country, achieving MFT requires that $\gamma$ is small enough, which also confirms that MFT can always be achieved if each country is purely welfare motivated $(\gamma=0)$. This result is consistent with what was observed in previous chapters, and our explanation is also the same. When $\gamma$ is sufficiently large, the distortion caused by politics will block the opportunity of forming any trade agreement. On the other hand, since $\gamma_{1}$ is an increasing function of $x$, an increase in the value of $x$ will enlarge the range of $\gamma$ 
in which MFT can be approved. As explained earlier in this chapter, the parameter $\mathrm{x}$ measures the comparative advantage of each country through international trade. With a larger value of $\mathrm{x}$, the benefit for each country from free trade is greater, which brings about a greater chance of achieving MFT. Another implication from this proposition is that the equilibrium outcome of trade negotiation can either be MFT through an MTA or without any agreement, while regional trade liberalisation does not appear as an equilibrium path at all. The rationale is that when $\gamma$ is relatively small, each country may have the incentive to form an FTA. However, the payoff under MFT is even larger, so negotiation is completed with an MTA. When the extent of political concern is large enough to block the formation of an MTA, the distortion caused by it can also block the formation of an FTA. Additionally, since both of the two negotiation outcomes (no agreement and MFT) are symmetric, the social welfare and the government payoff should always be equal for each country, and there is no first-mover advantage in this negotiation.

\subsection{Conclusion}

In this chapter, we construct a new political environment in which all sectors can lobby the local government. To incorporate the interaction between the lobbying actions from export sectors and the respective government policies, we allow each government to provide export subsidies. Owing to the implicit nature of export subsidies policies, we also assume that trade negotiation only concerns removing tariffs. In the current political framework, we find that the welfare effects of both FTAs and an MTA are ambiguous, and MFT leads to the optimal outcome regarding the total welfare of the world if and only if all export subsidies are removed. As well, we show that the 
equilibrium outcome of trade negotiation in this case can either be MFT through an MTA or without any agreement, while regional trade liberalisation does not appear as an equilibrium path at all. The result depends on the following parameters. One is the relative concern about political contributions to each government and the other is the endowment ratio between different sectors in each country. Given the endowment of each country, MFT is achieved through an MTA if the political concern is relatively small, and it improves the welfare of all countries. In contrast, when the political concern is sufficiently large, no trade agreement can be achieved.

Despite our improvement regarding the setup of the political framework by incorporating the lobbying activities of all sectors in this chapter, our study is still limited to a symmetric world. The fact that regional trade liberalisation does not appear as an equilibrium outcome may result from that limitation. Therefore, in the next chapter we will extend our analysis into an asymmetric world including two big countries and a small country. 


\section{Chapter 6}

\section{Trade Agreements in an Asymmetric World}

\subsection{Introduction}

In the previous chapter, we generalised the political framework to a case in which all sectors can lobby the local government. However, the study was still restricted in a symmetric world. Since the asymmetric characteristics across countries may be a crucial factor in determining the welfare effects of trade agreements and the outcome of trade negotiation, we extend our analysis into an asymmetric world in this chapter. We still focus on the questions discussed previously, aiming to examine the welfare effects of trade agreements, the incentive of forming trading blocs and the equilibrium outcome of trade negotiation in this new circumstance.

The setup of our trade model and political structure here is very similar to that used in Chapter 5, except that in the current chapter we assume that there are two relatively big countries and one small country. In this asymmetric world, we also find that the welfare effects of most trade agreements are ambiguous, although an FTA between a big country and a small country usually makes the big country worse 
off. The eventual extent of trade liberalisation still depends on the two parameters discussed in Chapter $5(\gamma$ and $x)$. Nevertheless, the equilibrium outcome of trade negotiation is quite different from what was obtained in the symmetric cases. We realise that trade negotiation ends up with a "hub-and-spoke" system, a single FTA or no agreement, while MFT can never be sustained as an equilibrium outcome. Given the endowment of each country, when political concerns are relatively small, a "huband-spoke" system with a big country as a hub can be achieved. As the weight put on political contributions increases, a bilateral FTA between the two big countries can be the equilibrium outcome. When political concerns become sufficiently large, there will be no agreement. Our explanation for why MFT cannot be achieved in this asymmetric framework is as follows. When political concerns are small enough, all the countries indeed have the incentive to form an MTA. Nevertheless, countries in this circumstance also have the incentive to form FTAs, and when FTAs are achieved, some countries, especially the two big countries, are not willing to move further to achieve MFT, mainly because of the distortion of terms of trade from additional trade liberalisation with the small country. Thus, the result in this chapter provides another example supporting the argument that FTAs can be "stumbling blocks" for global trade liberalisation.

The structure of this chapter is similar to the previous three chapters. Section 2 presents the trade framework and discusses some properties in the political equilibrium before any trade agreement is achieved. Section 3 compares the social welfare and government payoff of each country under different structures of trading blocs. We further assess the welfare effects of each trade agreement and whether countries have the incentive to approve this agreement. An analogous trade negotiation game 
is introduced in section 4 to investigate the equilibrium outcome of trade negotiation. The final section summarises the results.

\subsection{The Static Trade Model}

\subsubsection{Basic Framework}

Again, consider a world with three countries A, B and C, with three goods a, b and c. We assume that for each country $M \in\{A, B\}$, its endowment is the same as the setup in the previous two chapters, including $k$ units of good $\mathrm{m}$ and $x k$ units of each of other two goods, where $k>0$ and $x>1$. In contrast, country $\mathrm{C}$ is endowed with $k / 2$ unit of $\mathrm{c}$ and $x k / 2$ unit of each of a and b. On the demand side, all three goods are demanded in each country. The demand for good $j \in n$ in country $M \in\{A, B\}$ is still given by $D_{j}^{M}\left(p_{j}^{M}\right)=\alpha-\beta p_{j}^{M}$, where $p_{j}^{M}$ denotes the price of $\mathrm{j}$ in country $\mathrm{M}$, while the demand curve in country $\mathrm{C}$ is now expressed as $D_{j}^{C}\left(p_{j}^{C}\right)=\left(\alpha-\beta p_{j}^{C}\right) / 2$. This setup creates an asymmetric framework, in which both the total endowment and the demand for each good in country $\mathrm{C}$ are half as much as in the other two countries. The asymmetric setup will not change the trade pattern between these countries and therefore it can also be illustrated by Figure 3.1. However, since the endowment in country $\mathrm{C}$ is changed, its total social welfare becomes:

$$
W^{C}=\sum_{j \in n} \int_{p_{j}^{C}}^{\alpha / \beta} D\left(p_{j}^{C}\right) d p_{j}^{C}+\frac{x k}{2} \sum_{m \in\{a, b\}} p_{m}^{C}+\frac{k}{2} p_{c}^{C}+\sum_{M \in\{A, B\}} \tau_{c}^{M} \hat{E X_{c}^{M}}-\sum_{m \in\{a, b\}} \hat{S}_{m}^{C} \hat{E X_{m}^{C}} .
$$

The political structure here is the same as that in Chapter 5, and the lobbying process between the owners of endowments and the local government is also modelled 
as a Nash bargaining game, in which these two parties have equal bargaining powers $(\sigma=0.5)$, and therefore evenly divide the bargaining surplus.

\subsubsection{Equilibrium Tariffs and Export Subsidies in the Asym- metric World}

Following the same methodology as that used in previous chapters, we can solve the tariffs and export subsidies in the political equilibrium before the formation of any trade agreement. We find that the optimal levels of political tariffs and subsidies of each country are given by

$$
\begin{aligned}
& \tau_{a}^{B^{p}}=\tau_{b}^{A^{p}}=\frac{27 x k-27 k+27 \gamma x k+88 \gamma k}{115 \beta} ; \\
& \tau_{a}^{C^{p}}=\tau_{b}^{C^{p}}=\frac{32 x k-32 k+32 \gamma x k+83 \gamma k}{115 \beta} ; \\
& \tau_{c}^{A^{p}}=\tau_{c}^{B^{p}}=\frac{3 x k-3 k+3 \gamma x k+17 \gamma k}{20 \beta} ; \\
& S_{a}^{B^{p}}=S_{b}^{A^{p}}=\frac{18 k-18 x k+97 \gamma x k+18 \gamma k}{115 \beta} ; \\
& S_{a}^{C^{p}}=S_{b}^{C^{p}}=\frac{8 k-8 x k+107 \gamma x k+8 \gamma k}{115 \beta} ; \\
& S_{c}^{A^{p}}=S_{c}^{B^{p}}=\frac{k-x k+9 \gamma x k+\gamma k}{10 \beta} .
\end{aligned}
$$

The findings regarding the levels of political tariffs and subsidies we had in Chapter 5 are confirmed in this asymmetric framework. If all countries are only concerned about their own social welfare, they should impose a tax instead of a subsidy on their exports. Moreover, the levels of tariffs and subsidies chosen by each government are strictly increasing in its relative concerns about the political contributions $(\gamma)$. 
As well as these properties, which are consistent with the results obtained previously, we find that $\tau_{a}^{C p}=\tau_{b}^{C p}>\tau_{a}^{B^{p}}=\tau_{b}^{A^{p}}>\tau_{c}^{A^{p}}=\tau_{c}^{B^{p}}$. This means that the equilibrium tariffs in this asymmetric world may be discriminatory. In particular, each big country imposes a higher tariff on the imports from the small country than the other big country. The reasons are the following. First, according to the result of trade equilibrium, we find that the terms of trade of a big country will improve more significantly if a higher tariff is imposed on the imports from a small country. Second, we find the change in the import volume of a big country is relatively less sensitive to the change in the tariff on the small country. Thus, imposing a higher tariff on the small country at some stage can increase tariff revenue. In addition, since the terms-of-trade gain from a tariff for a small country is relatively less, it does not have enough incentive to impose a higher tariff to take revenge against the big country, even if the big country unilaterally increases its tariff. For this reason, the tariff level chosen by the small country is lower than that of the other two big countries.

\subsection{Trade Liberalisation in the Asymmetric World}

In this section, we compare the one-shot welfare of each country under different structures and examine whether countries have the incentive to form trading blocs or not as we did in previous chapters. Because of the asymmetry of the world, more scenarios need to be discussed.

When no trade agreement is reached between countries, each country sets the tariffs and export subsidies at the optimal political level, as obtained in the previous section. By substituting them into the welfare function of each country, we can obtain their equilibrium social welfare in this asymmetric framework. For a country 
$I \in N$, this can be denoted as $\hat{W}_{\text {none }}^{I^{p}}$. Following a similar procedure as used in previous chapters, we can solve the level of political contributions of each country in the equilibrium $\left(\hat{P C}_{\text {none }}^{I}\right)$. We have $\hat{P C}_{\text {none }}^{A}=\hat{P C}_{\text {none }}^{B}=\frac{9\left(2 x^{2}+1\right) \gamma k^{2}}{28 \beta}$ and $\hat{P C}_{\text {none }}^{C}=$ $\frac{\left(2 x^{2}+1\right) \gamma k^{2}}{4 \beta}$. Unsurprisingly, the level of political contributions in all the countries increases in $\gamma$, and it is relatively higher in the two big countries.

In the current analytical framework, two different types of bilateral FTAs can be formed. One is achieved between the two big countries and the other is between a big country and the small country. We consider the former type first. When A and B form a bilateral FTA, tariffs between them will be eliminated, i.e., $\tau_{a}^{B}=$ $\tau_{b}^{A}=0$. However, they can still independently impose tariffs on the non-member country $\mathrm{C}$, and provide subsidies on their exports. Here, the objective function for each government becomes $G^{I}\left(\left(0, \tau_{a}^{C}, 0, \tau_{b}^{C}, \tau_{c}^{A}, \tau_{c}^{B}\right), S\right)$. By solving the optimisation problem as we did previously, we obtain that $\tau_{a}^{B}=\tau_{b}^{A}=0, \tau_{a}^{C}=\tau_{b}^{C}=\frac{5 k(x-1+\gamma x+2 \gamma)}{34 \beta}$ and $\tau_{c}^{A}=\tau_{c}^{B}=\frac{3 x k-3 k+3 \gamma x k+17 \gamma k}{20 \beta}$. In terms of export subsidies, we have $S_{a}^{B}=S_{b}^{A}=$ $\frac{18 k-18 x k+67 \gamma x k-2 \gamma k}{85 \beta}, S_{c}^{A}=S_{c}^{B}=\frac{k-x k+9 \gamma x k+\gamma k}{10 \beta}$ and $S_{a}^{C}=\hat{S}_{b}^{C}=\frac{13 k-13 x k+157 \gamma x k+8 \gamma k}{170 \beta}$.

We find that all the properties regarding how the formation of a bilateral FTA affects the equilibrium levels of tariffs and export subsidies we had in Section 5.3 still hold in this asymmetric case. The FTA leads member countries to voluntarily liberalise their external tariffs against the non-member country. Also, the extent of reduction in external tariffs is strictly increasing in $\gamma$. In addition, both the export subsidy within the FTA and that from the non-member are decreased, while the subsidy from a member government on exports to the non-member does not change.

By comparing the circumstances before and after the formation of this bilateral FTA, we realise that the result regarding the welfare impacts and motivation of an 


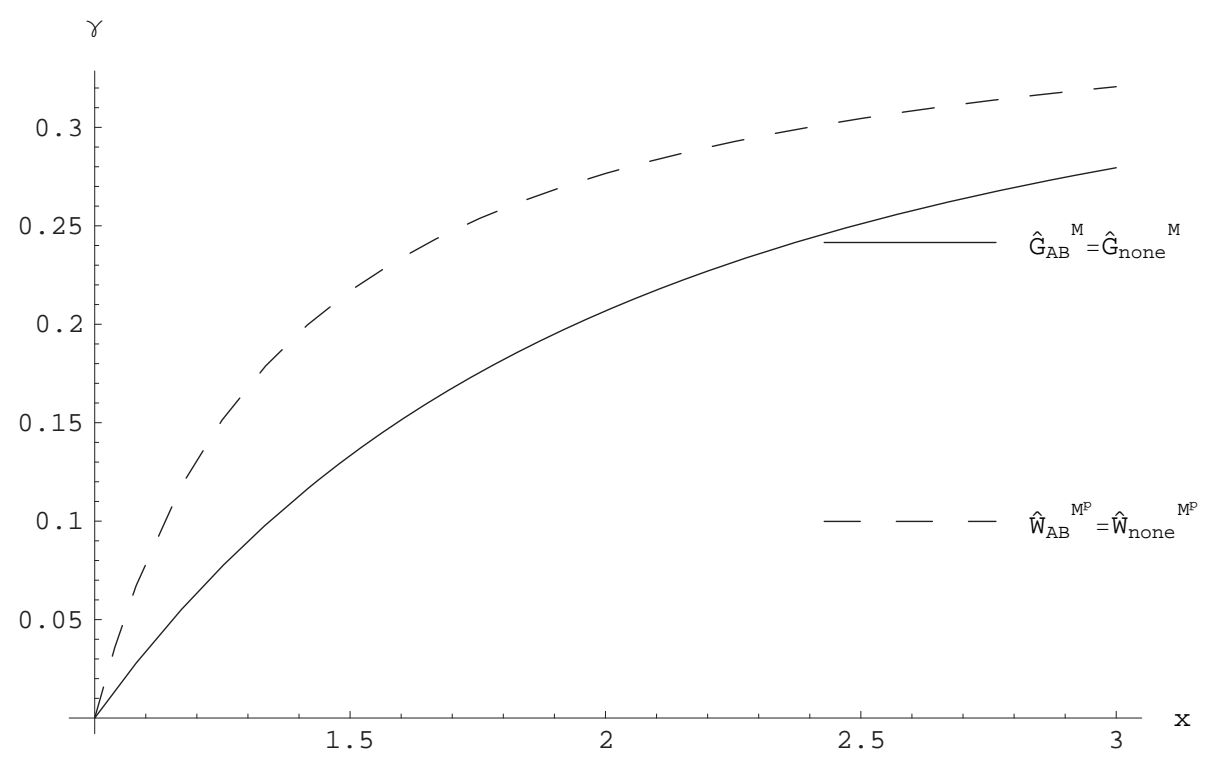

Figure 6.1: The Welfare Effects and Motivation of Forming an FTA between A and $\mathrm{B}$

FTA between two big countries are similar to our observation in Chapter 5 . The FTA has ambiguous welfare effects on both member and non-member countries. It is Pareto welfare improving if and only if $\gamma<\min \left\{\frac{3239(x-1)}{7(1213 x-753)}, \frac{1713(x-1)}{2197 x+1368}\right\}$. Moreover, political economy forces reduce the likelihood of forming the FTA. The two big countries have the incentive to form it if and only if $\gamma<\gamma_{60}$, where $\gamma_{60}=\frac{-18859932 x^{2}+75697349 x+1955 \sqrt{133} \sqrt{3490452 x^{4}-3835188 x^{3}+11025727 x^{2}-24507698 x+13826707}-56837417}{60982362 x^{2}+160901006 x+163268307}$.

As with the findings obtained in Chapter 5, the welfare effects and motivation of forming an FTA between A and B here also depend on the relationship between $x$ and $\gamma$. As illustrated by Figure 6.1, if these two parameters are located in the area below the solid curve, a welfare-improving FTA will be approved. If they are above the dashed curve, a welfare-reducing FTA will be prevented. If they are between these two curves, a welfare-improving FTA is blocked by political pressures. 
Because of the asymmetry of our current analytical framework, we also need to consider another type of FTA that is possible to be achieved between a big country and the small country. Suppose an FTA is formed between A and C. In this case, $\tau_{a}^{C}$ and $\tau_{c}^{A}$ are eliminated and the objective function of each government therefore becomes $G^{I}\left(\left(\tau_{a}^{B}, 0, \tau_{b}^{A}, \tau_{b}^{C}, 0, \tau_{c}^{B}\right), S\right)$. By solving the optimisation problem as before, we obtain that $\tau_{a}^{C}=\tau_{c}^{A}=0, \tau_{a}^{B}=\frac{x k-k+4 \gamma x k+4 \gamma k}{9 \beta}, \tau_{b}^{A}=\frac{27 x k-27 k+27 \gamma x k+88 \gamma k}{115 \beta}, \tau_{b}^{C}=$ $\frac{32 x k-32 k+32 \gamma x k+83 \gamma k}{115 \beta}$ and $\tau_{c}^{B}=\frac{3 x k-3 k+3 \gamma x k+17 \gamma k}{78 \beta}$. In terms of export subsidies, we have $S_{a}^{B}=\frac{38 k-38 x k+187 \gamma x k+28 \gamma k}{225 \beta}, S_{a}^{C}=\frac{8 k-8 x k+67 \gamma x k-2 \gamma k}{75 \beta}, S_{b}^{A}=\frac{18 k-18 x k+97 \gamma x k+18 \gamma k}{115 \beta}, S_{b}^{C}=$ $\frac{8 k-8 x k+107 \gamma x k+8 \gamma k}{115 \beta}, S_{c}^{A}=\frac{8 k-8 x k+57 \gamma x k-2 \gamma k}{65 \beta}$ and $S_{c}^{B}=\frac{21 k-21 x k+174 \gamma x k+11 \gamma k}{195 \beta}$.

It is simple to show that the FTA members in this case are also willing to voluntarily liberalise their external tariffs against the non-member country, indicating that the tariff complementarity effect also exists when an FTA is formed between a big country and a small country. However, our following findings reveal that the welfare effects of this type of FTA and the results regarding the motivation to form it are quite different from our previous case.

Proposition 22 In a circumstance without any trade agreement, a bilateral FTA between a big country and a small country reduces the welfare of the big member country while the welfare impacts on the other two countries are ambiguous.

Proof By substituting the equilibrium tariff and subsidy vector when a bilateral FTA is formed between A and C into the welfare function of each country, we obtain that

$$
\begin{aligned}
& \hat{W}_{A C}^{A^{p}}-\hat{W}_{\text {none }}^{A^{p}}=-\frac{k^{2}\left(\left(25475647(x-1)^{2}+2(58897867 x-53668127) \gamma(x-1)+(x(92320087 x+271448906)-216918593) \gamma^{2}\right)\right.}{1931061600 \beta} ; \\
& \hat{W}_{A C}^{B^{p}}-\hat{W}_{\text {none }}^{B^{p}}=-\frac{k^{2}\left(-712457557(x-1)^{2}+2(13843343 x-938636083) \gamma(x-1)+(x(740144243 x+3602142034)+2006136923) \gamma^{2}\right)}{48276540000 \beta} ; \\
& \hat{W}_{A C}^{C^{p}}-\hat{W}_{\text {none }}^{C^{p}}=\frac{k^{2}\left(40587499(x-1)^{2}-2(9166101 x-45279781) \gamma(x-1)+(165304539-x(58919701 x+167537238)) \gamma^{2}\right)}{1341015000 \beta}
\end{aligned}
$$


where $\hat{W}_{A C}^{I^{p}}$ denotes the welfare for country $I \in N$ in the political equilibrium when an FTA is formed between A and C.

Since $k>0, x>1, \beta>0$ and $\gamma \geq 0$, it is straightforward to show that $\hat{W}_{A C}^{A^{p}}<$ $\hat{W}_{\text {none }}^{A^{p}}$. However, the welfare effects on $\mathrm{B}$ and $\mathrm{C}$ are uncertain, depending on the relationship between $\gamma$ and $x$.

In terms of trade volumes, we find that when an FTA is achieved between A and C, country A's imports from both B and C increase, and country C's imports from both $\mathrm{A}$ and $\mathrm{B}$ also increase. Meanwhile, country B's imports are not affected. In other words, trade volume increases both between FTA members and between each member and the non-member.

It is surprising that this type of FTA makes a member country definitely worse off. To unveil the reason for this result, which is different from the ones obtained in the symmetric cases regarding the welfare effects of an FTA, we further investigate the impacts of the FTA on the different components of the welfare function separately. We realise that in country A, consumers definitely benefit from the FTA. Producers in sector c benefit, those in sector a become worse off and those in sector b are not affected. In total, the welfare effect on producers is uncertain. Therefore, the general outcome of welfare reduction in country A can only be explained by a severe loss of tariff revenue, which is mainly a result of the deterioration of terms of trade for the big country. The loss from terms of trade in this case is so significant that it dominates the gains from other components. On the other hand, the loss of small country $\mathrm{C}$ from terms of trade is not as much, which explains why country $\mathrm{C}$ is still likely to benefit from the FTA. In addition, we find that when an FTA is formed between A and C, the levels of political contributions in these two countries become $\hat{P C}_{A C}^{A}=\frac{3\left(39 x^{2}+7\right) \gamma k^{2}}{182 \beta}$ 
and $\hat{P C_{A C}^{C}}=\frac{\left(56 x^{2}+3\right) \gamma k^{2}}{112 \beta}$, respectively. It is apparent that $\hat{P C} C_{A C}^{A} \leq \hat{P C_{\text {none }}^{A} \text { and }}$ $\hat{P C}_{A C}^{C} \leq \hat{P C}_{\text {none }}^{C}$, where the equalities hold when $\gamma=0$. As a result, we can conclude that a big country has no incentive to approve an FTA with the small country. This outcome is also different from the ones obtained in the symmetric cases, suggesting that countries have the motivation of forming an FTA when political concerns are relatively small. The reason for this difference is that in the current case, the FTA unambiguously reduces both the social welfare and the level of political contributions the big country, while this type of effect was not observed in any of our symmetric cases.

Next, we extend our welfare and incentive analysis by incorporating the "hub-andspoke" system, of which there are two different types. One has a big country as the hub and the other has the small country as the hub. However, our previous analysis shows that a big country has no incentive to approve an FTA with the small country. Thus, the latter type is not very likely to occur and we focus more on the former type. We analogously proceed to assess the equilibrium social welfare and government payoff in this system and compare them with the results obtained in previous structures. Suppose that an additional FTA is achieved between A and C when there has already been an FTA between A and B, then a "hub-and-spoke" system is formed, in which A is the hub, and $\mathrm{B}$ and $\mathrm{C}$ are the two spokes. In a similar way to our previous analysis, we find that in the political equilibrium, the tariff levels between the two spokes are given by $\tau_{c}^{B}=\frac{3 x k-3+3 \gamma x k+17 \gamma k}{78 \beta}$ and $\tau_{b}^{C}=\frac{5(x k-k+\gamma x k+2 \gamma k)}{34 \beta}$, respectively. In terms of subsidies, we have $S_{a}^{B}=\frac{k-x k+4 \gamma x k}{5 \beta}, S_{a}^{C}=\frac{k-x k+9 \gamma x k}{10 \beta}, S_{b}^{A}=\frac{18 k-18 x k+67 \gamma x k-2 \gamma k}{85 \beta}, S_{b}^{C}=$ $\frac{13 k-13 x k+157 \gamma x k+8 \gamma k}{170 \beta}, S_{c}^{A}=\frac{8 k-8 x k+57 \gamma x k-2 \gamma k}{65 \beta}$ and $S_{c}^{B}=\frac{21 k-21 x k+174 \gamma x k+11 \gamma k}{195 \beta}$. We can further obtain that the political contributions in each country are given by $\hat{P C}_{H A}^{A}=$ 
$\frac{9 x^{2} \gamma k^{2}}{14 \beta} \leq \hat{P C_{A B}^{A}}, \hat{P C_{H A}^{B}}=\frac{3\left(14 x^{2}+7\right) \gamma k^{2}}{532 \beta}=\hat{P C}_{A B}^{B}$, and $\hat{P C}_{H A}^{C}=\frac{\left(56 x^{2}+3\right) \gamma k^{2}}{112 \beta} \leq \hat{P C_{A B}^{C}}$ respectively. Thus, compared to the circumstance with a single FTA between A and $\mathrm{B}$, an additional FTA between $\mathrm{A}$ and $\mathrm{C}$ makes both country A and country $\mathrm{C}$ receive fewer political contributions, while there is no change in country B.

Proposition 23 In a circumstance with a bilateral FTA between two big countries $A$ and $B$, an additional FTA between $A$ and $C$ reduces the welfare of $B$, while the welfare impacts on $A$ and $C$ are ambiguous.

\section{Proof}

If the additional FTA is formed by $\mathrm{A}$ and $\mathrm{C}$, the welfare change for $\mathrm{A}$ is given by $\hat{W}_{H A}^{A^{p}}-\hat{W}_{A B}^{A^{p}}=-\frac{k^{2}\left(-206903(x-1)^{2}+2(469357 x-1346477) \gamma(x-1)+(x(1145617 x+4971326)-85443) \gamma^{2}\right)}{39072800 \beta}$.

Similarly, the welfare effects on $B$ and $C$ are respectively given by

$\hat{W}_{H A}^{B^{p}}-\hat{W}_{A B}^{B^{p}}=-\frac{k^{2}\left(998991(x-1)^{2}+6(213657 x+108479) \gamma(x-1)+(9 x(31439 x+464226)+2268203) \gamma^{2}\right)}{117218400 \beta} ;$

$\hat{W}_{H A}^{C^{p}}-\hat{W}_{A B}^{C^{p}}=-\frac{k^{2}\left(-467379(x-1)^{2}+6(74047 x-90399) \gamma(x-1)+(3 x(303887 x+738562)-3948803) \gamma^{2}\right)}{29304600 \beta}$, where $\hat{W}_{H A}^{I^{p}}$ denotes the welfare for country $I \in N$ in the political equilibrium under the structure of a "hub-and-spoke" where A is the hub, and $\hat{W}_{A B}^{I^{p}}$ denotes its welfare when an FTA is formed between A and B.

Since $k>0, x>1, \beta>0$ and $\gamma \geq 0$, it is straightforward to show that the welfare of country B decreases $\left(\hat{W}_{H A}^{B^{p}}<\hat{W}_{A B}^{B^{p}}\right)$, while welfare effects on A and C are uncertain, depending on the relationship between $\gamma$ and $x$.

In general, this proposition is also consistent with our observation in Chapter 5 that a "hub-and-spoke" system makes the spoke that was a member of the previous FTA worse off, and that the welfare effects on the hub and the other spoke that was the non-member of the previous FTA are ambiguous. Moreover, it characterises that 
the welfare impacts of the additional FTA between A and C on member countries are similar to the results regarding the original FTA between A and B. On the other hand, the results are not consistent with the outcomes regarding the FTA between A and $\mathrm{C}$ when no FTA is formed between $\mathrm{A}$ and $\mathrm{B}$, where it was found that A had no incentive to form an FTA with C. Thus, it is interesting to ask why the big country A now can benefit from the additional FTA with the small country $\mathrm{C}$, although it could not before it had an FTA with B. As explained in previous chapters, this is because of the strong position of the hub, which gains significantly from the complete elimination of its tariffs and the competitive advantage of its exports in the market of each spoke country. In the current case, it is likely that the benefit of becoming a hub dominates the loss from the deterioration of the terms of trade for the big country.

In addition, we find that when $\gamma$ is relatively small, the small country $\mathrm{C}$ can also benefit from the additional FTA with A. This result is contrary to what was obtained in Chapter 5, suggesting that the non-member of an existing FTA is unwilling to become the spoke. The different outcome obtained here is also ascribed to the lower loss from the terms of trade for the small country.

Next, we turn to the discussion about the motivation of forming this additional FTA. Since we have realised that in terms of social welfare, both A and C are likely to benefit from this when $\gamma$ is relatively small, we can imagine that these two governments will have the incentive to form the FTA unless it causes a considerable loss of political contributions.

Proposition 24 In a circumstance with a bilateral FTA between $A$ and $B$, both $A$ and C have the incentive to approve an additional FTA to achieve a "hub-and-spoke" system, if and only if $\gamma<\min \left\{\gamma_{61}, \gamma_{62}\right\}$, where 


$$
\begin{aligned}
& \gamma_{61}=\frac{3\left(-1036658 x^{2}+2302244 x+221 \sqrt{14} \sqrt{15142400 x^{4}-1140160 x^{3}-2214623 x^{2}-52719874 x+40932257}-1265586\right)}{12763254 x^{2}+31019604 x+36293633} ; \\
& \gamma_{62}=\frac{-8917783 x^{2}+34500846 x+2210 \sqrt{19} \sqrt{1779084 x^{4}-4473816 x^{3}+11835913 x^{2}-17366714 x+8225533}-25583063}{21766723 x^{2}+94455194 x+27681183}
\end{aligned}
$$

Proof If we substitute the combination of $\hat{W}_{H A}^{A^{p}}$ and $\hat{P C}_{H A}^{A}$ and the combination of $\hat{W}_{H A}^{C^{p}}$ and $\hat{P C}_{H A}^{C}$ into the objective function of country A and country C respectively, we can find the government payoff of them under the "hub-and-spoke" system. Then we compare these with the values before the additional FTA is formed between A and $\mathrm{C}$, and obtain that the payoff difference for each country is given by

$$
\begin{aligned}
& \hat{G}_{H A}^{A}-\hat{G}_{A B}^{A}=-\frac{k^{2}\left(-3931157(x-1)^{2}+38(469357 x-1346477) \gamma(x-1)+(19 x(1145617 x+4971326)+27681183) \gamma^{2}\right)}{742383200 \beta} ; \\
& \hat{G}_{H A}^{C}-\hat{G}_{A B}^{C}=-\frac{k^{2}\left(-6543306(x-1)^{2}+84(74047 x-90399) \gamma(x-1)+(42 x(303887 x+738562)+36293633) \gamma^{2}\right)}{410264400 \beta} .
\end{aligned}
$$

We find $\hat{G}_{H A}^{A}-\hat{G}_{A B}^{A}>0$ iff $\gamma<\gamma_{62}$, and $\hat{G}_{H A}^{C}-\hat{G}_{A B}^{C}>0$ iff $\gamma<\gamma_{61}$. Thus, if and only if $\gamma<\min \left\{\gamma_{61}, \gamma_{62}\right\}$, both $\hat{G}_{H A}^{A}>\hat{G}_{A B}^{A}$ and $\hat{G}_{H A}^{C}>\hat{G}_{A B}^{C}$ hold, implying that both $\mathrm{A}$ and $\mathrm{C}$ have the incentive to approve the additional FTA, as was to be shown.

Finally, we complete this section by discussing the last possible circumstance on the path of trade liberalisation, i.e., MFT, in which all tariffs in the world are eliminated while export subsidies are still allowed. In this asymmetric world, we also find that removing all tariffs leads the world to achieve the maximum welfare if and only if all export subsidies are removed. Nevertheless, when all tariffs are removed, the subsidy of each country in the political equilibrium is $S_{a}^{B}=S_{b}^{A}=\frac{k-x k+4 \gamma x k}{5 \beta}$, $S_{a}^{C}=S_{b}^{C}=\frac{k-x k+9 \gamma x k}{10 \beta}$, and $S_{c}^{A}=S_{c}^{B}=\frac{2 k-2 x k+15 \gamma x k}{17 \beta}$, all of which increase in $\gamma$ and may not be 0 . Therefore, our next proposition discusses the welfare effects of MFT and investigates the condition under which social welfare is improved.

Proposition 25 (i) Compared to the circumstance without any trade agreement, 
MFT leads to ambiguous welfare impacts on each country. (ii) When a bilateral FTA is already achieved between $A$ and $B$, MFT reduces the welfare of both $A$ and $B$, while it makes the welfare impact on $C$ ambiguous. (iii) When a "hub-and-spoke" system is already achieved in which $A$ is the hub, MFT reduces the welfare of $B$, while it makes the welfare impacts on both $A$ and $C$ ambiguous. (iv) all these ambiguous results depend on the relative concern about the political contribution $(\gamma)$ and the endowment ratio between different sectors $(x)$ in each country.

Proof Let $\hat{W}_{m f t}^{I^{p}}$ be the equilibrium social welfare for country $I \in N$ under MFT. We obtain that

$\hat{W}_{m f t}^{A^{p}}-\hat{W}_{\text {none }}^{A^{p}}=\hat{W}_{m f t}^{B^{p}}-\hat{W}_{\text {none }}^{B^{p}}=$ $-\frac{k^{2}\left(-1471235(x-1)^{2}+2(4135705 x-8236789) \gamma(x-1)+(x(9742645 x+30587182)-14628891) \gamma^{2}\right)}{122304800 \beta}$;

$\hat{W}_{m f t}^{C^{p}}-\hat{W}_{\text {none }}^{C^{p}}=-\frac{k^{2}\left(-1574541(x-1)^{2}+2(286619 x-1316973) \gamma(x-1)+(x(2147779 x+5874214)-3269457) \gamma^{2}\right)}{30576200 \beta} ;$ $\hat{W}_{m f t}^{A^{p}}-\hat{W}_{A B}^{A^{p}}=\hat{W}_{m f t}^{B^{p}}-\hat{W}_{A B}^{B^{p}}=-\frac{k^{2}\left(2509(x-1)^{2}+2(3529 x-2645) \gamma(x-1)+(x(4549 x+21230)+405) \gamma^{2}\right)}{231200 \beta} ;$ $\hat{W}_{m f t}^{C^{p}}-\hat{W}_{A B}^{C^{p}}=-\frac{k^{2}\left(-2277(x-1)^{2}+2(443 x-1629) \gamma(x-1)+(x(3163 x+7622)-8001) \gamma^{2}\right)}{57800 \beta} ;$ $\hat{W}_{m f t}^{A^{p}}-\hat{W}_{H A}^{A^{p}}=\frac{k^{2}\left(-157731(x-1)^{2}-6(10587 x+74956) \gamma(x-1)+3(x(31403 x+115288)-12824) \gamma^{2}\right)}{9768200 \beta} ;$ $\hat{W}_{m f t}^{B^{p}}-\hat{W}_{H A}^{B^{p}}=-\frac{k^{2}\left(68268(x-1)^{2}+6(95686 x-138871) \gamma(x-1)+(6 x(84308 x+274399)-515717) \gamma^{2}\right)}{29304600 \beta} ;$ $\hat{W}_{m f t}^{C^{p}}-\hat{W}_{H A}^{C^{p}}=-\frac{k^{2}\left(-171765(x-1)^{2}+3(410 x-92451) \gamma(x-1)+(57 x(3035 x+7231)-26926) \gamma^{2}\right)}{7326150 \beta}$.

Since $k>0, x>1, \beta>0$ and $\gamma \geq 0$, the signs of $\hat{W}_{m f t}^{A^{p}}-\hat{W}_{\text {none }}^{A^{p}}, \hat{W}_{m f t}^{B^{p}}-\hat{W}_{\text {none }}^{C^{p}}$, $\hat{W}_{m f t}^{C^{p}}-\hat{W}_{\text {none }}^{C^{p}}, \hat{W}_{m f t}^{C^{p}}-\hat{W}_{A B}^{C^{p}}, \hat{W}_{m f t}^{A^{p}}-\hat{W}_{H A}^{A^{p}}$ and $\hat{W}_{m f t}^{C^{p}}-\hat{W}_{H A}^{C^{p}}$ are uncertain, depending on the relationship between $\gamma$ and $x$. In contrast, it is straightforward to show that $\hat{W}_{m f t}^{A^{p}}-\hat{W}_{A B}^{A^{p}}=\hat{W}_{m f t}^{B^{p}}-\hat{W}_{A B}^{B^{p}}<0$ and $\hat{W}_{m f t}^{B^{p}}-\hat{W}_{H A}^{B^{p}}<0$, as was to be shown.

This proposition confirms the finding in the symmetric case suggesting that if countries are allowed to provide export subsidies under political pressures, not only the welfare effects of discriminatory trade liberalisation (i.e., FTA) can be ambiguous, 
but the effects of multilateral trade liberalisation may also be ambiguous. For most of these ambiguous cases, achieving a welfare improving trade agreement requires $\gamma$ to be relatively small. One exceptional outcome occurs in the circumstance of a "hub-and-spoke" system, when A is the hub. We find in this case that country A can benefit from MFT when $\gamma$ is relatively large. This result, from another perspective, confirms that the hub is a desirable position especially when $\gamma$ is small, which can be even better than MFT. On the other hand, there are also some circumstances in which MFT can definitely make at least one country worse off. For instance, when an FTA is already achieved between A and B, MFT will make both of these two big countries worse off. In addition, in the case of a "hub-and-spoke" system, when A is the hub, the welfare of the spoke B will decrease if MFT is achieved. Indeed, both of these two examples as well as Proposition 22 imply that in most of the cases when the two big countries form a trade agreement with the small country, they get little benefit from it. This can be explained by the more significant deterioration of terms of trade for a big country from trade liberalisation. In addition, the levels of political contributions in each country under MFT are given by $\hat{P C}_{m f t}^{A}=\hat{P C}_{m f t}^{B}=\frac{9 x^{2} \gamma k^{2}}{14 \beta}$

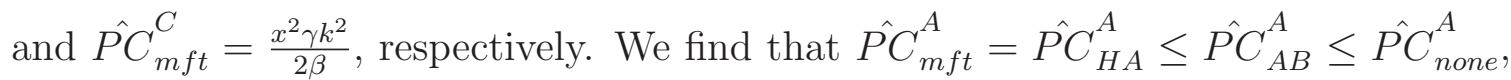
$\hat{P C}_{m f t}^{B} \leq \hat{P C}_{H A}^{B}=\hat{P C}_{A B}^{B} \leq \hat{P C}_{\text {none }}^{B}$ and $\hat{P C}_{m f t}^{C} \leq \hat{P C}_{H A}^{C} \leq \hat{P C}_{A B}^{C}=\hat{P C}_{\text {none }}^{C}$. This result supports another observation in the symmetric cases that a government will always receive fewer political contributions whenever it approves a trade agreement. Thus, we find a general conclusion covering all of our analytical frameworks regarding the relationship between the welfare effects of a trade agreement and motivation for a government to approve it, that is, no government will support a welfare-reducing 
trade agreement, although it may block a welfare-improving trade agreement. According to the results obtained from Proposition 25, we can then suggest that in the current framework, countries are only likely to approve an MTA when originally there is no agreement. We further find that each country has the incentive to form an MTA if and only if $\gamma<\gamma_{63}$, where $\gamma_{63}=\frac{-28949935 x^{2}+86607458 x+1564 \sqrt{7} \sqrt{89965575 x^{4}-246119265 x^{3}+520415992 x^{2}-662336489 x+298074187}-57657523}{68198515 x^{2}+214110274 x+172783563}$.

Since $\gamma_{63}$ increases in $x$, the condition requires $\gamma$ to be relatively small and $x$ to be relatively large. This result is consistent with the finding in the symmetric case. Also, it is similar to the result regarding the motivation of forming an FTA between two big countries.

\subsection{Dynamic Negotiation Game}

In this section, we analyse the stability issue of trade negotiation in this asymmetric world. We apply the same sequential negotiation game as used in Chapter 5 . We still examine the subgame perfect Nash equilibrium outcome(s) of this game to focus on similar questions as discussed in previous chapters. The equilibrium outcome is derived by backward induction.

Proposition 26 The subgame perfect Nash equilibrium outcome of the trade negotiation game depends on the relationship of $\gamma$ and $x$. (i) If $\gamma<\gamma_{65}$, where $\gamma_{65}=\frac{-144117710331 x^{2}+275187048150 x-131069337819}{292697561751 x^{2}+843834086802 x+1336090161379}+$ $\frac{10166 \sqrt{399} \sqrt{535361003100 x^{4}-1895578616400 x^{3}+2746262908093 x^{2}-1947233979386 x+561188684593}}{292697561751 x^{2}+843834086802 x+1336090161379}$, a "hub-and-spoke" system in which $B$ is the hub is the unique equilibrium outcome. (ii) If $\gamma_{65}<\gamma<\min \left\{\gamma_{61}, \gamma_{62}\right\}$, both of the two "hub-and-spoke" systems where a big 


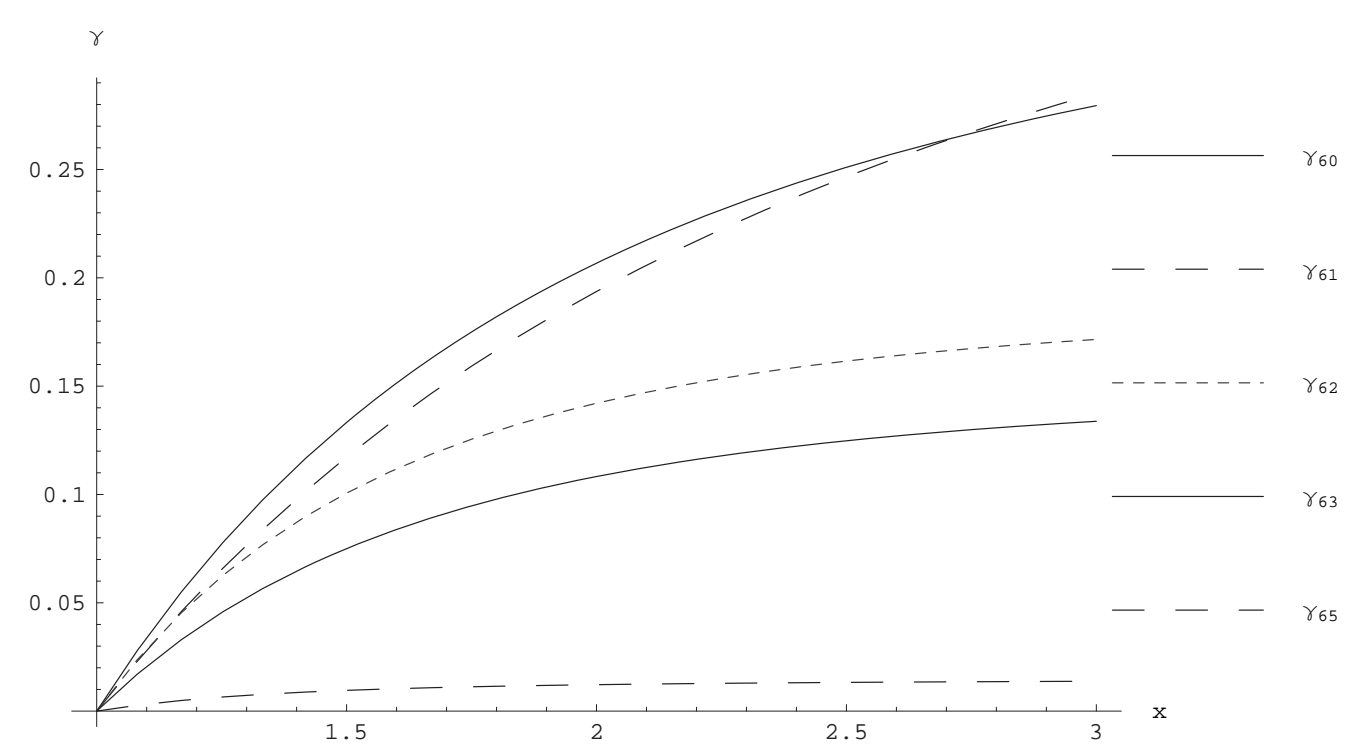

Figure 6.2: Curves Determining the Equilibrium Outcome

country is the hub are the equilibrium outcomes. (iii) If $\min \left\{\gamma_{61}, \gamma_{62}\right\}<\gamma<\gamma_{60}$, the unique equilibrium outcome is given by an FTA between $A$ and $B$. (iv) If $\gamma>\gamma_{60}$, the unique equilibrium outcome is no trade agreement.

Proof As illustrated by Figures 6.2 and 6.3, the two-dimensional space of $\gamma$ and $x$ is divided by curves into several regions. We find that all of $\gamma_{60}, \gamma_{61}, \gamma_{62}, \gamma_{63}$ and $\gamma_{65}$ are increasing functions of $x$, and that $\gamma_{65}<\gamma_{63}<\min \left\{\gamma_{61}, \gamma_{62}\right\}<\gamma_{60}$. This implies that when $\gamma>\gamma_{60}$, as illustrated by the red region in Figure 6.3, no agreement will be motivated. Moreover, if $\gamma$ is located between $\min \left\{\gamma_{61}, \gamma_{62}\right\}$ and $\gamma_{60}$ (represented by the black region), the two big countries will form an FTA but will not go any further. In addition, if $\gamma$ drops below $\min \left\{\gamma_{61}, \gamma_{62}\right\}$, located in the yellow, blue or green area, not only can an FTA be motivated between A and B, but there is also the incentive to achieve an additional FTA between one of the original FTA members and the small country. Thus, a "hub-and-spoke" system will be achieved 


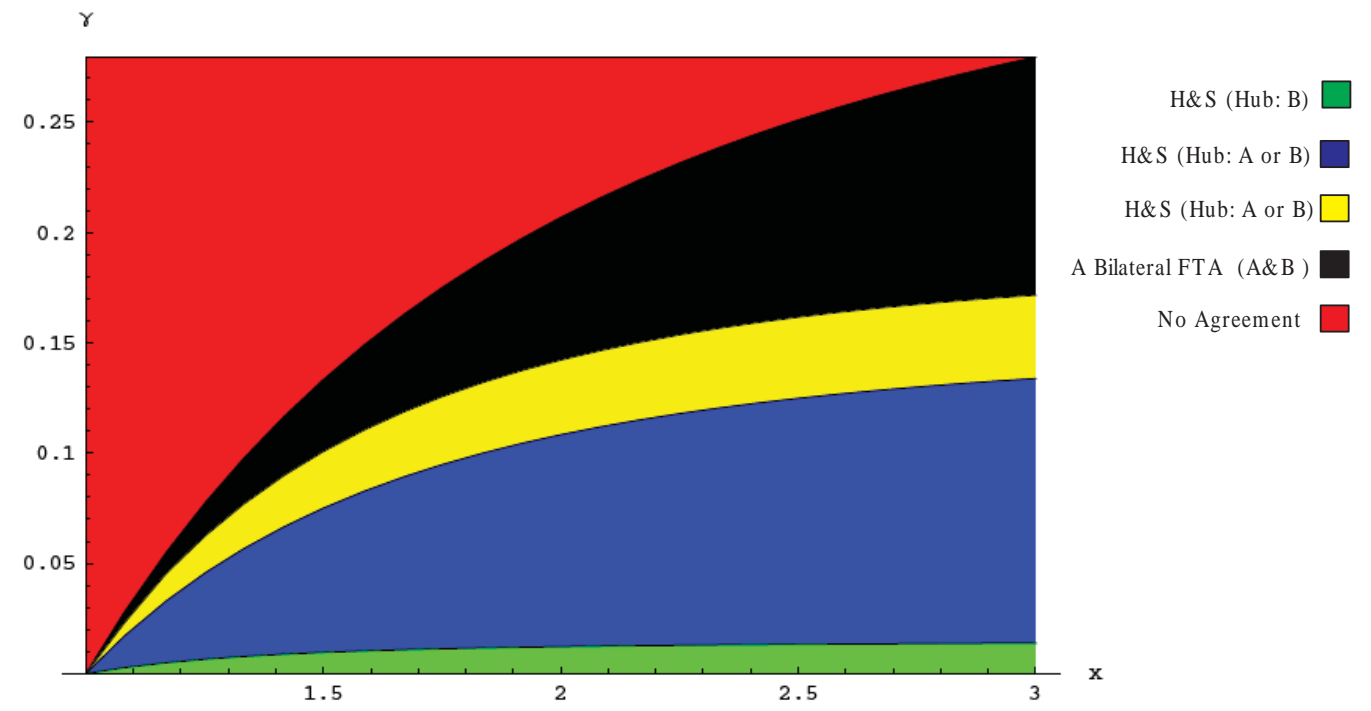

Figure 6.3: The Equilibrium Outcome of Trade Negotiation

with a big country as the hub. The answer to whether A or B will become the hub depends on the relationship between $\gamma$ and $\gamma_{65}$. It seems that both are willing to become the hub rapidly, and $\mathrm{A}$ has a first-mover advantage. In particular, A can offer two overlapping FTAs simultaneously and become the hub in the first period if two other countries accept the offer. The problem is that if A does so, B will not accept because it is better for B to stay outside the FTA between A and C than to become the spoke. Since A is not interested in a single FTA with C at this stage, A will not offer two FTAs and cannot become the hub in the first period. However, there is still an opportunity for A to become the hub, and that is not to offer any agreement in the first period. In this case, B will offer an FTA to A in the second period because $\mathrm{B}$ cannot become the hub directly either for the same reason as A in the first period. Then it is likely for $\mathrm{C}$ to offer $\mathrm{A}$ an additional FTA to make A become the hub in the third period. If this occurs, the continuation payoff of $\mathrm{A}$ 
is given by $\hat{G}_{n o n e}^{A}+\hat{G}_{A B}^{A}+\hat{G}_{H A}^{A}$. An alternative option for A is to offer B a single FTA, then B will offer C another FTA in the second period, so a "hub-and-spoke" system will be achieved with $\mathrm{B}$ as the hub, and the payoff of $\mathrm{A}$ here is given by $\hat{G}_{A B}^{A}+\hat{G}_{H B}^{A}+\hat{G}_{H B}^{A}$. It is found that $\hat{G}_{n o n e}^{A}+\hat{G}_{A B}^{A}+\hat{G}_{H A}^{A}>\hat{G}_{A B}^{A}+\hat{G}_{H B}^{A}+\hat{G}_{H B}^{A}$ iff $\gamma>\gamma_{65}$. Thus, when $\gamma>\gamma_{65}$, offering nothing by A can create an equilibrium path. However, this is only true if $\mathrm{C}$ offers an FTA to $\mathrm{A}$ in the third period. Indeed, it is also likely that $\mathrm{C}$ will offer to $\mathrm{B}$ instead, which will yield the same payoff to $\mathrm{C}$. If this is the case, A will not keep inactive at the beginning but offer a single FTA to B. Thus, when $\gamma_{65}<\gamma<\min \left\{\gamma_{61}, \gamma_{62}\right\}$, as represented by the blue and yellow area, offering B a single FTA by A in the first period can lead to an equilibrium outcome. In addition, if $\gamma<\gamma_{65}$, as illustrated by the green region, offering $\mathrm{B}$ a single FTA is certainly the best option by $\mathrm{A}$, and results in the unique equilibrium outcome in this case. All these equilibrium results can be confirmed in detail by backward induction.

This proposition reveals several interesting implications. First, it suggests that for any combination of $\gamma$ and $x$, MFT will never be achieved. This result is inconsistent with the findings in any of our symmetric cases. Our explanation for why MFT cannot be achieved in this asymmetric framework is as follows. Unlike what was illustrated by Figure 5.2 in the symmetric case, Figure 6.2 shows that in the current circumstance the curve determining whether countries have the incentive to form an MTA is located below the curves determining whether countries have the incentive to form FTAs. Thus, when political concerns are small enough, located in the green or blue region in Figure 6.3, all countries have the incentive to form an MTA. Nevertheless, countries in this circumstance also have the incentive to form FTAs, and when FTAs are achieved, 
some countries, especially the two big countries, are not willing to move further to achieve MFT, mainly owing to the distortion of the terms of trade from additional trade liberalisation with the small country. This result also implies that the option of bilateral FTAs does not cause an initially infeasible MFT to become feasible, while a previously feasible MFT is likely to be blocked by the option of FTAs (if $\gamma$ and $x$ are located in the green or blue region in Figure 6.3). Thus, it provides another example supporting the argument that FTAs can be "stumbling blocks" for global trade liberalisation.

Second, the eventual extent of trade liberalisation, reflected by the equilibrium outcome of trade negotiation, also depends on the relationship between $\gamma$ and $x$. As shown in Figure 6.3, if these two parameters are located in the red region, no trade agreement will be approved. If they are located in the black region, an FTA can be achieved between A and B. If they are in the yellow, blue or green region, a "hub-and-spoke" system will be the equilibrium outcome. This implies that, given the endowment of each country, the continuous reduction in political concerns will eventually lead to more trade agreements. As explained in previous chapters, this is a result of the distortion caused by political concerns, which can block the opportunity of forming trade agreements when political concerns are sufficiently large. On the other hand, since all the curves in Figure 6.2 are increasing functions of $x$, an increase in the value of $\mathrm{x}$ will enlarge the range of $\gamma$ in which trade agreements can be approved. This is because, with a larger endowment ratio among sectors for each country, the benefit from free trade is greater, thus there is a greater chance of achieving trade agreements. In addition, the first-mover advantage does not appear significantly in the negotiation and in most of the cases B benefits more than A. 


\subsection{Conclusion}

In this chapter, we extend our analysis of trade agreements into an asymmetric world, including two big countries and one small country. In this asymmetric framework, we also find that the welfare effects of most trade agreements are ambiguous, although an FTA between a big country and a small country usually makes the big country worse off. The eventual extent of trade liberalisation still depends on the two parameters discussed in Chapter $5(\gamma$ and $\mathrm{x})$. Nevertheless, the equilibrium outcome of trade negotiation is completely different from what was obtained in the symmetric cases. We realise that trade negotiation ends up with a "hub-and-spoke" system, a single FTA or no agreement, while MFT can never be sustained as an equilibrium outcome. Given the endowment of each country, when political concerns are relatively small, a "huband-spoke" system with a big country as a hub can be achieved. As the weight put on political contributions increases, a bilateral FTA between the two big countries can be the equilibrium outcome. When political concerns become sufficiently large, there will be no agreement. This result provides another example in which the formation of FTAs is a "stumbling block" for global trade liberalisation.

Despite our extension in this chapter, our study is still limited to a specific case, in which the size of each big country is twice as large as the small one. Further research can generalise this assumption about asymmetry to examine how robust our current results are. In addition, our current findings can hardly explain the FTAs between a big country and a small country in the real world. Thus, there may be other benefits for a big country from a bilateral FTA with a small country that are beyond our modelling here. For instance, as suggested by Limao (2007), RTAs can be motivated by capturing non-trade benefits from partners. If we take into account this factor in 
our future research, we may be able to provide new insights for the FTAs between a big country and a small country. 


\section{Chapter 7}

\section{Conclusion and Further Research}

On the basis of the three-country and three-good "competing-exporters trade model" developed by Bagwell and Staiger (1999) and a trade negotiation game between these countries, our thesis examines the welfare effects of trade agreements, the incentive of forming trading blocs and the equilibrium outcome of trade negotiation in several different frameworks. The main contribution of this study is to provide new insights for welfare, stability and dynamic time-path issues of trade liberalisation, especially the debate between multilateralism and regionalism.

We start with a framework in which all countries are welfare maximising. In contrast to the results of Mukunoki and Tachi (2006), suggesting that an FTA improves the welfare of member countries at the expense of the rest of the world, we find that at the early stage of trade negotiation, an FTA is Pareto welfare improving, although member countries gain more than the non-member. A different outcome arises here mainly because the FTA members reduce their external tariffs against the non-member. Moreover, although being the hub is still the best position, a spoke position is even worse than being outside a single FTA. This outcome is also different from the one obtained by Mukunoki and Tachi (2006), suggesting that the 
spoke position is better than that of the non-member. This difference arises also because in our framework the FTA members reduce their external tariffs against the non-member when the first FTA is formed, bringing about significant benefit to the non-member. In addition, by endogenising tariffs, we clarify some ambiguity resulting from Mukunoki and Tachi (2006) and obtain unambiguous welfare effects of all the trade agreements. Based on the welfare ranking between different positions, we find that the unique equilibrium outcome of trade negotiation is given by MFT through an MTA. This is consistent with the symmetric case of Melatos and Woodland (2007), although their use of the core cannot identify the path(s) to reach the outcome.

Our welfare-maximising analysis is followed by the examination of cases in which each government is politically motivated. In these political economy frameworks, we realise that a government will always receive fewer political contributions whenever it approves a trade agreement. Thus, any government will never support a welfarereducing trade agreement, although it may block a welfare-improving trade agreement. Our results show that political economy forces usually reduce the likelihood of forming trade agreements and when the political concern is sufficiently large, all trade agreements can be prevented by political pressures. These results are consistent with the findings obtained by Ornelas (2005), while we confirm his arguments for the case of overlapping FTAs.

Chapter 4 analyses a circumstance where the political pressures are only from the import competing sector, we find that the welfare effects of most trade agreements are analogous to what is obtained in the previous welfare-maximising framework except that the welfare ranking between an "outside country" and a spoke becomes ambiguous. Moreover, the equilibrium outcome of trade negotiation in this case depends on 
the following two parameters. One is the relative concern to each government about political contributions and the other is the relative bargaining power of each government against the lobby group. As long as either of these parameters is small enough, MFT can be achieved and the path to achieving this outcome depends on whether the outside country has the incentive to endorse an additional FTA to become a spoke. If this motivation exists, MFT will be achieved through overlapping FTAs. Otherwise, it will be achieved through an MTA. As the value of these two parameters increases, it is likely that a single FTA is the equilibrium outcome. If both of them become sufficiently large, no agreement will be achieved.

Chapters 5 and 6 generalise the political framework to two cases in which all sectors are allowed to lobby the local government. To take into account the interaction between the lobbying actions from export sectors and the respective government policies, we allow each government to provide export subsidies. Under this new assumption, we find that the welfare effects of most trade agreements are ambiguous, although an FTA between a big country and a small country in the asymmetric case usually makes the big country worse off. Moreover, the equilibrium outcomes of trade negotiation from these two chapters are completely different. In the symmetric case, the equilibrium outcome can either be MFT through an MTA or without any agreement, while regional trade liberalisation does not appear as an equilibrium path at all. On the contrary, we realise in the asymmetric case that trade negotiation ends up with a "hub-and-spoke" system, a single FTA or no agreement, while MFT can never be sustained as an equilibrium outcome. The results in these two chapters are also consistent with those obtained by Melatos and Woodland (2007), implying that asymmetry across countries can be an important determinant of the potential 
outcome of trade liberalisation. We extend their analysis into a political economy framework.

Our findings also suggest that the option of bilateral FTAs does not make an initially infeasible MFT become feasible, while the previously feasible MFT is likely to be blocked by the option of an FTA. Thus, our thesis provides some evidence to support the argument that the formation of RTAs can be a "stumbling block" for global trade liberalisation.

Although our thesis contributes to the "stumbling block" literature, further research should continue to search for the sorts of RTAs likely to encourage further multilateral trade liberalisation. For instance, our analytical framework can further be generalised with regards to the number of countries, the degree of endowment asymmetry, the preference of consumers, the payoff function of governments, the political process and the trade negotiation process. These extensions will help us to investigate the key determinants of the outcome of trade negotiation. In particular, the timing of our trade negotiation game, especially when $\mathrm{C}$ is the leader in the last period, may drive a number of results, so extending the game to infinite periods should be considered. Also, as suggested by Levy (1997), a multi-sector lobbying model should be used to capture the conflict between different sectors. In addition, most of the existing studies assume that multilateral trade negotiation intends to eliminate all tariffs at once, while in practice this process is gradual. Thus, it is interesting to discuss the case in which a multilateral trade agreement can only partly eliminate tariffs in each period of time. When trade negotiation becomes a gradual process, a country can even participate simultaneously in both bilateral and multilateral negotiation.

Further research can also go beyond the trade framework of Bagwell and Staiger 
(1999), which has ignored the role that production plays in the world economy. By incorporating production into our analysis, we may provide more insights for welfare, motivation and stability issues of trade liberalisation. For example, Davis and Weinstein (2001) and Schott (2003) find that potential heterogeneity of output within industries across countries will lead different countries to specialise in largely exclusive subsets of goods most suited to their mix of endowments, forming multiple diversification cones. In this circumstance, RTAs between countries from different cones may be more likely to occur than multilateral trade liberalisation, which would bring about further competition for countries from the same cone. 


\section{Appendix}

\section{Proof of Proposition 13.}

(i) It is simple to show that $\sigma_{1}<\sigma_{0}$. Thus, if $\sigma<\sigma_{1}$, it guarantees not only that $\hat{G}_{\text {spoke }}>\hat{G}_{\text {out }}$, but also that $\hat{G}_{\text {in }}>\hat{G}_{\text {non }}$. In addition, we have $\hat{G}_{\text {hub }}>\hat{G}_{m f t}>\hat{G}_{\text {spoke }}$ and $\hat{G}_{h u b}>\hat{G}_{i n}>\hat{G}_{\text {spoke }}$ always hold.

By using the method of backward induction, we at first consider the last period. According to the setup of the game, it is possible that all the eight trading blocs structures shown in Figure 3.2 can occur at the end of the second period. If MFT has been achieved in the second period as shown by $3.2(\mathrm{~h})$, it will also be maintained in the third period; if the negotiation outcome at the end of the second period is the case of 3.2(b), (e) or (f), MFT will be achieved in the third period; for the remaining four cases, the outcome in the last period will be a "hub-and-spoke" system in which $\mathrm{C}$ is the hub given by $3.2(\mathrm{~g})$.

Then, we consider the second period. Five outcomes are possible to occur at the end of the first period, as shown by figure 3.2(a), (b), (c), (e) and (h). Similarly, if MFT has been achieved in the first period, it will also be maintained in the second period. For the remaining four cases, by taking into account the outcomes derived in the third period, we find that if the negotiation outcome at the end of the first period is the case of 3.2(c) or (e), MFT will be achieved in the second period; otherwise, the outcome in the second period will be a "hub-and-spoke" system in which B is the hub given by $3.2(\mathrm{f})$.

We finally consider the first period. By taking into account the outcomes derived for the second and third periods, we find the outcome in the first period will be a "hub-and-spoke" system in which A is the hub given by 3.2(d). In summary, MFT is the unique equilibrium outcome and it will be achieved through the following path: in the first period, A offers overlapping bilateral FTAs to B and C, and both of them 
accept it; in the second period, B offers $\mathrm{C}$ an additional FTA and $\mathrm{C}$ accepts it. Thus, MFT is reached by overlapping FTAs at the end of the second period.

(ii) If $\sigma_{1}<\sigma<\min \left\{\sigma_{2}, \sigma_{3}\right\}$, it guarantees $\hat{G}_{\text {out }}>\hat{G}_{\text {spoke }}, \hat{G}_{m f t}>\hat{G}_{\text {in }}$, and $\hat{G}_{m f t}>\hat{G}_{n o n}$.

Consider the circumstances where $\hat{G}_{m f t}>\hat{G}_{\text {out }}$ first. If a "hub-and-spoke" system in which $\mathrm{C}$ is the hub has been achieved in the second period as shown by $3.2(\mathrm{~g})$, it will also be maintained in the third period. For the remaining cases, the outcome in the last period will be MFT. By taking into account the outcomes derived in the third period, we find the outcome in the second period will always be MFT. In the first period, by taking into account the outcomes derived for the second and third periods, A will offer an MTA and both B and C will accept it. Thus, MFT is the unique equilibrium outcome and it will be achieved through an MTA in the first period.

Then we consider the circumstances where $\hat{G}_{m f t} \leq \hat{G}_{\text {out }}$. If the negotiation outcome at the end of the second period is the case of 3.2(b), (c), (d), (g), or (h), it will also be maintained in the third period. For the remaining three cases, MFT will be achieved in the last period. In the second period, if the outcome at the end of the first period is the case of 3.2(b), (c), or (h), it will also be maintained in the second period. For the remaining two cases, MFT will be achieved in the second period. By taking into account the outcomes derived for the second and third periods, A will offer an MTA in the first period and both $\mathrm{B}$ and $\mathrm{C}$ will accept it. Thus, MFT is the unique equilibrium outcome and it will be achieved through an MTA in the first period.

(iii) If $\max \left\{\sigma_{1}, \sigma_{3}\right\}<\sigma<\sigma_{4}$, it guarantees that $\hat{G}_{\text {out }}>\hat{G}_{\text {spoke, }}, \hat{G}_{\text {in }}>\hat{G}_{\text {non }}$, $\hat{G}_{\text {in }}>\hat{G}_{\text {out }}, \hat{G}_{\text {in }}>\hat{G}_{m f t}$, and $\hat{G}_{m f t}>\hat{G}_{\text {out }}$.

If the negotiation outcome at the end of the second period is the case of 3.2(c), (d), (g), or (h), it will also be maintained in the third period. If no agreement is achieved at the end of the second period, the outcome in the last period will be an FTA between A and C or between B and C. For the remaining three cases, MFT will be achieved in the third period. In particular, when the outcome at the end of the second period is an FTA between A and B, MFT will be achieved through two additional overlapping FTAs in the last period.

In the second period, if the outcome at the end of the first period is the case of $3.2(\mathrm{~b})$ or $(\mathrm{h})$, it will also be maintained in the second period. If no agreement is 
achieved at the end of the first period, the outcome in the second period will be an FTA between B and C. For the remaining two cases, MFT will be achieved in the second period.

By taking into account the outcomes derived for the second and third periods, A will offer a single FTA to B in the first period and B will accept it. In summary, MFT is the unique equilibrium outcome and it will be achieved through the following path: in the first period, A offers an FTA to B, and B accepts it; in the second period, the FTA between A and B is maintained while no additional agreement is achieved; In third period, $\mathrm{C}$ offers overlapping bilateral FTAs to $\mathrm{A}$ and $\mathrm{B}$, and both of them accept it. Thus, MFT is reached by overlapping FTAs at the end of the third period.

(iv) If $\max \left\{\sigma_{3}, \sigma_{4}\right\}<\sigma<\sigma_{0}$, it guarantees that $\hat{G}_{\text {out }}>\hat{G}_{\text {spoke }}, \hat{G}_{\text {in }}>\hat{G}_{\text {non }}$, $\hat{G}_{\text {in }}>\hat{G}_{m f t}$, and $\hat{G}_{\text {out }}>\hat{G}_{m f t}$.

Consider the circumstances where $\hat{G}_{\text {in }}>\hat{G}_{\text {out }}$ first. If the negotiation outcome at the end of the second period is the case of 3.2(b), (c), (d), (g), or (h), it will also be maintained in the third period. If no agreement is achieved at the end of the second period, the outcome in the last period will be an FTA between A and $\mathrm{C}$ or between $\mathrm{B}$ and C. For the remaining two cases, MFT will be achieved in the third period.

In the second period, if the outcome at the end of the first period is the case of $3.2(\mathrm{~b})$, (c) or (h), it will also be maintained in the second period. If no agreement is achieved at the end of the first period, the outcome in the second period will be an FTA between A and B or between B and C. For the remaining case, MFT will be achieved in the second period. By taking into account the outcomes derived for the second and third periods, A is likely to offer an FTA to B in the first period and B will accept it. $\mathrm{A}$ is also likely to offer an FTA to $\mathrm{C}$ and $\mathrm{C}$ will accept it. In addition, if A offers overlapping FTAs to both B and C, only B will accept it. In summary, there are two equilibrium outcomes. One is given by an FTA between A and B and the other is given by an FTA between A and C. Both of these outcomes will be achieved in the first period.

The circumstances where $\hat{G}_{\text {in }} \leq \hat{G}_{\text {out }}$ are very similar except that besides the two equilibrium outcomes in the previous case, an FTA between B and C can also be sustained as an equilibrium outcome and it will be achieved in the second period.

(v) If $\sigma>\max \left\{\sigma_{0}, \sigma_{2}\right\}$, it guarantees that $\hat{G}_{\text {out }}>\hat{G}_{\text {spoke }}, \hat{G}_{\text {non }}>\hat{G}_{\text {in }}$, and $\hat{G}_{\text {non }}>$ $\hat{G}_{m f t}$. 
If the negotiation outcome at the end of the second period is the case of $3.2(\mathrm{a}),(\mathrm{b})$, (c), (d), (g), or (h), it will also be maintained in the third period. For the remaining two cases, MFT will be achieved in the third period. In the second period, if the outcome at the end of the first period is the case of 3.2(e), MFT will be achieved in the second period. For the remaining four cases, the outcome will be maintained in the second period. By taking into account the outcomes derived for the second and third periods, no agreement will be achieved in the first period. Thus, no agreement is the unique equilibrium outcome. 


\section{References}

Aghion, P., P. Antràs, and E. Helpman (2007). Negotiating Free Trade. Journal of International Economics 73(1), 1-30.

Bagwell, K. and R. Staiger (1997). Multilateral Tariff Cooperation during the Formation of Free Trade Areas. International Economic Review 38(2), 291-319.

Bagwell, K. and R. Staiger (1999). Regionalism and Multilateral Tariff Cooperation. In J. Piggott and A. Woodland (Eds.), International Trade Policy and the Pacific Rim. St. Martins Press.

Baldwin, R. (1995). A Domino Theory of Regionalism. In R. Baldwin, P. Haaparanta, and J. Kiander (Eds.), Expanding Membership of the European Union, pp. 25-53. Cambridge University Press.

Baldwin, R. (2006). Multilateralising Regionalism: Spaghetti Bowls as Building Blocs on the Path to Global Free Trade. World Economy 29(11), 1451-1518.

Baldwin, R. (2008). Big-Think Regionalism: A Critical Survey. NBER Working Paper.

Bhagwati, J. (1971). Trade-diverting Customs Unions and Welfare Improvement: A Clarification. The Economic Journal 81(323), 580-587.

Bhagwati, J. (1991). The World Trading System at Risk. Princeton University Press.

Bhagwati, J. (1993). Regionalism and Multilateralism: An Overview. In J. Melo 
and A. Panagariya (Eds.), New Dimensions in Regional Integration, pp. 22-51. Cambridge University Press.

Bhagwati, J. (1995). US Trade Policy: The Infatuation with Free Trade Areas. In J. Bhagwati and A. Krueger (Eds.), The Dangerous Drift to Preferential Trade Agreements, pp. 1-18. American Enterprise Institute.

Bhagwati, J. and A. Panagariya (1996a). Preferential Trading Areas and Multilateralism: Strangers, Friends or Foes? In J. Bhagwati and A. Panagariya (Eds.), The Economics of Preferential Trade Agreements, pp. 1-78. AEI Press.

Bhagwati, J. and A. Panagariya (1996b). The Theory of Preferential Trade Agreements: Historical Evolution and Current Trends. American Economic Review $86(2), 82-87$.

Bond, E. and C. Syropoulos (1996). The Size of Trading Blocs, Market Power and World Welfare Effects. Journal of International Economics 40(3-4), 411-437.

Burfisher, M., S. Robinson, and K. Thierfelder (2004). Regionalism: Old and New, Theory and Practice. International Food Policy Research Institute MTID Discussion Papers.

Chang, W. and A. Winters (2002). How Regional Blocs Affect Excluded Countries: The Price Effects of MERCOSUR. American Economic Review 92(4), 889-904.

Davis, D. and D. Weinstein (2001). An Account of Global Factor Trade. American Economic Review $91(5)$, 1423-1453.

Deardorff, A. and R. Stern (1994). Multilateral Trade Negotiations and Preferential Trading Arrangements. In A. Deardorff and R. Stern (Eds.), Analytical and Negotiating Issues in the Global Trading System, pp. 53-85. University of Michigan Press.

Ethier, W. (1998). Regionalism in a Multilateral World. Journal of Political Economy $106(6), 1214-1245$. 
Frankel, J., E. Stein, and S. Wei (1995). Trading Blocs and the Americas: The Natural, the Unnatural, and the Super-Natural. Journal of Development Economics $47(1), 61-96$.

Grossman, G. and E. Helpman (1995). The Politics of Free Trade Agreements. American Economic Review 85(4), 667-690.

Howse, R. (2003). Back to Court after Shrimp/Turtle: Indias Challenge to Labor and Environmental Linkages in the EC Generalized System of Preferences. Working Paper.

Kemp, M. and H. Wan (1976). An Elementary Proposition Concerning the Formation of Customs Unions. Journal of International Economics 6(1), 95-97.

Kennan, J. and R. Riezman (1990). Optimal Tariff Equilibria with Customs Unions. Canadian Journal of Economics 23(1), 70-83.

Krishna, P. (1998). Regionalism and Multilateralism: A Political Economy Approach. Quarterly Journal of Economics 113(1), 227-250.

Krugman, P. (1991). Is Bilateralism Bad? In E. Helpman and A. Razin (Eds.), International Trade and Trade Policy, pp. 9-23. MIT Press.

Krugman, P. (1993). Regionalism versus Multilateralism: Analytical Notes. In J. Bhagwati, J. Melo, and A. Panagariya (Eds.), New Dimensions in Regional Integration, pp. 58-84. Cambridge University Press.

Levy, P. (1997). A Political-Economic Analysis of Free-Trade Agreements. American Economic Review 87(4), 506-519.

Limao, N. (2007). Are Preferential Trade Agreements with Non-trade Objectives a Stumbling Block for Multilateral Liberalization? Review of Economic Studies $74(3), 821-855$.

Lipsey, R. (1957). The Theory of Customs Unions: Trade Diversion and Welfare. Economica 24(93), 40-46. 
Maggi, G. and A. Rodriguez-Clare (1998). The Value of Trade Agreements in the Presence of Political pressures. Journal of Political Economy 106(3), 574-601.

McLaren, J. (2002). A Theory of Insidious Regionalism. Quarterly Journal of Economics $117(2), 571-608$.

Meade, J. (1955). The Theory of Customs Unions. North-Holland.

Melatos, M. and A. Woodland (2007). Endogenous Trade Bloc Formation in an Asymmetric World. European Economic Review 51(4), 901-924.

Mukunoki, H. (2005). Comparing Alternative Paths to Free Trade under Endogenous Political Pressures. GEM Discussion Paper Series.

Mukunoki, H. and K. Tachi (2006). Multilateralism and Hub-and-Spoke Bilateralism. Review of International Economics 14(4), 658-674.

Mundell, R. (1964). Tariff Preferences and the Terms of Trade. Manchester School of Economics and Social Studies 32, 1-13.

Ohyama, M. (1972). Trade and Welfare in General Equilibrium. Keio Economic Studies 9(2), 37-73.

Ornelas, E. (2005). Endogenous Free Trade Agreements and the Multilateral Trading System. Journal of International Economics 67(2), 471-497.

Panagariya, A. and R. Findlay (1996). A Political Economy Analysis of Free Trade Areas and Customs Unions. In J. Bhagwati, R. Feenstra, G. Grossman, and D. Irwin (Eds.), The Political Economy of Trade Policy: Papers in Honor of Jagdish Bhagwati, pp. 265-87. MIT Press.

Panagariya, A. and P. Krishna (2002). On the Existence of Necessarily Welfare Improving Free Trade Areas. Journal of International Economics 57(2), 353367.

Pomfret, R. (1997). The Economics of Regional Trading Arrangements. Clarendon Press. 
Richardson, M. (1993). Endogenous Protection and Trade Diversion. Journal of International Economics 34(3-4), 309-324.

Richardson, M. (1995). Tariff Revenue Competition in a Free Trade Area. European Economic Review 39(7), 1429-1437.

Riezman, R. (1999). Can Bilateral Trade Agreements Help to Induce Free Trade? Canadian Journal of Economics 32(3), 751-766.

Saggi, K. (2009). The MFN Clause, Welfare, and Multilateral Cooperation between Countries of Unequal Size. Journal of Development Economics 88(1), 132-143.

Saggi, K. and H. Yildiz (2009). Bilateralism, Pure Multilateralism, and the Quest for Global Free Trade. Working Paper.

Schott, P. (2003). One Size Fits All? Heckscher-Ohlin Specialization in Global Production. American Economic Review 93(3), 686-708.

Srinivasan, T. (1993). Regionalism versus Multilateralism: Analytical Notes. Comment. In J. Melo and A. Panagariya (Eds.), New Dimensions in Regional Integration, pp. 84-89. Cambridge University Press.

Summers, L. (1991). Regionalism and the World Trading System. In Policy Implications of Trade and Currency Zones, pp. 295-301. Federal Reserve Bank of Kansas City.

Vanek, J. (1965). General Equilibrium of International Discrimination: The Case of Customs Unions. Harvard University Press.

Viner, J. (1950). The Customs Union Issue. Carnegie Endowment for International Peace.

Winters, A. (1997). Regionalism and the Rest of the World: The Irrelevance of the Kemp-Wan Theorem. Oxford Economic Papers 49(2), 228-234.

Wonnacott, P. and M. Lutz (1989). Is There a Case for Free Trade Areas? In J. Schott (Ed.), Free Trade Areas and US Trade Policy, pp. 59-84. Institute for 
International Economics.

Wonnacott, R. (1996). Free-Trade Agreements: For Better or Worse? American Economic Review 86(2), 62-66.

Yi, S. (1996). Endogenous Formation of Customs Unions under Imperfect Competition: Open Regionalism is Good. Journal of International Economics 41(1-2), $153-177$. 